UNIVERSIDADE DE SÃO PAULO

INSTITUTO DE QUÍMICA

\title{
REDUÇÃO ELETROQUÍMICA DE CINAMATOS DE METILA ORTO-SUBSTITUÍDOS
}

DISSERTAÇÃO DE MESTRADO

CAMILA DOS SANTOS GONÇALVES

CAMILA@CHEMIST.COM 


\section{Resumo}

Neste trabalho são descritas a síntese e a redução eletroquímica em DMF de alguns cinamatos de metila substituídos no anel aromático. O objetivo deste estudo foi verificar a influência de vários substituintes sobre o curso da reação de eletrohidrodimerização (EHD). Os substratos utilizados foram os o-metil(1), o-cloro- (2), o-nitro- (3), m,p-dicloro- (4), m-cloro- (5) e p-cloro(6), m-nitro- (7), o-metoxicarbonil- (8) cinamatos de metila. As técnicas empregadas foram a voltametria cíclica ${ }^{1}$ (verificação dos potenciais de redução) e eletrólises preparativas a potencial controlado.

Quando o substrato 1 foi eletrolisado, uma mistura de dois estereoisômeros do 4,5-bis-(o-metilfenil)-2-oxo-ciclopentanocarboxilato de metila, ainda não descritos na literatura, foi obtida, um resultado diferente das EHD de cinamatos descritas que conduzem a um único estereoisômero com elevada diastereosseletividade.

O o-clorocinamato de metila (2) investigado em dois potenciais diferentes, sofreu uma desalogenação e forneceu o cinamato de metila $(-1,25 \vee v s$. Ag/Agl) e este foi transformado em seu hidrodímero cíclico em $-1,45 \mathrm{~V}$ vs. Ag/Agl. Nos substratos 4 e 6 ocorreu uma

1 A. J. Bard, L. R. Fauklner, Electrochemical Methods : Fundamentals and Applications, 2 ${ }^{\text {a }}$ edição, Wiley, 2000. 
competição entre a desalogenação e a dimerização enquanto que no caso de 5 somente foi observada a EHD. Foi sugerido um mecanismo para a desalogenação.

Após eletrólises em vários potenciais, os nitroderivados 3 e 7 conduziram a misturas dos reagentes de partida e os ácidos carboxílicos correspondentes, mas não foram observados produtos de EHD.

As eletrólises do o-metoxicinamato de metila (8) não forneceram o dímero esperado na redução de cinamatos, mas compostos policíclicos inéditos cuja formação pode ser convenientemente explicada por meio de ciclizações de Dieckmann que envolvem o grupo metoxicarbonílico do anel aromático. 


\section{ABSTRACT}

The synthesis and electrochemical reduction in DMF of some ring substituted cinnamic esters are described. The main objective if this work is to verify the influence of the substituents on the electrohydrodimerization (EHD). The substrates studied were the methyl esters of o-methyl- (1), o-chloro- (2), o-nitro- (3), m,p-dichloro(4), m-chloro- (5), p-chloro- (6), m-nitro- (7) and o-methoxycarbonyl(8) cinnamic acids. Their electrochemistry was investigated employing cyclic voltammetry (determination of the reduction potentials) and preparative electrolysis at controlled potential.

When substrate 1 was electrolyzed, a mixture of two stereoisomers of methyl 4,5-bis-(o-methylphenyl)-2-oxo-cyclopentanecarboxylate, not yet described in literature, was obtained, a result which differs from the usual EHD of cinnamates, which lead to only one stereoisomer with high diastereoselectivity.

Methyl o-chlorocinnamate (2) electrolysed at $-1,25 \mathrm{~V} v \mathrm{Ag} / \mathrm{Agl}$ was dehalogenated and afforded methyl cinnamate. When the electrolysis was performed at $-1,45 \mathrm{~V}$, the main product was the cyclic expected hydrodimer of methyl cinnamate. In the case of substrates 4 and 6 a competition of dehalogenation and cimerization was observed whereas for $\mathbf{5}$ only the EHD occurred. A mechanism for the dehalogenation is suggested. 
Several electrolysis at different potentials, of the nitroderivatives 3 and 7 yielded mixtures of starting material and the corresponding carboxylic acids. In this no EHD products were observed.

The electrochemical reduction of methyl o-methoxycarbonylcinnamate (8) did not lead to the expected EHD dimer, but new polycyclic compounds were isolated. Their formation is conventiently explained by Dieckmann cyclization which involve the methoxycarbonyl group of the aromatic ring. 


\section{Introdução: Ácidos e ésteres cinâmicos}

O ácido cinâmico e alguns de seus derivados, como os ésteres, foram alvo de significativo interesse em estudos eletroquímicos, já que apresentam unidades fenilpropênicas ativadas devido à presença de grupos sacadores de elétrons como $-\mathrm{COOH}$ e $-\mathrm{COOR}$. Desta maneira, estes compostos insaturados agem como aceptores de Michael, podendo sofrer reações eletroquímicas de dimerização, acoplamento cruzado e eletro-ciclização.

A redução eletroquímica destas olefinas ativadas é conhecida como eletroidrodimerização, um importante método eletrossintético ${ }^{2}$, que pode ser exemplificado através da conhecida transformação da acrilonitrila em adiponitrila ${ }^{3}$, processo utilizado na produção do Nylon 66 Esquema II.1).

2<smiles></smiles><smiles>N#CCCCCC#N</smiles>

Esquema II.1 Reação da formação da adiponitrila

${ }^{2}$ (a) M. F. Nielsen e J. H. P. Utley, "Reductive Coupling" em Organic Electrochemistry, 4⿳亠丷a edição, H. Lund e O. Hammerich, editores, Marcel Dekker, Inc., 2001, Cap. 21. (b) R. Beck, Angew. Chem. 1972, 4, 798. (c) J. Utley, Chem. Soc. Rev. 1997, 26, 157.

3 M. M. Baizer, Tetrahedron Lett. 1963, 15, 973. 
Inicialmente, os estudos sobre a redução eletroquímica destes compostos foram feitos com ácido cinâmico em meio alcalino com cátodo de mercúrio ${ }^{4}$ e verificou-se a ocorrência da hidrogenação da dupla ligação carbono-carbono (Esquema II.2).

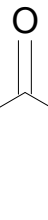

$$
\mathrm{OH} \frac{\mathrm{NaOH}, \mathrm{Na}_{2} \mathrm{SO}_{4}}{\text { Cátodo de } \mathrm{Hg}}
$$

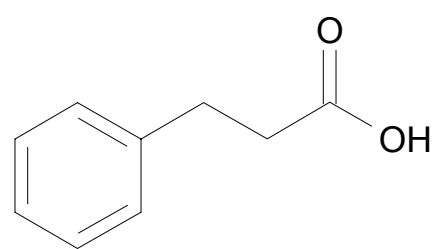

Esquema II.2 Redução eletroquímica do ácido cinâmico em meio básico.

O primeiro estudo que levou a obtenção de compostos provenientes da dimerização eletroquímica de ácido cinâmico e alguns derivados substituídos no anel aromático foi feito por Wilson e Wilson ${ }^{5}$. Neste trabalho foi descrita a redução eletroquímica do ácido cinâmico com o objetivo de obter o ácido 3,4-difeniladípico utilizando cátodo de mercúrio em solução aquosa de ácido sulfúrico contendo cerca de $5 \%$ de álcool etílico. Os autores verificaram a formação do dímero esperado ao lado de um produto não identificado em mesma proporção. O rendimento máximo obtido foi de $55 \%$ de ácido

4 A. W. Ingersoll, Org. Synth. Coll. Vol. I, 1929, 311.

${ }^{5}$ C. L. Wilson e K. B. Wilson; Trans. Electrochem. Soc., 1943, 84, 153. 
difeniladípico contendo quantidades aproximadamente iguais dos diastereômeros $d$ / / e meso (Esquema II.3).<smiles>O=C(O)/C=C/c1ccccc1</smiles><smiles></smiles>

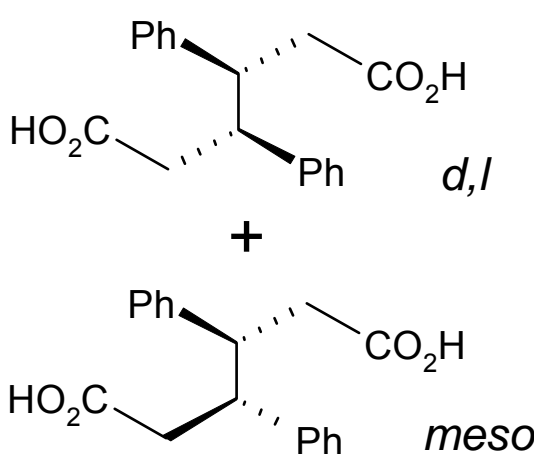

Esquema II.3 Redução eletroquímica do ácido cinâmico em meio ácido.

Além de examinar alguns efeitos como o da pureza do cátodo de mercúrio, agitação, solvente orgânico (homogeneidade) e pureza do substrato, Wilson e Wilson também estudaram a redução eletroquímica de ésteres cinâmicos e alguns ácidos cinâmicos com substituintes no anel aromático.

Como produto da eletrólise do éster foi obtido o dímero (adipato), porém com um rendimento menor do que o obtido para o ácido cinâmico. No estudo dos ácidos substituídos, os substratos estudados foram os ácidos o-cloro-, $m$-hidroxi, $p$-metoxi- e o-cianocinâmicos, sendo que o produto principal obtido para estes compostos foi o ácido adípico correspondente com bons rendimentos, com exceção do ciano derivado, cujo produto principal não foi identificado. 
Neste trabalho foi proposta a preparação de derivados de criseno a partir do aquecimento do ácido 3,4-difeniladípico em ácido sulfúrico $85 \%$ durante duas horas. A mistura de ácidos racêmico e meso levou aos cis- e trans-dicetoexaidrocrisenos respectivamente (Esquema II.4).

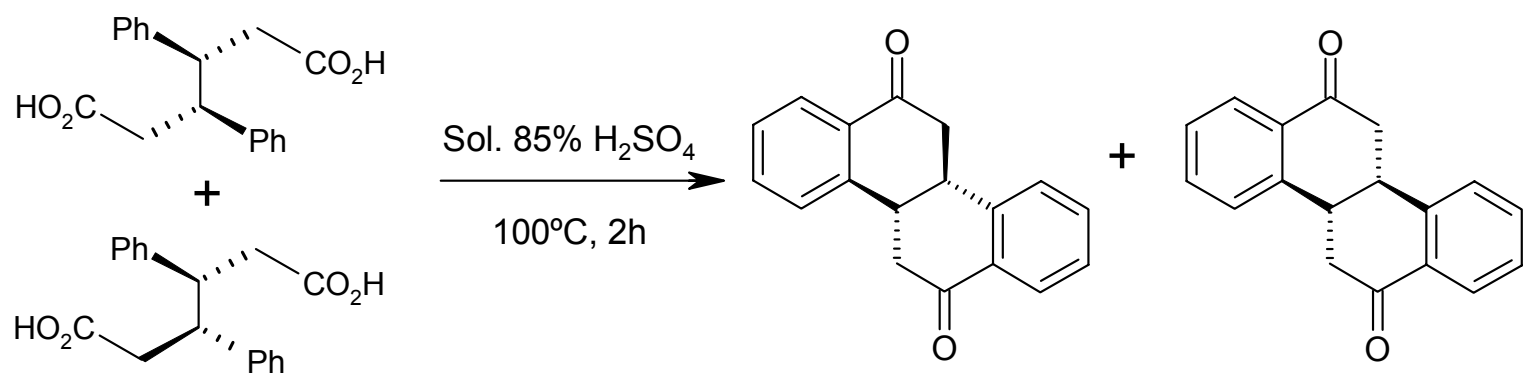

Esquema II.4 Ciclização intramolecular do ácido difeniladípico.

Continuando a investigação da redução dos ácidos cinâmicos, Wilson e Goodings ${ }^{6}$ relataram o efeito do substituinte no anel aromático na redução eletroquímica dos ácidos $o-, m$ - e $p$-nitro-, p-amino-, o-carboxi- e p-sulfocinâmicos utilizando cátodo de mercúrio em meio ácido.

$\mathrm{Na}$ redução dos nitro-derivados houve a formação de sais de amônio, porém não foram observados dímeros. No caso dos ácidos p-amino- e p-sulfocinâmicos ocorreu a redução da dupla ligação

\footnotetext{
${ }^{6}$ C. L. Wilson, E. P. Goodings; Trans. Electrochem. Soc., 1945, $\underline{88}, 77$.
} 
levando aos ácidos 3-fenilpropanóicos correspondentes. Quando o ácido o-carboxicinâmico foi eletrolisado, não houve a redução, fato que foi justificado através da lactonização do composto no meio ácido, onde as eletrólises eram realizadas.

Ono e $\mathrm{Hayashi}^{7 a}$ estudaram a redução eletroquímica do ácido cinâmico com o objetivo de discutir o mecanismo e as mudanças de produtos causadas pela alteração das condições experimentais.

Efetuando experimentos com diferentes cátodos, foram identificados três produtos, a saber: os ácidos $\beta$-fenilpropiônico (Figura II.1.A), 3,4-difeniladípico (Figura II.1.B) e 3-cicloexilpropanóico (Figura II.1.C). A Tabela II.1 resume os resultados obtidos utilizando como eletrodos chumbo, zinco amalgamado $(\mathrm{Hg}-\mathrm{Zn})$, mercúrio e platina platinizada.

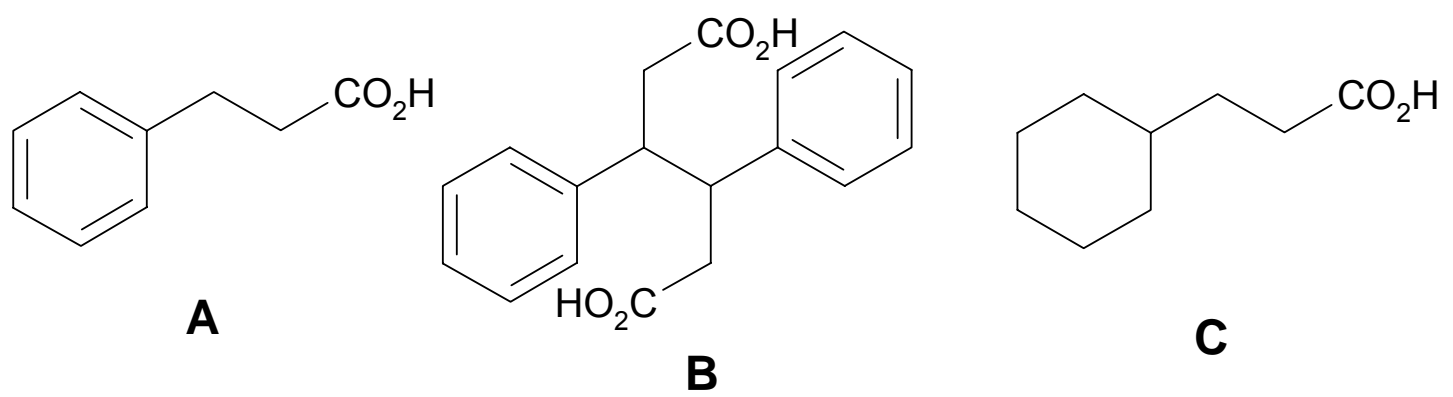

Figura II.1 Produtos da redução do ácido cinâmico.

${ }^{7}$ (a) S. Ono e T. Hayashi, Bull. Chem. Soc. Jpn. , 1953, 26, 11, (b) S. Ono e T. Hayashi, Bull. Chem. Soc. Jpn. , 1953, 26, 268. 
Tabela II.1 Efeito do material do cátodo sobre o curso da redução eletroquímica do ácido cinâmico

\begin{tabular}{cccccc}
\hline Cátodo & $\mathrm{H}_{2} \mathrm{SO}_{4}$ & D. C. $^{\text {a }}$ & \multicolumn{3}{c}{ Produtos (Figura I.1) } \\
& $(\%)$ & $\left(\mathrm{A} . \mathrm{dm}^{2}\right)$ & $\mathrm{A}$ & $\mathrm{B}$ & $\mathrm{C}$ \\
\hline $\mathrm{Pb}$ & 75 & 3,0 & 70 & 10 & -- \\
$\mathrm{Hg}-\mathrm{Zn}$ & 75 & 10,0 & 40 & 24 & -- \\
$\mathrm{Hg}$ & 75 & 10,0 & 10 & 24 & -- \\
$\mathrm{Pt}^{\mathrm{b}}$ & 75 & 5,0 & -- & -- & 75 \\
$\mathrm{~Pb}$ & 28 & 3,0 & 45 & 18 & -- \\
$\mathrm{Hg}-\mathrm{Zn}$ & 28 & 10,0 & 15 & 40 & -- \\
$\mathrm{Hg}$ & 28 & 10,0 & 6 & 44 & -- \\
$\mathrm{Pt}^{\mathrm{b}}$ & 28 & 5,0 & -- & -- & 70 \\
\hline
\end{tabular}

Condições experimentais: Católito: $14,8 \mathrm{~g}$ de ácido cinâmico,

$60 \mathrm{~mL}$ de etanol. Carga: 4,5 F. Temperatura: $25-35^{\circ} \mathrm{C}$.

${ }^{a}$ D.C. - Densidade de Corrente.

${ }^{\mathrm{b}}$ Pt platinizada.

Com exceção da platina platinizada, as eletrólises com todos os outros materiais de cátodo conduziram a misturas de A (ácido 3fenilpropanóico) e B (ácido 3,4-difeniladípico) em proporções variáveis. A redução em cátodo de platina platinizada conduziu ao ácido 3-cicloexilpropanóico (C) como produto principal ocorrendo a hidrogenação do anel aromático. O grupo carbonila mostrou ser resistente à redução nestas condições experimentais. 
Alguns experimentos feitos sob atmosfera de $\mathrm{H}_{2}$ e pressão foram inconclusivos. As eletrólises com eletrodos de chumbo, mercúrio e zinco amalgamado, com várias concentrações de ácido sulfúrico, mostraram que a temperatura afeta a formação dos compostos bimoleculares. Os autores ${ }^{7 a}$ sugerem um mecanismo para a redução do ácido cinâmico nestes cátodos.

Posteriormente Ono e Hayashi ${ }^{7 \mathrm{~b}}$ examinaram o comportamento polarográfico do ácido cinâmico em misturas dioxano - água com vários tipos de eletrólitos suporte. Em meio neutro uma onda polarográfica bem definida de dois passos (ca. $-1,5 \vee$ e $-2,0 \vee v s$ E.C.S.) foi observada e, ao adicionar base, a primeira onda diminuiu. Em meio ácido também foram registradas duas ondas polarográficas (ca. $-1,5 \vee$ e $-1,9 \vee$ vs E.C.S.), das quais a segunda diminuía com o aumento da concentração de ácido clorídrico.

O estudo do cinamato de etila resultou em uma onda polarográfica simples (ca. $-1,7 \vee$ vs. E.C.S.) em solução neutra, mas, em meio alcalino duas ondas foram observadas (ca. $-1,7 \mathrm{~V}$ e $-2,0 \mathrm{~V}$ vs. E.C.S.), das quais a primeira decresce a medida em que o éster hidrolisa.

Baizer e Anderson ${ }^{8}$ estudaram as hidrodimerizações eletrolíticas de uma variedade de derivados de ácidos $\alpha, \beta$-insaturados, entre outros, os compostos da Tabela II.2, mostrando um aumento do

\footnotetext{
${ }^{8}$ M. M. Baizer e J. D. Anderson, J. Electrochem. Soc., 1964, 111, 223.
} 
rendimento com relação ao processo de redução com amalgama, com exceção do cinamato de etila.

Tabela II.2 Comparação entre método com amalgama (A) e o eletrolítico (B) para a hidrodimerização de ésteres em eletrólito quaternário de amônio.

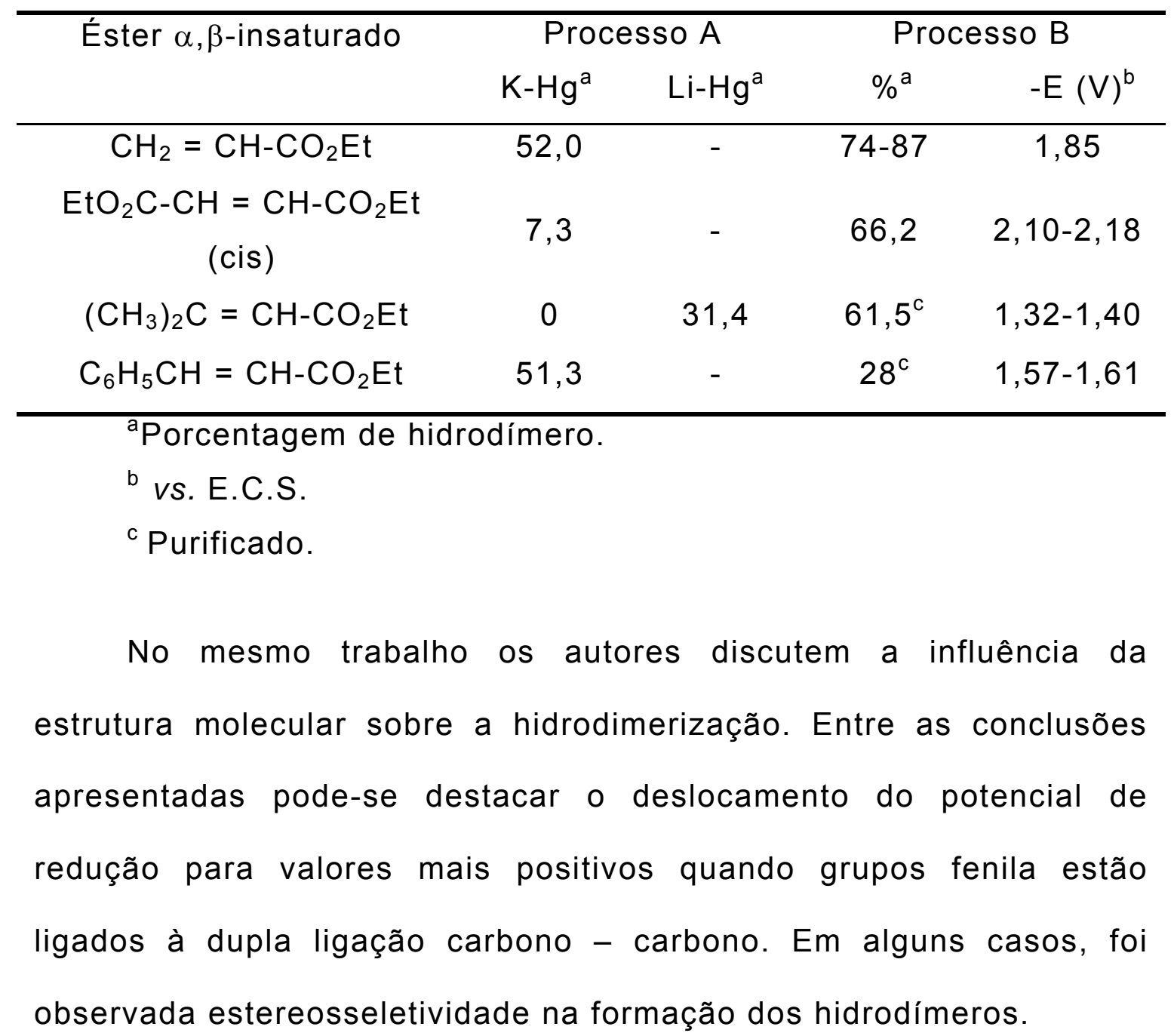


Dando continuidade ao seu trabalho de redução eletroquímica de olefinas ativadas, Baizer et al. ${ }^{9}$ investigaram 0 acoplamento redutivo de um conjunto de olefinas diativadas, $\mathrm{XCH}=\mathrm{CHY}$, entre as quais o cinamato de etila. Inicialmente foi feito um estudo polarogáfico e voltamétrico ${ }^{9 a}$, no qual foi analisado o perfil eletroquímico dos substratos tanto em água quanto em $N, N$-dimetilformamida (DMF), na tentativa de verificar características mecanísticas da reação.

No estudo polarográfico os resultados obtidos em meio anidro mostraram duas ondas polarográficas, cada uma correspondendo a um passo de um elétron. A partir da adição de água ao meio este polarograma foi modificado apresentando apenas uma pequena inflexão entre as duas ondas polarográficas que somadas indicam um processo de dois elétrons.

A voltametria cíclica reproduziu os resultados obtidos através da polarografia, além de ser utilizada para o cálculo de algumas constantes de velocidade de reação do ânion-radical formado a partir do cinamato de etila em DMF anidro, em diferentes concentrações de substrato e em presença de água.

Os autores concluem que a rota principal para a formação das espécies diméricas envolve o ataque do ânion-radical ao substrato de partida.

${ }^{9}$ (a) J. P. Petrovich, M. M. Baizer e M. R. Ort, J. Electrochem. Soc., 1969, 116, 743; (b) J. P. Petrovich, M. M. Baizer e M. R. Ort, J. Electrochem. Soc., $1969, \underline{116}, 749$. 
$\mathrm{Na}$ seqüência, Baizer et al. ${ }^{9 \mathrm{~b}}$ realizaram eletrólises preparativas com estes substratos. As reações foram feitas em solução aquosa concentrada de p-toluenossulfonato de tetraetilamônio (Et ${ }_{4} \mathrm{NOTs}$ ) misturada com um co-solvente, DMF ou acrilonitila, e utilizando cátodo de mercúrio. No caso do cinamato de etila, a eletrólise forneceu uma mistura de produtos (Esquema II.5).

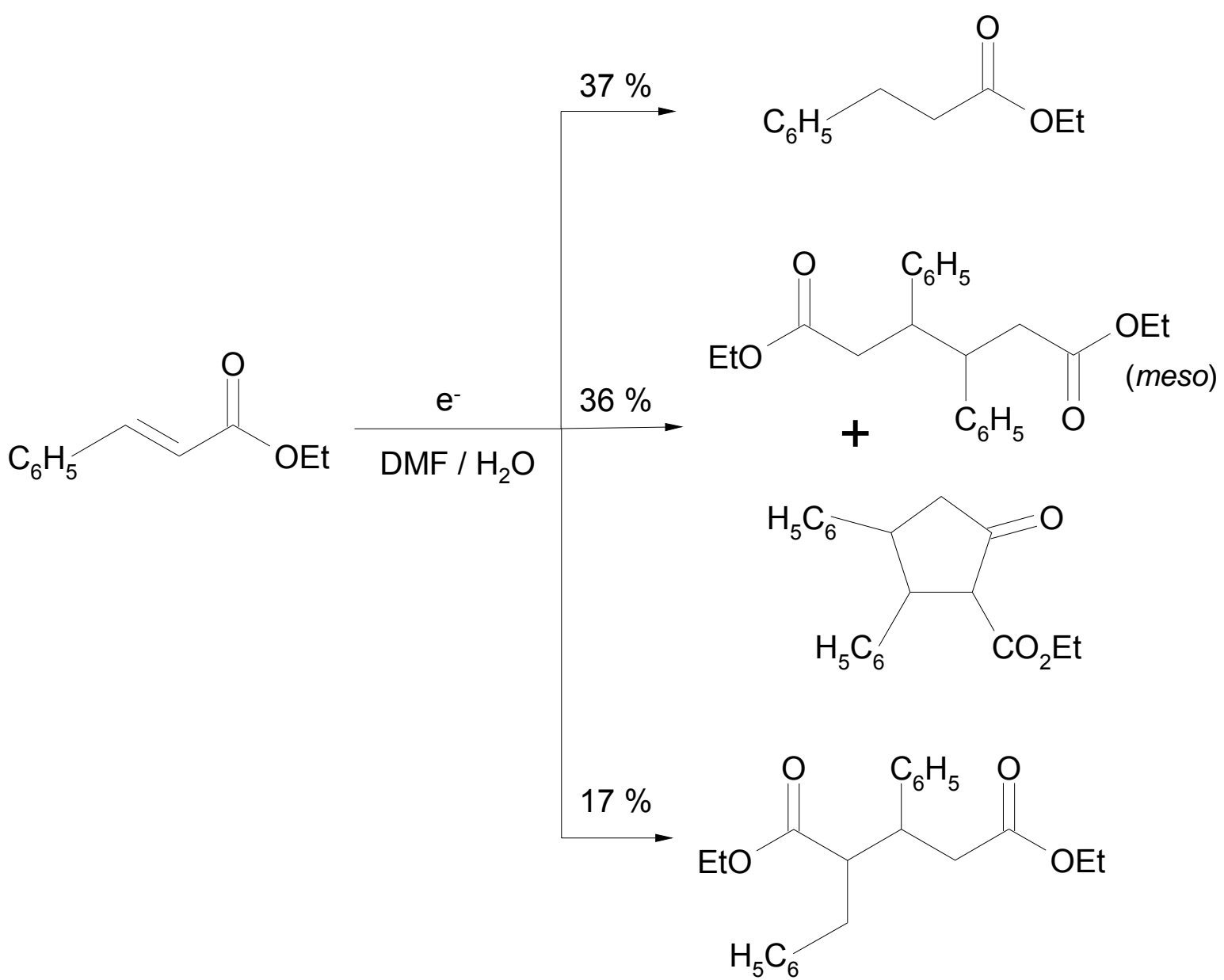

Esquema II.5 Produtos de eletrólise do cinamato de etila em DMF e água. 
Com base na análise cuidadosa dos produtos de acoplamento obtidos e descritos neste trabalho ${ }^{10 b}$ e considerando os fatos relatados na publicação anterior ${ }^{10 a}$, Baizer et al. Sugerem um esquema mecanístico para o acoplamento redutivo de $\mathrm{XCH}=\mathrm{CHY}$ (Esquema II.6).

$$
\mathrm{CHX}=\mathrm{CHY} \stackrel{1 \mathrm{e}^{-}}{\longrightarrow}\left[\begin{array}{c}
\mathrm{CHX}-\mathrm{CHY} \\
\mathrm{A}
\end{array}\right]^{\bullet}
$$

Rota A: $\mathrm{A}+\mathrm{XHC}=\mathrm{CHY} \longrightarrow$ Dímero $^{*} \frac{\mathrm{e}^{-}}{2 \mathrm{H}_{2} \mathrm{O}} \overrightarrow{\text { Hidrodímero }}$

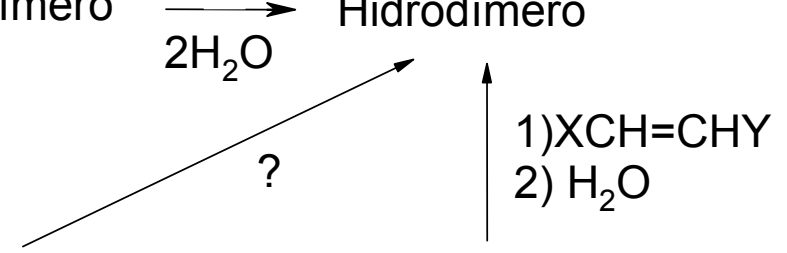

Rota B: $\mathrm{A}+\mathrm{H}_{2} \mathrm{O} \longrightarrow[\mathrm{CHX}-\mathrm{CHY}]^{\bullet} \mathrm{H} \stackrel{\mathrm{e}^{-}}{\longrightarrow}[\mathrm{CHX}-\mathrm{CHY}]^{-} \mathrm{H}$

Dímero $^{\bullet}=\left[\begin{array}{l}\mathrm{XHC}-\mathrm{CHY} \\ \mathrm{XHC}-\mathrm{CHY}\end{array}\right]^{\bullet}$ e/ou $\left[\begin{array}{r}\mathrm{XHC}-\mathrm{CHY} \\ \mathrm{YHC}-\mathrm{CHX}\end{array}\right]^{\bullet}$

Hidrodímero $={\underset{\mathrm{XHC}}{\mathrm{XHC}}-\mathrm{CHY}}^{\mathrm{CHY}} \underset{\mathrm{YHC}-\mathrm{CHX}}{\mathrm{XHC}-\mathrm{CHY}}$

Esquema II.6 Mecanismo de eletro-hidrodimerização (EHD) proposto por Baizer et al. ${ }^{9}$.

Estudos polarográficos e eletrólises preparativas de vários ésteres do ácido cinâmico e derivados metoxilados no anel aromático 
foram realizados por Klemm et al. ${ }^{10 a, b}$. Na Tabela II.3 estão reunidos os potenciais de redução de meia onda de alguns dos substratos investigados.

Tabela II.3 Potencial de redução de meia onda de compostos modelo<smiles>[R]C=CC#Cc1ccc([R])c([R])c1</smiles>

\begin{tabular}{|c|c|c|c|c|c|}
\hline \multicolumn{4}{|c|}{ Substrato } & \multirow{2}{*}{$\begin{array}{c}\text { Potencial da } \\
1^{\text {a }} \text { onda }\end{array}$} & \multirow{2}{*}{$\begin{array}{c}\text { Potencial da } \\
2^{\mathrm{a}} \text { onda }\end{array}$} \\
\hline & $\mathrm{R}$ & $\mathrm{R}_{1}$ & $\mathrm{R}_{2}$ & & \\
\hline$a$ & $E \mathrm{Et}$ & $\mathrm{H}$ & $\mathrm{H}$ & $-1,86^{b}$ & $2,23^{b}$ \\
\hline \multirow[t]{2}{*}{$b$} & $\mathrm{CH}_{2} \mathrm{C} \equiv \mathrm{CH}$ & $\mathrm{H}$ & $\mathrm{H}$ & $-1,77^{b}$ & $2,16^{b}$ \\
\hline & & & & $-1,71^{\mathrm{c}}$ & $1,91^{\mathrm{c}}$ \\
\hline \multirow[t]{2}{*}{ c } & $\mathrm{CH}_{2} \mathrm{C} \equiv \mathrm{CPh}$ & $\mathrm{H}$ & $\mathrm{H}$ & $-1,76^{b}$ & -- \\
\hline & & & & $-1,67^{c}$ & $1,89^{c}$ \\
\hline d & Et & $\mathrm{OMe}$ & OMe & $-1,94^{b}$ & $2,26^{b}$ \\
\hline
\end{tabular}

${ }^{a}$ V vS. E.C.S.

${ }^{\mathrm{b}} \mathrm{MeCN}$ anidra / 0,05 $\mathrm{M} \mathrm{Et}_{4} \mathrm{NBr}(\mathrm{TEAB})$

${ }^{c}$ MeCN anidra / 0,05 M TEAB / 3,85\% de água.

${ }^{10}$ (a) L. H. Klemm, D. R. Olson e D. V. White, J. Org. Chem., 1971, $\underline{36}$, 3740; (b) L. H. Klemm e D. R. Olson, J. Org. Chem., 1973, 소, 3390. 
A coulometria do 3,4-dimetoxicinamato de etila (substrato d, Tabela II.3), em 2,06 V vs. E.C.S. e acetonitrila anidra contendo 0,1 M de brometo de tetraetilamônio (TEAB) revelou o consumo de carga de 1,07 F na primeira onda de redução polarográfica. Os resultados das eletrólises preparativas são mostrados na Tabela II.4.

Tabela II.4 Produtos de hidrodimerização cíclica de ésteres cinâmicos

$$
\mathrm{Ar}-\mathrm{CH}=\mathrm{CH}=\mathrm{CO}_{2} \mathrm{R}
$$

\begin{tabular}{ccc}
\hline \multicolumn{2}{c}{ Substratos } & Hidrodímero cíclico ${ }^{a}$ \\
\hline $\mathrm{Ar}$ & $\mathrm{R}$ & Rendimento (\%) \\
\hline $3,4-\mathrm{OCH}_{2} \mathrm{OC}_{6} \mathrm{H}_{3}$ & $\mathrm{Me}$ & 60 \\
$\mathrm{C}_{6} \mathrm{H}_{5}$ & $\mathrm{Et}$ & 52 \\
$\mathrm{C}_{6} \mathrm{H}_{5}$ & $\mathrm{C}_{6} \mathrm{H}_{5} \mathrm{C} \equiv \mathrm{CCH}_{2}$ & 8 \\
$\mathrm{C}_{6} \mathrm{H}_{5}$ & $(\mathrm{E}) \mathrm{C}_{6} \mathrm{H}_{5} \mathrm{C} \equiv \mathrm{CCH}_{2}$ & 13 \\
$3,4-(\mathrm{MeO}){ }_{2} \mathrm{C}_{6} \mathrm{H}_{3}$ & $\mathrm{Et}$ & 52 \\
$3,4-(\mathrm{MeO}){ }_{2} \mathrm{C}_{6} \mathrm{H}_{3}$ & $\mathrm{t}-\mathrm{Bu}$ & 7 \\
$3,5-(\mathrm{MeO})_{2} \mathrm{C}_{6} \mathrm{H}_{3}$ & $\mathrm{Et}$ & 28 \\
\hline
\end{tabular}

a Hidrodímero cíclico:

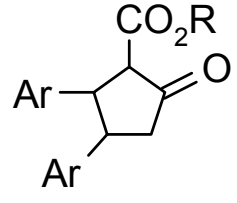

A estereosseletividade da hidrodimerização eletroquímica destes ésteres foi verificada neste estudo. Os autores ${ }^{10 b}$ propuseram a hipótese do produto ser fruto do acoplamento $\beta$ - $\beta$ de dois ânions- 
radicais, originando um diânion que por condensação de Dieckmann fecharia o anel formando o composto cíclico com estereoquímica trans entre os grupos aromáticos com elevada estereosseletividade (Esquema II.7).

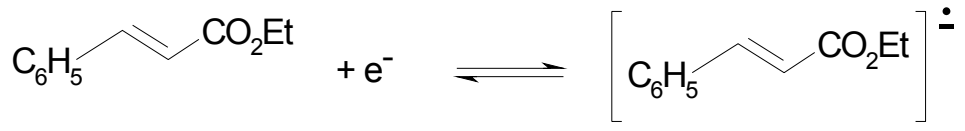

$$
\begin{aligned}
& 2\left[\mathrm{C}_{6} \mathrm{H}_{5} \mathrm{CO}_{2} \mathrm{Et}\right]^{=} \rightleftharpoons\left[\begin{array}{ll}
\mathrm{C}_{6} \mathrm{H}_{5} & \mathrm{CO}_{2} \mathrm{Et} \\
\mathrm{C}_{6} \mathrm{H}_{5} & \mathrm{CO}_{2} \mathrm{Et}
\end{array}\right]^{2-} \stackrel{\mathrm{BH}}{\longrightarrow} \begin{array}{llll}
\mathrm{C}_{6} \mathrm{H}_{5} & \therefore \mathrm{CO}_{2} \mathrm{Et} \\
& \mathrm{C}_{6} \mathrm{H}_{5} & \mathrm{CO}_{2} \mathrm{Et}
\end{array}
\end{aligned}
$$

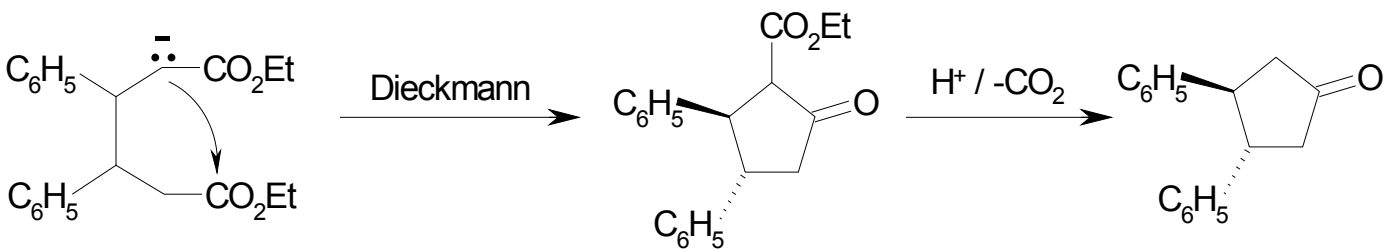

Esquema II.7 Proposta mecanistica de eletro-hidrodimerização (EHD) feita por Klemm e Olson ${ }^{10 b}$.

Para explicar a estereoquímica, os autores propõem que os átomos de oxigênio carbonílicos estariam dirigidos para o eletrodo e as moléculas do substrato ficariam em planos paralelos próximos, com o grupo arila volumoso de uma molécula por cima do hidrogênio $\beta$ da outra molécula (Figura II.2). 


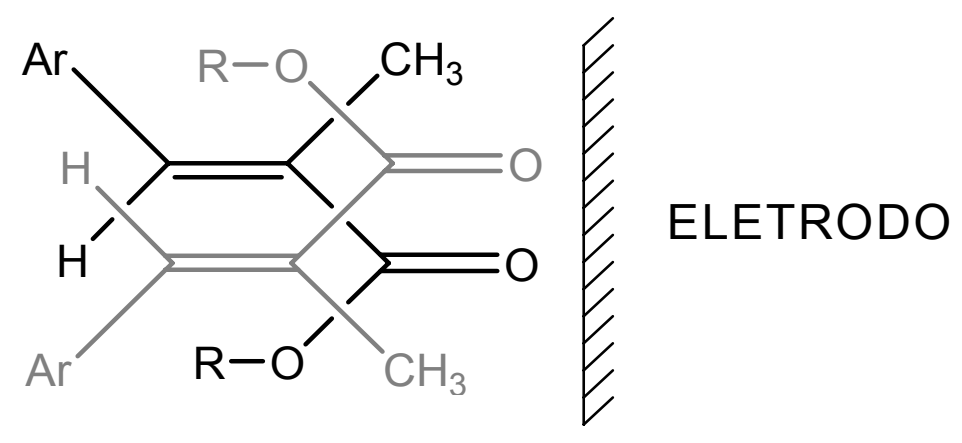

Figura II.2 Acoplamento de EHD proposto por Klemm e Olson ${ }^{10 \mathrm{~b}}$.

Nesta situação o acoplamento $\beta-\beta$ poderia ocorrer simultaneamente com a adição de um elétron a cada molécula. Com grupos $\mathrm{R}$ longos ou volumosos a aproximação necessária para um eficiente acoplamento $\beta$ - $\beta$ seria dificultada e, conseqüentemente, os rendimentos do hidrodímero cíclico diminuiriam, o que foi observado experimentalmente.

Com o intuito de verificar esta proposta foi feito o estudo dos acoplamentos de diferentes ésteres cinâmicos. Os rendimentos obtidos variam de 50 a $78 \%$, mas aparentemente o tamanho de $\mathrm{R}$ não influenciou tanto os resultados quanto sua natureza química (Tabela II.4).

Em estudos de cinética eletroquímica a baixa temperatura, Grypa e Maloy ${ }^{11 a}$ investigaram o comportamento do fumarato de dietila e do cinamato de etila em experimentos de cronocoulometria de duplo

${ }^{11}$ (a) R. D. Grypa e J. T. Maloy, J. Electrochem. Soc., 1975, 122, 509. (b) B. M. Bezilla e J. T. Maloy, J. Electrochem. Soc., 1979, 126, 579. 
degrau de potencial. Ambos os substratos parecem sofrer EHD através de ânions-radicais, em todas as temperaturas estudadas (203 - 316 K). Com base no mecanismo de dimerização íon-radical, as constantes de velocidade de dimerização dos ânions-radicais a $25^{\circ} \mathrm{C}$ (cinamato de etila: $k=225 \mathrm{~L} \mathrm{~mol}^{-1} \mathrm{~s}^{-1}$; fumarato de dietila: $k=45 \mathrm{~L} \mathrm{~mol}^{-1} \mathrm{~s}^{-1}$ ) e as respectivas energias de ativação (cinamato de etila: $\mathrm{E}^{\neq}=6,2 \mathrm{kcal} \mathrm{mol}^{-1}$; fumarato de dietila: $\mathrm{E}^{\neq}=4,6 \mathrm{kcal} \mathrm{mol}^{-1}$ ) foram calculadas.

Dando continuidade a este trabalho foram estudadas as reduções dos ésteres cinâmicos metílico e etílico, em meio de DMF, utilizando como eletrólito suporte iodeto de tetra-n-butilamônio (TBAI), em diversas temperaturas ${ }^{11 b}$. Um programa de simulação digital foi escrito considerando a reação de EHD como um pré-equilíbrio entre ânions-radicais e diânions rapidamente estabelecido, seguido por uma etapa lenta de $1^{\underline{a}}$ ordem. Esta simulação permitiu obter ordens de reação aparentes teóricas entre 1 e 2 .

Comparações dos dados experimentais e teóricos obtidos através da simulação permitiram determinar as constantes de velocidade, a $25^{\circ} \mathrm{C}$, para os cinamatos de metila e etila como sendo $9,2 \mathrm{~s}^{-1}$ e $3,7 \mathrm{~s}^{-1}$, respectivamente e as energias de ativação foram 5,8 e $5,9 \mathrm{kcal} \mathrm{mol}^{-1}$. Na mesma temperatura as constantes de equilíbrio para o pré-equilíbrio ânions-radicais-diânions foram: cinamato de etila: $K=109,0 \mathrm{M}^{-1}$ e cinamato de metila: $K=53,1 \mathrm{M}^{-1}$. As ordens de reação aparente variaram entre 1,6 e 1,7 (Esquema II.8). 


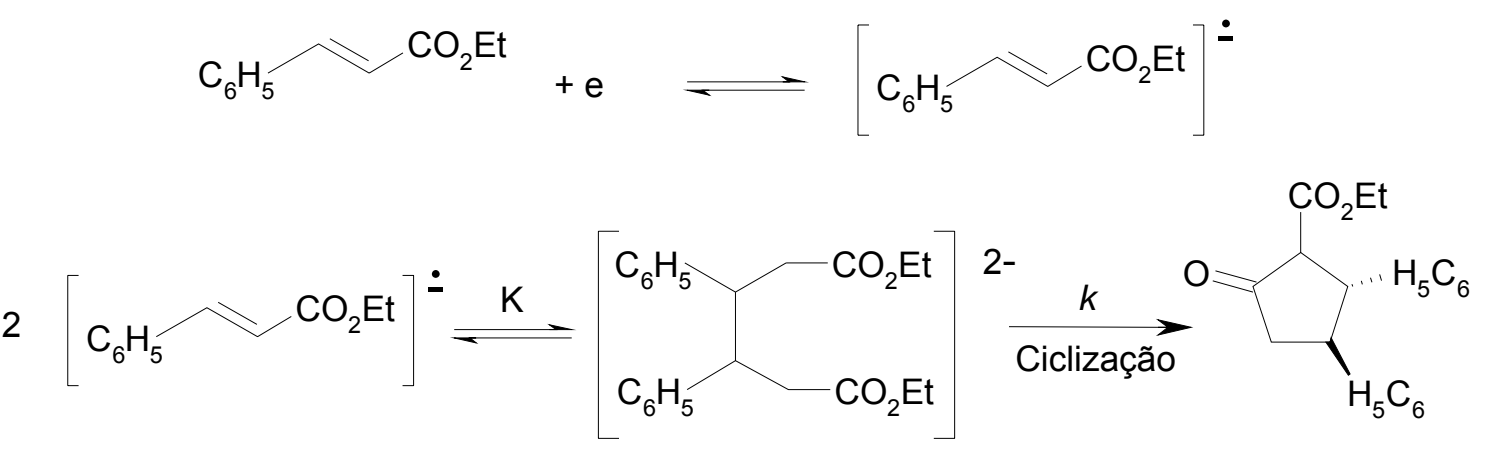

Esquema II.8 EHD proposta por Bezilla e Maloy ${ }^{11 b}$ com cálculos de $\mathrm{K}$ e $k$.

Com o objetivo de investigar o mecanismo da EHD em solventes de baixa acidez (MeCN e DMF), Savéant et al. ${ }^{12}$ fizeram estudos polarográficos, de voltametria de varredura linear e cíclica, coulometria e eletrólises preparativas de diversos compostos $\alpha, \beta$ insaturados incluindo os cinamatos de metila e etila.

Uma conclusão geral dos autores ${ }^{12 a}$, pelo menos para a faixa de concentração milimolar dos substratos, foi a de ocorrer um acoplamento radicalar de dois ânions-radicais formados em uma primeira etapa e não um ataque deste ânion-radical sobre o substrato. Esta explicação é válida para os casos em que a cinética geral da reação era independente de um doador de próton. Em condições diversas um mecanismo igual envolvendo radicais parece ser o mais

12 (a) E. Lamy, L. Nadjo e J. M. Savéant, J. Electroanal Chem., 1973, 42, 189; (b) E. Lamy, L. Nadjo e J. M. Savéant, J. Electroanal Chem., 1974, $\underline{50}, 141$. 
provável, apesar de alguma ambigüidade na interpretação dos dados cinéticos. No Esquema 11.9 é mostrada a seqüência de reações sugerida.

$$
\begin{aligned}
& \mathrm{A}+\mathrm{e}^{-} \longrightarrow \mathrm{A}^{-} \\
& 2 \mathrm{~A}^{-} \longrightarrow \mathrm{D}^{2-} \quad \text { (etapa lenta) } \\
& \mathrm{D}^{2-}+\mathrm{TH} \longrightarrow \mathrm{DH}^{-}+\mathrm{T}^{-} \\
& \mathrm{DH}^{-}+\mathrm{TH} \longrightarrow \mathrm{DH}_{2}+\mathrm{T}^{-} \\
& \mathrm{A}=\text { substrato } \\
& \mathrm{D}=\text { hidrodímero } \\
& \mathrm{TH}=\text { doador de próton }
\end{aligned}
$$

Esquema II.9 Proposta de seqüência de reações para a EHD.

Em comunicação posterior Savéant et al. ${ }^{12 b}$ discutem os papéis da protonação e solvatação com base nos dados experimentais anteriores $^{12 a}$ e alguns resultados adicionais, concluindo que a solvatação por água do ânion-radical aumenta a sua velocidade de dimerização.

Muitas investigações foram feitas sobre o mecanismo e a cinética de dimerizações eletroquímicas utilizando compostos-modelo como o fumarato de dietila ${ }^{13,14}$, o cianoantraceno ${ }^{15,16}$ e o cinamato

${ }^{13}$ (a) W. V. Childs, J. T. Maloy, C. P. Keszthelyi e A. J. Bard, J. Electrochem. Soc., 1971, 118, 874; (b) V. J. Puglisi e A. J. Bard, J. Electrochem. Soc., 1972, 119, 829; (c) Idem, 1973, 120, 748. 
de metila ${ }^{17,}{ }^{18}$. Para este ultimo composto foram feitas medidas de constantes de velocidade e equilíbrio em meio anidro e com adição de água $^{17}$, que ao serem analisadas levaram à conclusão de que o curso da reação está intimamente ligado com a concentração de água no meio. Parker $^{17}$ propõe que a hidrodimerização na ausência de água envolveria o ataque do ânion-radical no substrato e a sua velocidade estaria relacionada com a concentração do substrato e a concentração do ânion-radical ao quadrado (Equação II.1).

$$
\begin{gathered}
\mathrm{A}+\mathrm{e}^{-} \rightleftharpoons \mathrm{A}^{\dot{ }} \\
\mathrm{A}^{\dot{\bullet}}+\mathrm{A} \stackrel{k_{2}}{\longrightarrow}[\mathrm{A}-\mathrm{A}]^{\bullet} \\
{[\mathrm{A}-\mathrm{A}]^{\circ}+\mathrm{A}^{-} \stackrel{k_{3}}{\longrightarrow}[\mathrm{A}-\mathrm{A}]^{2-}+\mathrm{A}} \\
k=k_{2} k_{3}[\mathrm{~A}:]^{2}[\mathrm{~A}]
\end{gathered}
$$

Equação II.1 Equação cinética para a EHD em condições anidras.

${ }^{14}$ (a) V. D. Parker, Acta. Chem. Scand., 1981, B35, 147; (b) Idem, 1983, B34, 393.

15 (a) C. Amatore, J. Pinson e J. M. Savéant, J. Electroanal. Chem., 1982 137, 143; (b) J. M. Savéant, Acta. Chem. Scand., 1983, B37, 365.

${ }^{16}$ O. Hammerich e V. D. Parker, Acta. Chem. Scand., 1983, B37, 379.

${ }^{17}$ V. D. Parker, Acta. Chem. Scand., 1981, B35, 149.

${ }^{18}$ (a) L. N. Nekrasov e A. P. Korotkov, Soviet. Electrochem., 1980, 16, 142; (b) Idem, 1982, 18, 35. 
Cabe ressaltar que as condições experimentais usadas por Parker, com a exclusão total de água da acetonitrila, conseguida pela adição de alumina neutra à solução, não são aquelas empregadas em eletrólises preparativas. Nestas, geralmente, não são tomadas as precauções para eliminar a água residual da acetonitrila purificada em laboratório.

Os resultados das investigações, feitas por Nekrasov e Korotkov ${ }^{18}$, sobre a redução de ácido cinâmico e seus ésteres em solventes apróticos, com eletrodo de disco e anel - disco rotatórios, foram interpretados pelos autores como coerentes com uma dimerização envolvendo ânions-radicais. Foi também estudada a influência da natureza do eletrólito de suporte e a do solvente na velocidade das dimerizações dos ânions-radicais ${ }^{18 b}$. A formação de pares iônicos envolvendo os cátions do eletrólito de suporte e os ânions-radicais intermediários foi sugerida como responsável pela aceleração da reação de dimerização. Os autores verificaram que a formação dos pares iônicos era favorecida com cátions de menor raio iônico e em solventes de menores constante dielétrica e poder doador. 
Com a realização do estudo eletroquímico do ácido cinâmico e seu respectivo éster metílico, Kanestuna e Nonaka ${ }^{19}$ observaram que a estereoquímica dos produtos estava relacionada com a forma pela qual o ânion-radical intermediário era adsorvido no eletrodo. No mecanismo sugerido pelos autores, essa adsorção ocorreria pelo carbono $\beta$ (Figura II.3).

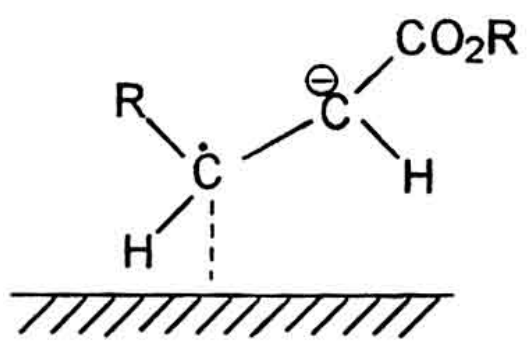

catodo

Figura II.3 Adsorção do ânion-radical.

O Esquema II.10 resume as propostas mecanísticas feitas pelos autores, justificadas pela adsorção do substrato no eletrodo.

${ }^{19}$ H. Kanestuna e T. Nonaka, Denki Kagaku, 1981, 49, 526. (Chem. Abstr.: 95:219861b). 


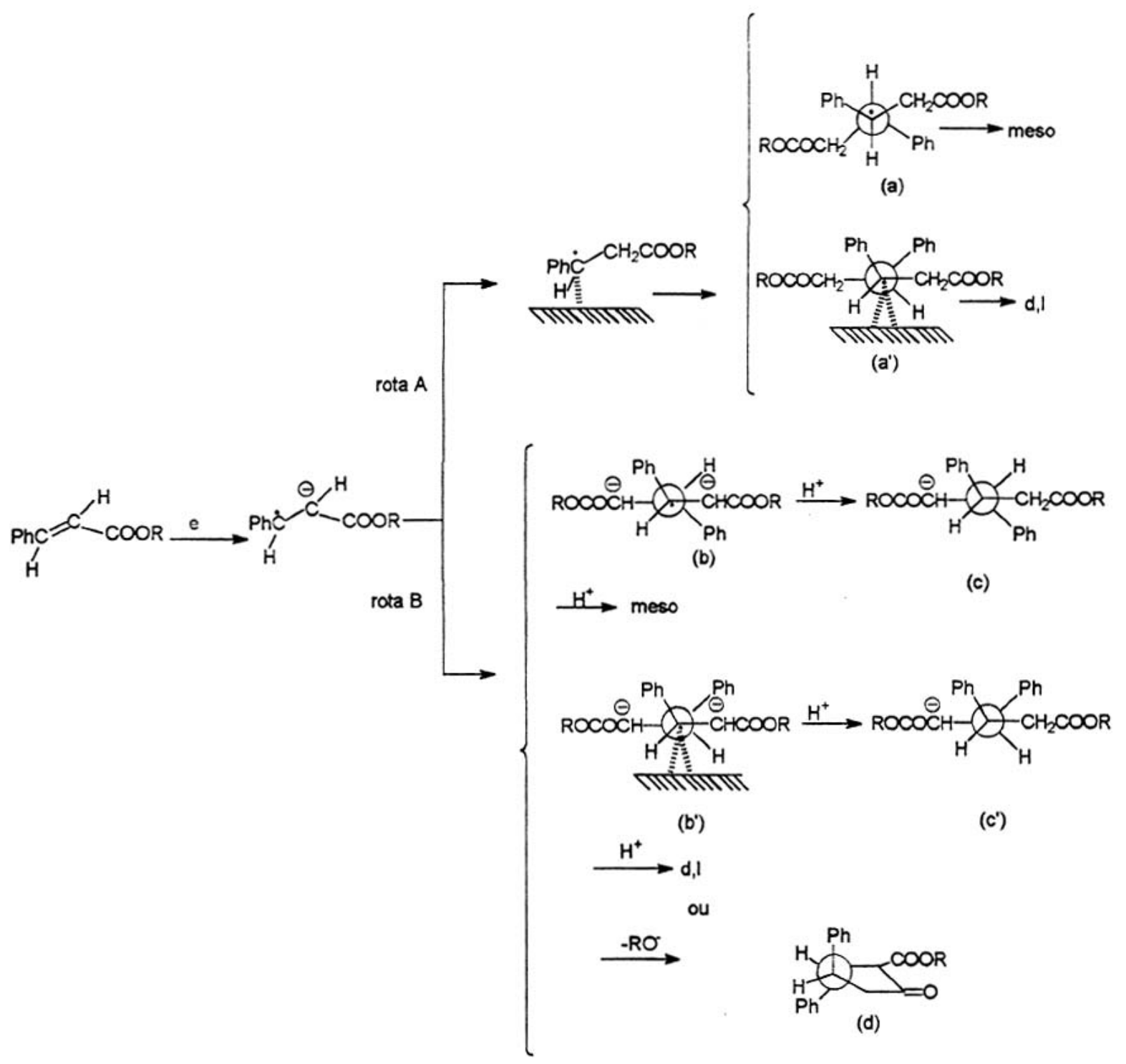

Esquema II.10 Mecanismo considerando a estereosseletividade. 
Se o ânion-radical intermediário fosse protonado (rota A (a)Esquema II.10) e o radical resultante dessorvido no cátodo, não haveria o controle estereoquímico do eletrodo e a dimerização dos radicais no meio da solução conduziria predominantemente ao hidrodímero meso via um estado de transição de menor energia do que aquele que conduz ao diastereômero $d, l$.

Por outro lado, caso os radicais continuassem adsorvidos, a adsorção seria favorável com os hidrogênios dirigidos à superfície do eletrodo (rota A (a') - Esquema II.10) e sua dimerização conduziria ao diastereomero $d, I$. Como os estereoisômeros meso e $d, I$ foram obtidos na proporção $1: 1$, os autores sugerem a ocorrência dos dois mecanismos. A rota A foi considerada para as eletrólises em condições próticas.

Quando o processo eletroquímico era realizado em condições suficientemente apróticas, a rota B (Esquema II.10) parecia ser a preferida. Esta envolve o acoplamento de ânions-radicais e, se a adsorção não desempenhasse um papel importante, o diastereômero meso seria formado preferencialmente. A formação de um derivado da ciclopentanona, com os grupos arila em trans como único produto (Esquema II.10 - rota B, (d) ) ocorreria pela dimerização dos ânionsradicais, mono-protonação e ciclização de Dieckmann. 
Do ponto de vista sintético, Nishiguchi e Hirashima ${ }^{20}$ trabalharam com a síntese de derivados da ciclopentanona a partir da EHD de diversos ésteres cinâmicos obtendo rendimentos de 52 - 78 \% como consta na Tabela II.5. Os autores não caracterizaram a estereoquímica dos hidrodímeros cíclicos.

Tabela II.5 Síntese de derivados da ciclopentanona (B) pela redução eletroquímica de cinamatos de metila substituídos (A).<smiles>[R]/C(Br)=C\C(OC)OC</smiles>

A<smiles></smiles>

$\mathrm{R} \quad \mathrm{CO}_{2} \mathrm{Me}$

B

\begin{tabular}{ccccc}
\hline & $\mathrm{Ar}$ & $\mathrm{R}$ & Rendimento $(\%)^{\mathrm{a}}$ & pf. [ $\left.{ }^{\circ} \mathrm{C}\right]$ \\
\hline 1 & $\mathrm{C}_{6} \mathrm{H}_{5}$ & $\mathrm{H}$ & 76 & $126-127$ \\
2 & $\mathrm{C}_{6} \mathrm{H}_{5}$ & $\mathrm{CH}_{3}$ & 67 & $83-87$ \\
3 & $\mathrm{C}_{6} \mathrm{H}_{5}$ & $\mathrm{C}_{2} \mathrm{H}_{5}$ & 63 & $75-80$ \\
4 & $\mathrm{C}_{6} \mathrm{H}_{5}$ & $\mathrm{C}_{6} \mathrm{H}_{5}$ & 78 & $131-133$ \\
5 & $p-\mathrm{CH}_{3} \mathrm{O}-\mathrm{C}_{6} \mathrm{H}_{5}$ & $\mathrm{H}$ & 52 & $121-123$ \\
6 & $p-\mathrm{CH}_{3}-\mathrm{C}_{6} \mathrm{H}_{5}$ & $\mathrm{H}$ & 64 & $115-116$ \\
7 & $p-\mathrm{Cl}-\mathrm{C}_{6} \mathrm{H}_{5}$ & $\mathrm{H}$ & 75 & $134-135$ \\
\hline
\end{tabular}

a Célula com agitação, diafragma de cerâmica; cátodo: cobre; ânodo: platina; solvente: DMF; eletrólito suporte: $\mathrm{Et}_{4}$ NOTs; temperatura: 10 $15^{\circ} \mathrm{C}$; potencial: $-1,9$ a $-2,2 \mathrm{~V}$ vs. E.C.S.; 4,0 F.

${ }^{20}$ (a) I. Nishiguchi e T. Hirashima, Angew. Chem. Int. Ed. Engl., 1983, 22, 52; (b) Idem, Angew. Chem. Int. Ed. Engl. Suppl. 1983, 70. 
Utilizando as mesmas condições ${ }^{20}$ Fukuda et al. ${ }^{21}$ prepararam a partir do $m$-clorocinamato de metila o respectivo ( \pm )-4,5-bis-(2clorofenil)-2-oxo-ciclopentanocarboxilato de metila com rendimento de $35 \%$ (Esquema II.11). Este foi utilizado como matéria prima para a preparação de novos ligantes bis (triarilfosfino) quirais.

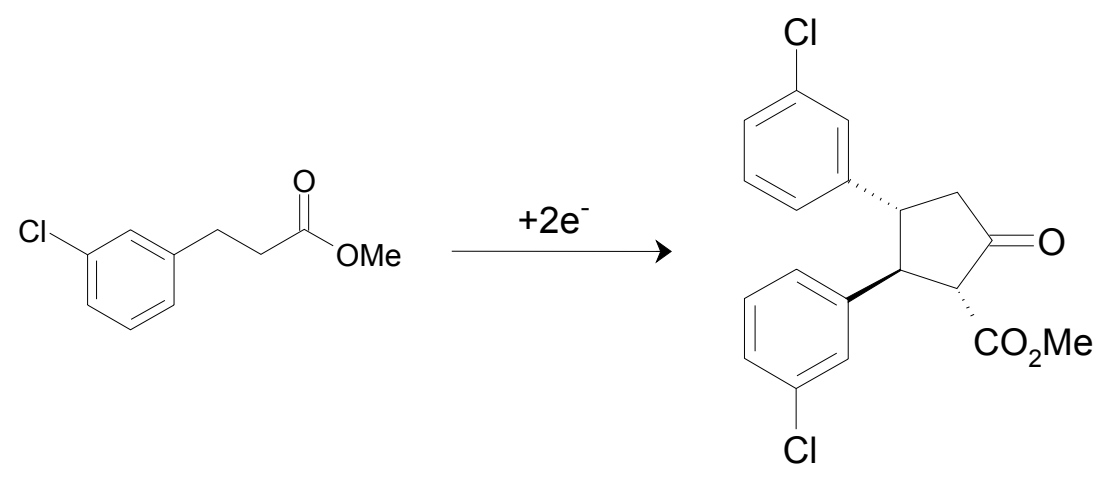

Esquema II.11 Hidrodimerização do $m$-clorocinamato de metila.

A obtenção de hidrodímeros cíclicos trans, trans com elevada estereosseletividade na eletrorredução de cinamatos levou Kise et al. ${ }^{22}$ a investigar o acoplamento redutivo de $\mathrm{N}$-trans-cinamoil2-oxazolidinonas quirais. $(3 R, 4 R)-$ e $(3 S, 4 S)$-difeniladipatos de dimetila foram sintetizados com rendimentos de $30-80 \%$ e excessos enantioméricos entre 43 a $70 \%{ }^{22 a}$ (Esquema II.12).

21 N. Fukuda, K. Mashima, Y. Matsumura e H. Takaya, Tetrahedron Lett., 1990, 31, 7185.

22 (a) N. Kise, M. Echigo e T. Shono, Tetrahedron Lett., 1994 35, 189; (b) N. Kise, S. Mashiba e N, Ueda, J. Org. Chem., 1998, 조, 7931. 


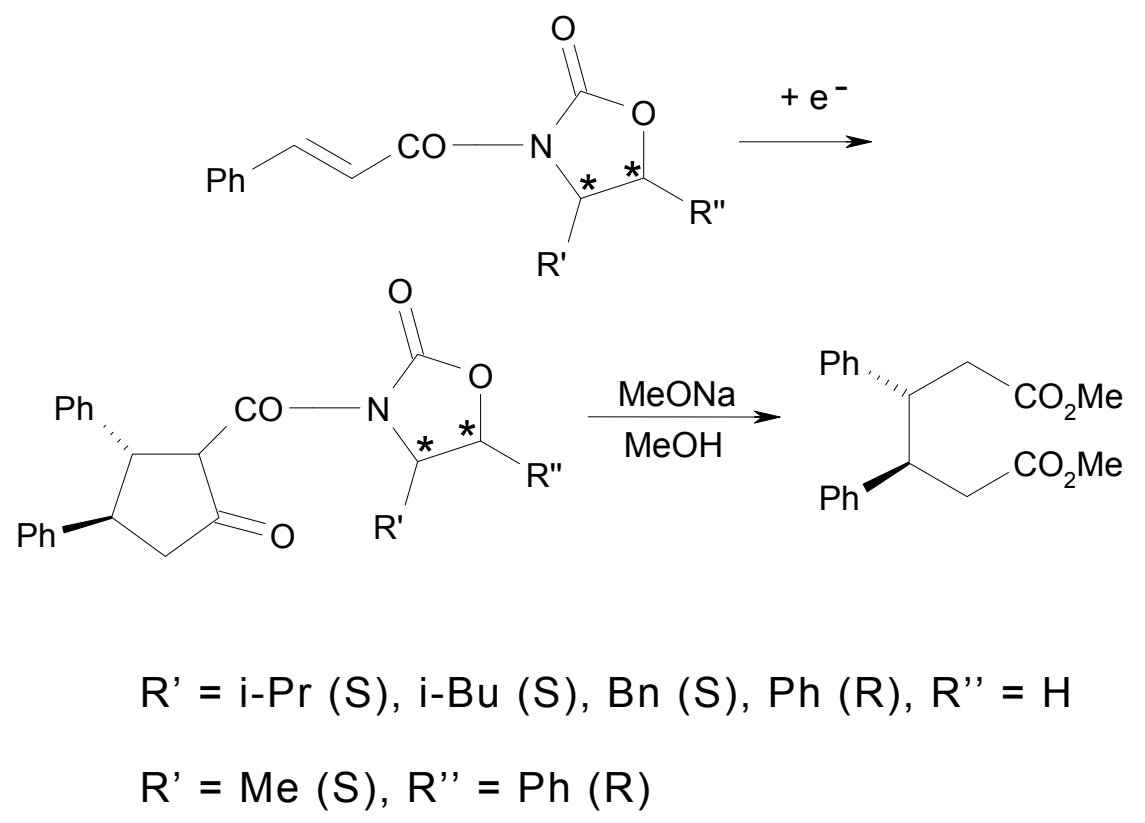

Esquema II.12 Acoplamento redutivo de N-trans-cinamoil-2oxazolidinona.

Antes de investigar o acoplamento eletrorredutivo intramolecular das $N$-trans-cinamoil-2-oxazolidinonas quirais, Kise et al. ${ }^{22 a}$ examinaram a hidrodimerização intramolecular de diésteres quirais preparados a partir de derivados do ácido (L)-tartárico e cloreto de trans-cinamoíla. Os resultados obtidos, no entanto, mostraram que os 3,4-difeniladipatos não eram formados nem com bons rendimentos nem com excessos enantioméricos (e.e.) satisfatórios (Esquema II.13). 


\begin{tabular}{|c|c|c|c|}
\hline $\mathrm{CO}_{2}$ & $R$ & $(1)+e^{-}$ & $\mathrm{Ph}$ \\
\hline $\mathrm{CO}_{2}$ & $\mathrm{R}$ & $\begin{array}{l}\text { (2) } \mathrm{NaOH} \text { aq } \\
\text { (3) } \mathrm{HCl} / \mathrm{MeOH}\end{array}$ & $n$ \\
\hline & & Rendimentos (\%) & (e.e. \%) \\
\hline & $\mathrm{R}=\mathrm{Me}$ & 42 & 50 \\
\hline & $\mathrm{R}=\mathrm{CO}_{2} \mathrm{Et}$ & 36 & 36 \\
\hline & $\mathrm{R}=\mathrm{CH}_{2} \mathrm{OBr}$ & 46 & 38 \\
\hline
\end{tabular}

Esquema II.13 Hidrodimerização intramolecular de diésteres quirais.

Kise et al. ${ }^{22 b}$ reexaminaram e apliaram a investigação do acoplamento estereosseletivo de 3-trans-cinamoiloxazolidinonas por meio da eletrorredução. A redução eletroquímica feita em célula não dividida e à corrente controlada mostrou ser mais conveniente do que a descrita anteriormente efetuada a potencial controlado $22 a$.

Foi examinada a influência dos eletrólitos de suporte sobre a estereosseletividade da eletrorredução da (S)-4-isobutil-3-transcinamoiloxazolidinona (Esquema II.12, R' = $i-\mathrm{Bu}, \mathrm{R}^{\prime \prime}=\mathrm{H}$ ). Em $0,3 \mathrm{M}$ $\mathrm{Et}_{4} \mathrm{NOTs} / \mathrm{MeCN}$, uma mistura de dois diastereômeros do hidrodímero cíclico todo trans na proporção $85: 15$ foi isolada, enquanto em 1,7 M $\mathrm{LiClO}_{4} / \mathrm{THF}$ houve formação de uma mistura de diastereômeros de 
hidrodímeros, que após transformação nos adipatos mostraram ser constituídos dos isômeros $d, I$ e meso na proporção 48:52 (Esquema II.14). Os autores discutem a estereosseletividade das dimerizações com base nas conformações dos ânions-radicais intermediários e cálculos teóricos semi-empíricos.<smiles>[X]C(=O)CCC(c1ccccc1)C(CC(=O)O[Ga])c1ccccc1</smiles><smiles>COC(=O)CC(CC(=O)OC)C(c1ccccc1)c1ccccc1</smiles>
$48 \%$ (e.e. $78 \%$ )
$52 \%$

Esquema II.14 Formação e estereoquímica dos adipatos.

A introdução de substituintes nas posições meta ou para do grupo arila, do substrato não inibiu o acoplamento eletrorredutivo nem mostrou influenciar a estereosseletividade, mas quando a posição orto foi substituída, o rendimento e a estereosseletividade do hidrodímero cíclico diminuíram.

Para melhor observação da seletividade da dimerização, Utley et al., através do uso de álcoois quirais, prepararam e estudaram 
diversos ésteres cinâmicos ${ }^{23}$. A redução destes compostos procede via acoplamento e condensação intramolecular com alta estereosseletividade e bons rendimentos de misturas diastereoméricas dos ésteres do composto todo trans $( \pm)$-2-carboxi3,4-difenilciclopentanona.

Inicialmente, foram feitos estudos voltamétricos e coulométricos, onde foram obtidos os potenciais de redução dos compostos para então serem feitas as eletrólises preparativas a potencial controlado, cujos resultados estão na Tabela II.6. Um fato interessante a ser observado é a formação de ácido cinâmico para alguns compostos.

Os excessos diastereoméricos (e.d.) observados na EHD foram modestos (0-40 \%), com exceção do composto J (Tabela II.6), em que um dos diastereômeros foi obtido com e.d. maior do que 95 \%. Esta elevada estereosseletividade foi contestada por Kise et al. ${ }^{22 b}$.

Fussing et al. ${ }^{24}$ determinaram constantes de velocidade ( $\left.\mathrm{k}_{\mathrm{obs}}\right)$ e ordens de reação para a redução catódica, em soluções de DMF, de uma série de ésteres do ácido cinâmico. A adição de água causou um aumento nas velocidades de reação de dimerização. As evidências experimentais combinadas permitiram aos autores sugerir 0

23 J. H. P. Utley, M Güllü e M. Motevalli, J. Chem. Soc. Perkin Trans 2 1995, 1961.

${ }^{24}$ I. Fussing, M. Güllü, O. Hammerich, A. Hussain, M. F. Nielsen e J. H. P. Utley, J. Chem. Soc. Perkin Trans 2 1996, 649. 
acoplamento ânion-radical - ânion-radical como a etapa chave, envolvendo uma complexação crucial com a água antes da ocorrência da dimerização (Esquema II.15).

Tabela II.6 Eletrólises preparativas de alguns cinamatos quirais ${ }^{a}$.

(E)-PhCH=CHCO<smiles>CC1CCC(C(C)C)CC1</smiles>

A<smiles>COC(=O)[C@H](OC=CC=Cc1ccccc1)C(=O)OCc1ccccc1</smiles><smiles>CCOC(C)C=CC=CC=[PH2-]</smiles>

D<smiles>CC1(C)C2CCC1(C)C(C=C=C[InH])O2</smiles>

B

(E)- $\mathrm{PhCH}=\mathrm{CHCO}_{2}^{\prime \prime \prime}, \mathrm{CO}_{2}$

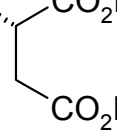

C

(E)-PhCH=CHCO $\mathrm{R}(\mathrm{Me}) \mathrm{N}$

E R=Me F R $=\mathrm{CHMe}_{2}$
G $\mathrm{R}=\mathrm{Bu}$ H R $=\mathrm{C}(\mathrm{O}) \mathrm{Et}$

I $\mathrm{R}=\mathrm{Me}$

\begin{tabular}{|c|c|c|c|}
\hline & $-\mathrm{E}_{\mathrm{pc}}(v s . \mathrm{Ag} / \mathrm{AgBr})$ & Carga (F) & Rendimento $(\%)^{a}$ \\
\hline A & 1,90 & 1,05 & 92 \\
\hline B & 2,20 & 2,20 & $--^{b}$ \\
\hline C & $1,20^{\mathrm{c}}$ & 1,50 & $--^{b}$ \\
\hline D & 1,96 & 1,20 & 89 \\
\hline$E$ & 1,65 & 1,68 & 73 \\
\hline $\mathbf{F}$ & 1,50 & 1,56 & 81 \\
\hline G & 1,80 & 1,20 & $--^{d}$ \\
\hline H & $1,45^{c}$ & 1,00 & 95 \\
\hline I & 1,85 & 1,12 & 76 \\
\hline $\mathbf{J}$ & 1,75 & 1,50 & 98 \\
\hline
\end{tabular}


${ }^{c}$ TEAB; ${ }^{d}$ Produto impuro contendo hidrodímero cíclico.

(1) $2 \mathrm{MX} \stackrel{2 e}{=} 2 \mathrm{MX}^{*}$

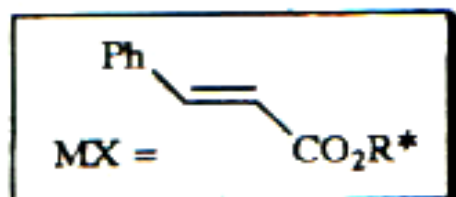

(2) $2 \mathrm{MX}^{--}+\mathrm{H}_{2} \mathrm{O} \frac{k_{1}}{k_{-1}}\left[\begin{array}{l}\mathrm{M}-\mathrm{X}--\mathrm{H}^{\prime} \\ \mathrm{M}-\mathrm{X}^{--\mathrm{H}^{\prime}}\end{array}\right]^{2-\frac{k_{2}}{k_{-2}}}\left[\left.\right|_{\mathrm{M}-\mathrm{X}} ^{\mathrm{M}-\mathrm{XH}}\right]_{\mathrm{O}}^{-}+\mathrm{HO}^{-}$

(3) $\left[\left.\right|_{\mathrm{M}-\mathrm{X}} ^{\mathrm{M}-\mathrm{XH}}\right]_{\mathrm{O}}^{-} \frac{k_{3}}{\frac{k_{-3}}{\mathrm{M}-\mathrm{XH}}}\left[\left.\right|_{\mathrm{M}-\mathrm{X}} ^{-}\right]_{\mathrm{C}} \frac{\mathrm{H}^{+}}{-\mathrm{H}^{+}}\left[\left.\right|_{\mathrm{M}-\mathrm{XH}} ^{\mathrm{M}-\mathrm{XH} \mathrm{I}}\right]_{\mathrm{C}}$

linear hydrodimers

(4) $\left[\prod_{M-X}^{M-X H}\right]_{C}^{-} \frac{k_{4}}{k_{-4}}$

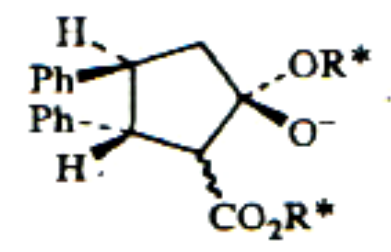

(5)

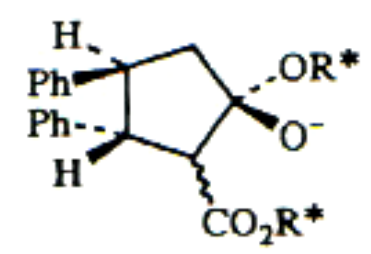<smiles>CCCC</smiles>

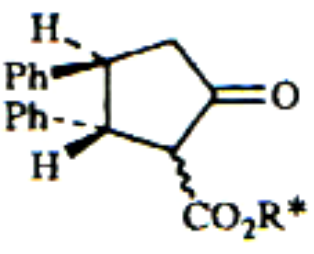

(6)

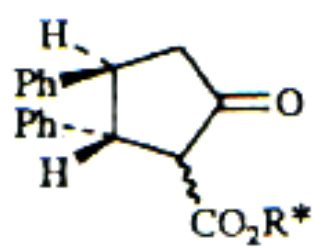<smiles>C[13CH2][13CH2][13CH3]</smiles><smiles>[R20]C(=O)C1=C([O-])CC([R])[C@H]1[C@H]([2H])c1ccccc1</smiles> 
Esquema II.15 Mecanismo considerando a cinética e a estereoquímica.

A elevada estereosseletividade na redução aos todo trans 3,4difenilciclopentanona-2-carboxilatos pode ser explicada convenientemente por meio de um complexo de dois ânions-radicais com água (Esquema II.16).
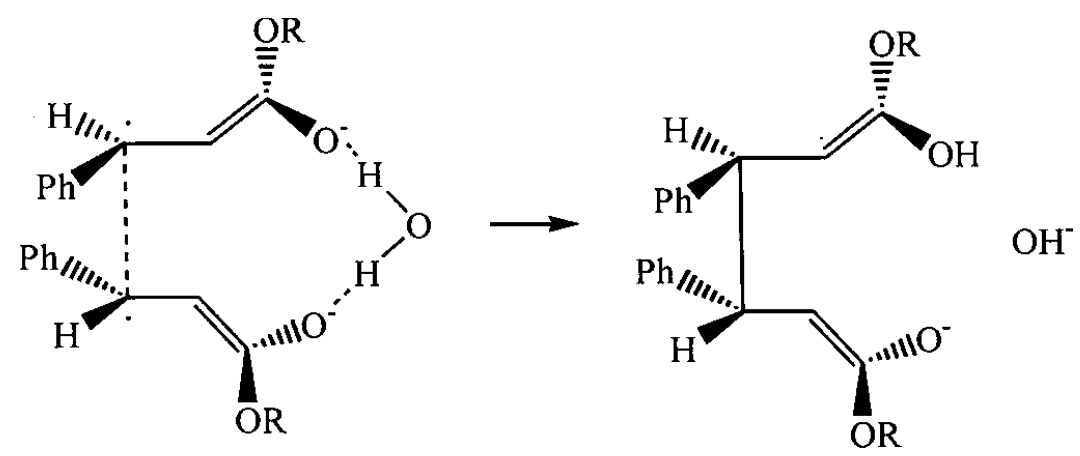

Esquema II.16 Interações de hidrogênio entre a água e o substrato durante a dimerização.

Fussing et al. ${ }^{25}$ investigaram a influência do solvente sobre o mecanismo e estereoquímica da EHD de ésteres cinâmicos em metanol e compararam os resultados obtidos com aqueles das reduções em $\mathrm{DMF}^{24}$. As principais mudanças, relacionadas com a

25 I. Fussing, O. Hammerich, A. Hussain, M. F. Nielsen e J. H. P. Utley, Acta Chem. Scand. 1998, 52, 328. 
maior acidez e a capacidade de formar ligações de hidrogênio do metanol, foram: (a) deslocamentos anódicos de $80-130 \mathrm{mV}$ dos potenciais de redução formais; (b) maiores velocidades de reação dos ânions-radicais, (c) os produtos das reduções em escala preparativa em metanol eram misturas dos ésteres saturados (carga: $2 \mathrm{~F}$ ) e os isômeros meso e $( \pm)$ do hidrodímero linear (carga: $1 \mathrm{~F}$ ) enquanto em DMF o único produto era o ciclizado; (d) a estereoquímica do produto de acoplamento exclusivamente $( \pm)$, em DMF, mudou para quantidades iguais de meso e $( \pm)$ em $\mathrm{MeOH}$. Estas alterações puderam ser racionalizadas em um mecanismo que envolve a formação inicial de um ânion-radical formando uma ligação de hidrogênio entre $\mathrm{MeOH}$ e o oxigênio carbonílico do intermediário (Esquema II.17).

Com o intuito de explicar a falta de estereosseletividade na hidrodimerização em metanol, os autores ${ }^{25}$ sugerem que em DMF o acoplamento envolve um complexo bem estruturado entre dois ânionsradicais e água, com uma configuração favorável para o acoplamento $( \pm)$. Esta situação seria bem diversa em metanol, onde a dimerização parece envolver radicais neutros. A ausência de carga nestes radicais não reduziria apenas a repulsão eletrostática no estado de transição como também tornaria os complexos de ligação de hidrogênio com metanol menos organizados estruturalmente do que o complexo entre o ânion-radical e a água em DMF. 


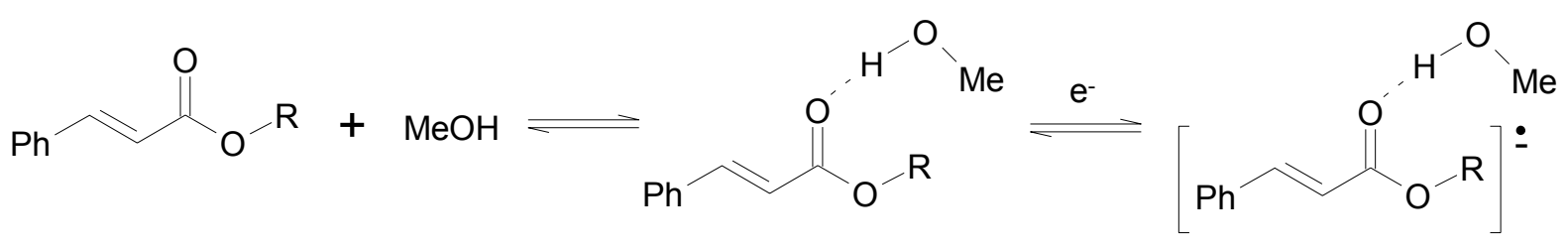

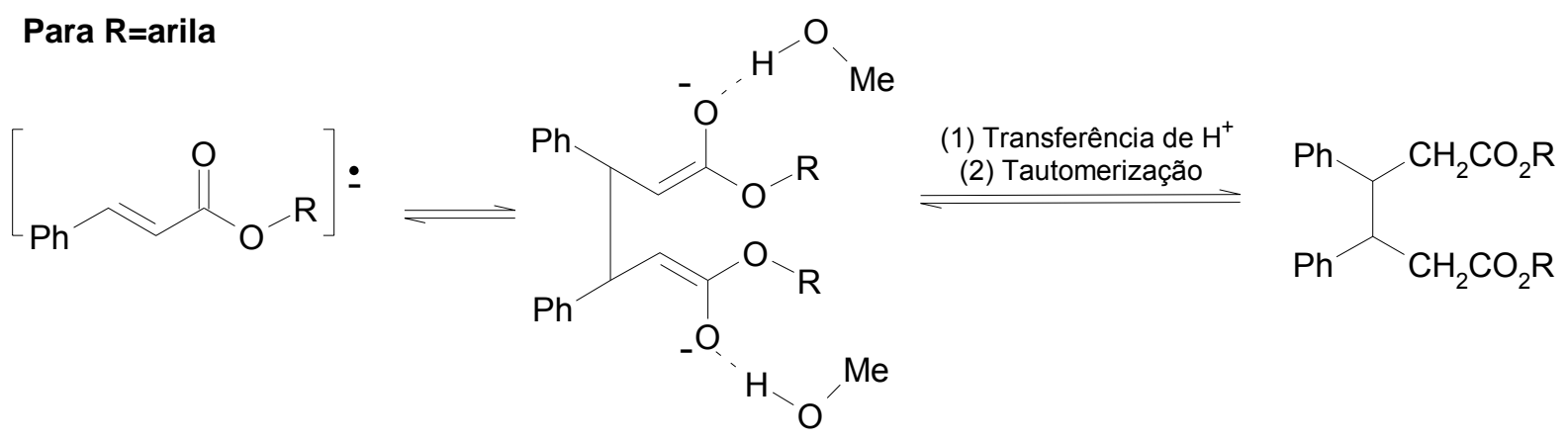

Para $\mathrm{R}=$ alquila

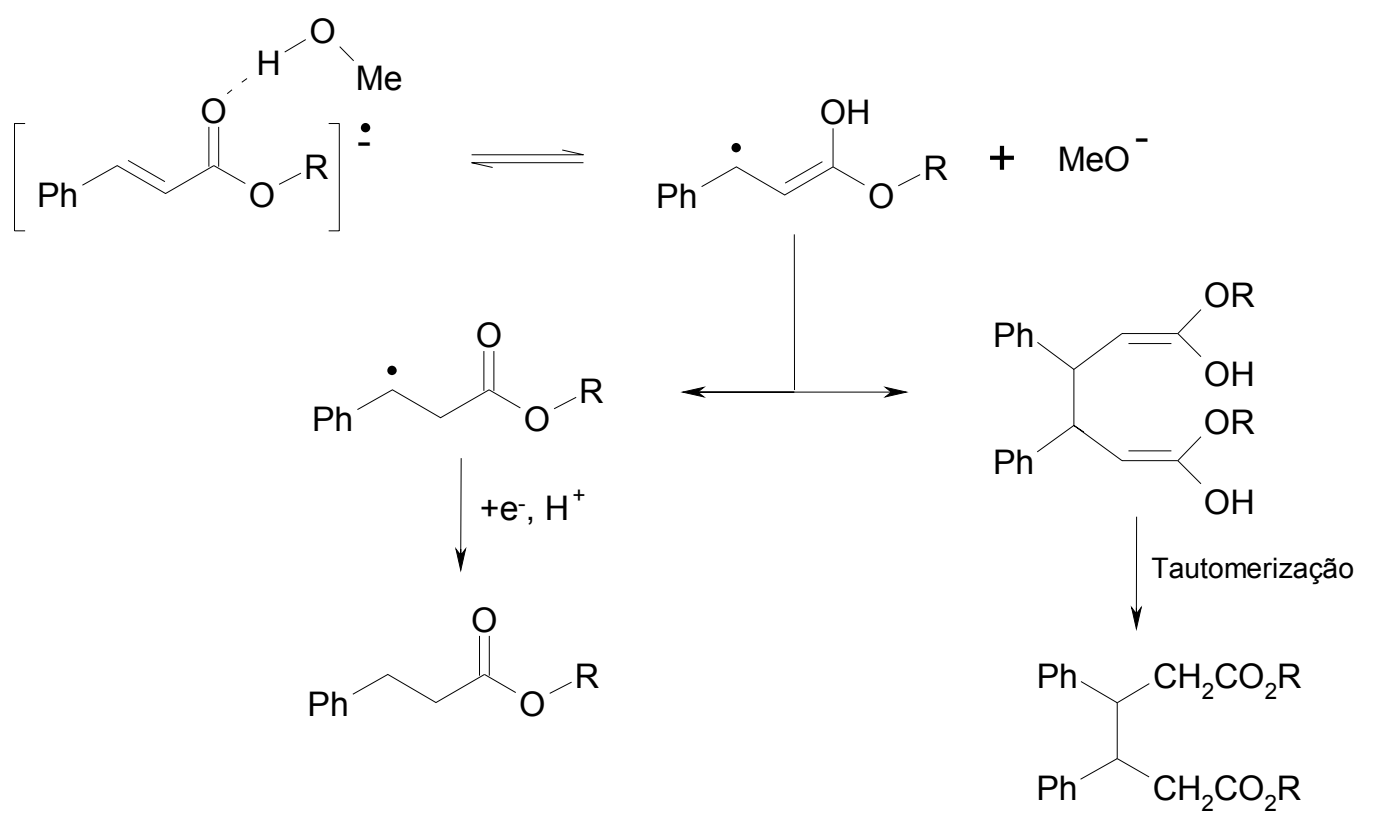


Esquema II.17 Mecanismo de EHD de cinamatos de metila em metanol.

Em estudos sobre a redução eletroquímica dos tioésteres do ácido cinâmico para e meta substituídos ${ }^{26}$ (Figura II.4) foi observada a formação do derivado da ciclopentanona em bons rendimentos (67 - $85 \%$ ), com exceção dos nitroderivados.

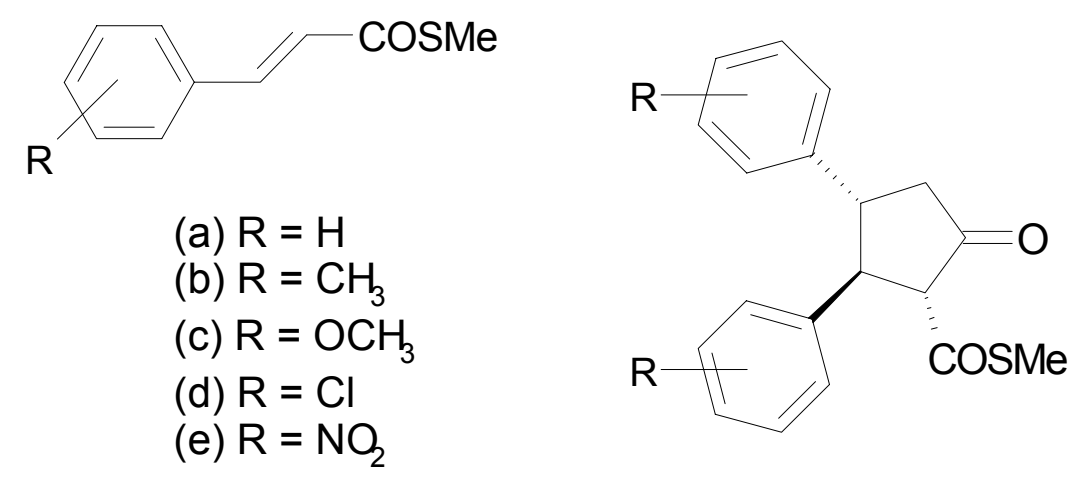

Figura II.4 Tioésteres e seus respectivos produtos de redução.

Uma reação interessante é a ciclização eletroquímica de cinamatos de metila com dieletrófilos em presença de um sal de alumínio previamente formado in situ pela eletrólise de um ácido carboxílico com um ânodo de sacrifício de alumínio ${ }^{27}$. Bons rendimentos de produtos cíclicos de três, cinco e seis membros foram

${ }^{26}$ (a) J. Gruber, F. F. Camilo, J. Chem. Soc., Perkin Trans. 1, 1999, 127; (b) idem, Helv. Chim. Acta, 1999, ⒉ 389.

${ }^{27}$ M. Güllü, Tetrahedron Lett., 1999, 40, 3225. 
obtidos nas reações de cinamato de metila com diclorometano, 1,3-dibromobutano e 1,4-dibromobutano (Esquema II.18).

Pré-eletrólise:

$$
\mathrm{Al}_{(\text {anodo) }}+3 \mathrm{R}-\mathrm{CO}_{2} \mathrm{H} \underset{\mathrm{TEAB}}{\stackrel{\mathrm{DMF}}{\longrightarrow}} \mathrm{Al}\left(\mathrm{R}-\mathrm{CO}_{2}\right)_{3}+3 / 2 \mathrm{H}_{2}
$$<smiles>CC(=O)/C=C/c1ccccc1</smiles>
$\mathrm{Ph}$

$\mathrm{Ph}$<smiles>CC(=O)/C=C/c1ccccc1</smiles><smiles>[Mg]Br</smiles><smiles>CC(=O)CC1CCCC1c1ccccc1</smiles>

Produto principal

Rend.: $87 \%$
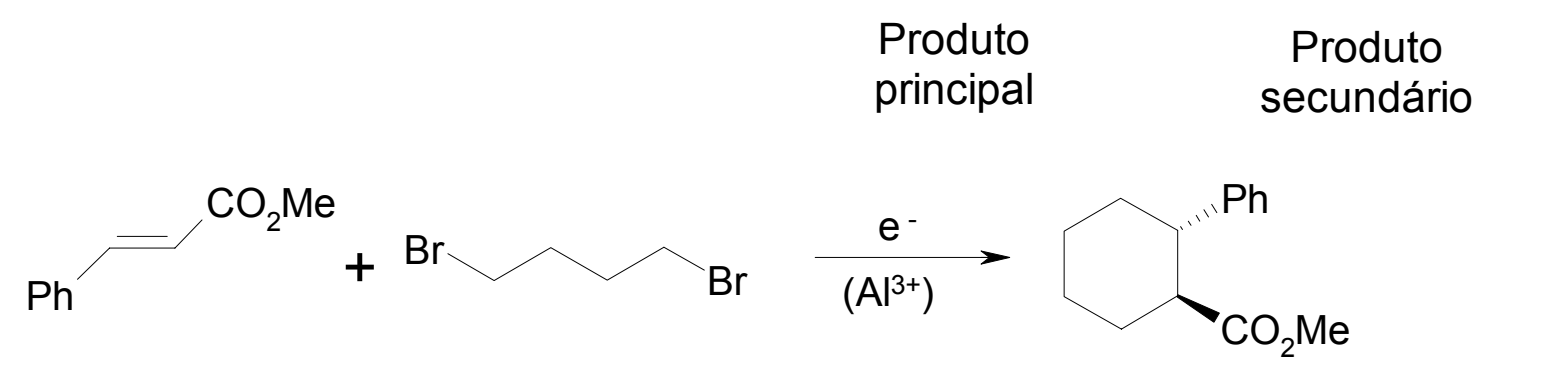

Rend.: $63 \%$

Esquema II.18 Ciclização eletroquímica de cinamato de metila e dieletrólifos.

Em estudos eletroquímicos envolvendo compostos-modelo, realizados em nosso laboratório, foram examinadas as reduções de vários cinamatos contendo substituintes metoxila no anel aromático, 
usando acetonitrila (MeCN) e DMF como solventes e mercúrio, alumínio e platina como cátodos ${ }^{28}$.

Em todas as eletrólises os hidrodímeros isolados apresentavam a estereoquímica trans acima referida, com exceção dos substratos I e II (Figura II.5), que conduziram ao lado do estereoisômero esperado com os grupos arila em trans, o correspondente cis, cuja formação ainda não fora relatada na literatura.

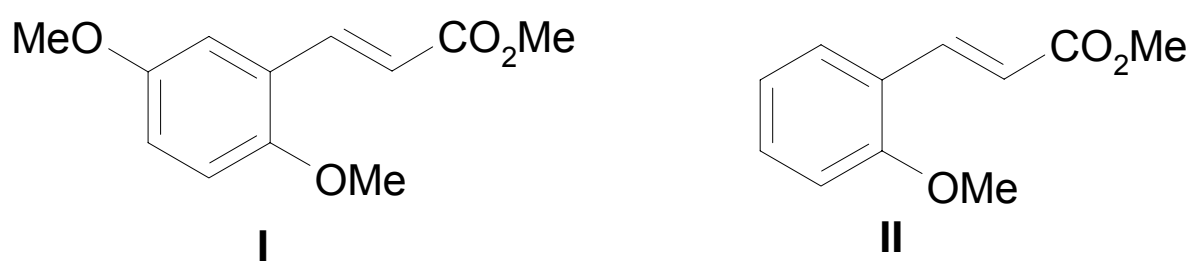

Figura II.5 Ésteres metoxilados.

Evidências indicam que o metóxi grupo presente na posição orto seja responsável pela obtenção do isômero cis, porém, a nosso ver, não existe uma explicação simples sobre a maneira como este grupo interfere no curso da formação do hidrodímero cíclico.

No entanto, este estereoisômero não foi observado por Kise et al. ${ }^{29}$ em seu estudo sobre o acoplamento estereosseletivo de ésteres cinâmicos promovidos através da redução eletroquímica que também incluiu o composto II.

${ }^{28}$ S. Sakata, Tese de Doutorado - IQ USP 1998.

${ }^{29}$ N. Kise, S. litaka, K. Iwasaki e N. Ueda, J. Org. Chem. 2002, $\underline{67}$, 8305. 
Kise et al. ${ }^{29}$ investigaram a eletrorredução de cinamatos de metila substituídos no anel aromático em acetonitrila, em cela dividida e corrente constante. Foram obtidos os hidrodímeros cíclicos todo trans estereosseletivamente, com excessos diastereoméricos entre 58 a $90 \%$. Em todos os casos pequenas quantidades (rendimentos menores do que $10 \%)$ dos hidrodímeros meso também eram formadas. É digno de nota que, na redução do o-metoxicinamato de metila foi obtido o hidrodímero cíclico todo trans, porém com baixo rendimento ao lado do hidrodímero meso e o 3 (o-metoxifenil)-propanoato de metila. (Esquema II.19).

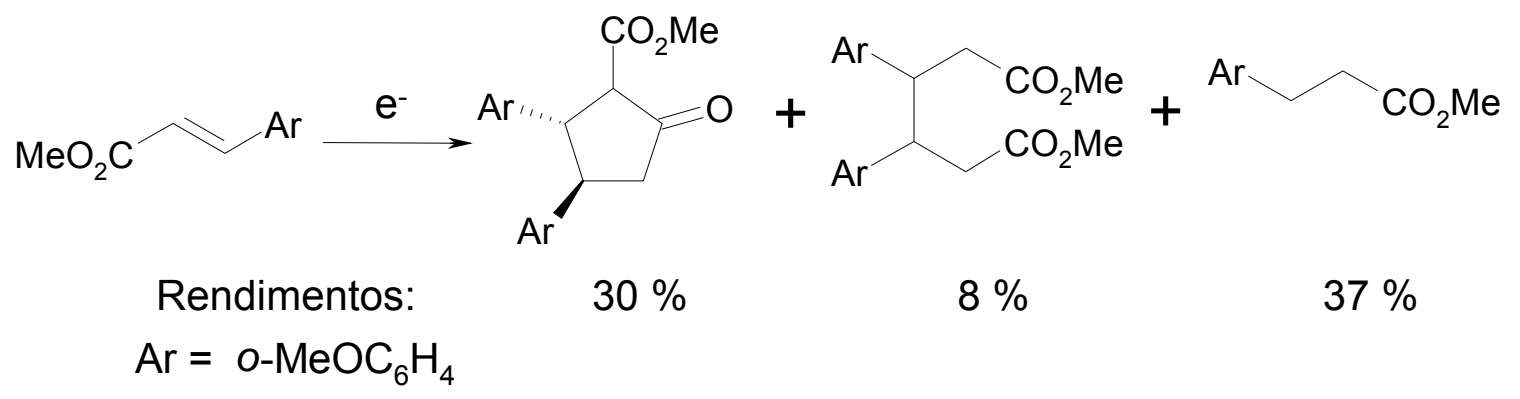

\section{Esquema II.19}

Com substituintes nas posições meta e para, os rendimentos do hidrodímero cíclico foram semelhantes aos do cinamato de metila. Os autores com base em cálculos semi-empíricos concluíram que o estado de transição que conduz ao hidrodímero $d, I$ era mais estável do que o que leva ao meso. Desta maneira não aceitavam qualquer das sugestões dadas anteriormente ${ }^{24}$ sobre a elevada seletividade $d, I$. 
Recentemente foi descrito ${ }^{30}$ também 0 acoplamento redutivo seguido de condensação de Dieckmann, induzidos por Sml $\mathrm{Sm}_{2}$. Entre os substratos estudados encontra-se o cinamato de metila, o qual foi transformado em hidrodímeros cíclicos com estereoquímica tanto cis como trans entre os grupos fenila (Esquema II.20 e Tabela II.7).
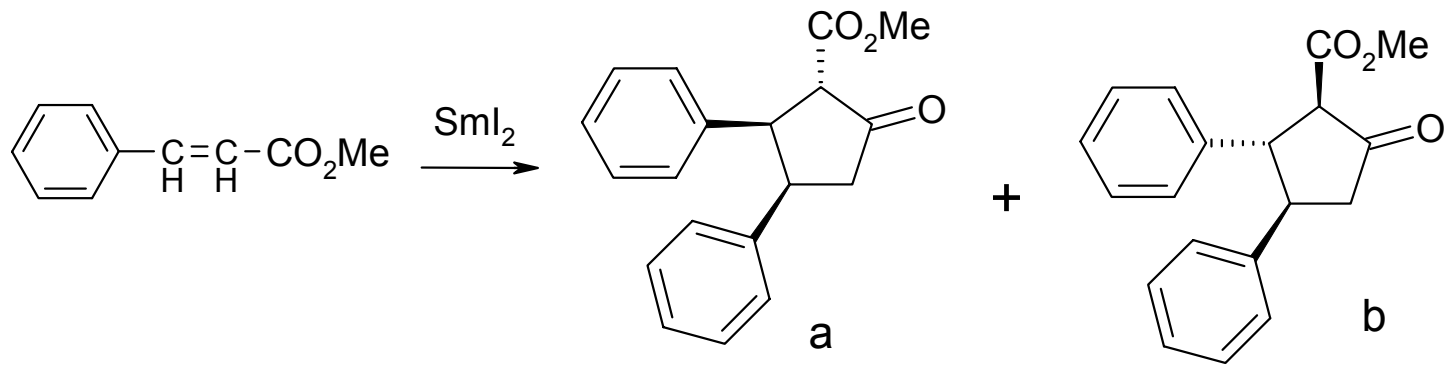

Esquema II.20 Reação do cinamato de metila com iodeto de samário levando as hidrodímeros cíclicos.

Tabela II.7 Rendimentos das reação do cinamato de metila com iodeto de samário em diferentes condições.

\begin{tabular}{ccc}
\hline Tempo de reação & Rendimento* & a:b \\
\hline $2,5 \mathrm{~h}^{\mathrm{a}}$ & $47 \%$ & $3: 1$ \\
$5 \mathrm{~min}^{\mathrm{b}}$ & $70 \%$ & $1: 2$ \\
\hline
\end{tabular}

* Rendimento dos produtos isolados.

a Condições: 0,75 equiv. de $\mathrm{Sml}_{2}$.

${ }^{b}$ Condições: 3,3 equiv. de HMPA [( $\left.\left.\mathrm{Me}_{2} \mathrm{~N}\right)_{3} \mathrm{PO}\right]$ e 1,1 equiv de $\mathrm{Sml}_{2}$.

${ }^{30}$ I. Shinohara, M. Okue, Y. Yamada, H. Nagaoka, Tetrahedron Lett., 2003, 44, 4649 . 


\section{Objetivos}

A redução eletroquímica de cinamatos de metila em DMF ou acetonitrila conduz aos hidrodímeros, 2-oxo-c-4-t-5-diarilciclopentanor-1-carboxilatos de metila, com elevada estereosseletividade conforme relatado na introdução.

A surpreendente obtenção de uma mistura do estereoisômero esperado e de um de seus diastereômeros, o 2-oxo-t-4-t-5-diarilciclopentano-r-1-carboxilato de metila, na eletrorredução do o-metoxicinamato de metila ${ }^{28}$, nos levou a investigar a influência redução de outros substituintes na posição orto do anel aromático do cinamato de metila sobre o curso estereoquímico da. Os substituintes escolhidos foram os grupos metila, cloro, nitro e metoxicarbonila. 


\section{Resultados e Discussão}

\section{Preparação dos substratos}

O o-metilcinamato de metila (1) foi sintetizados de acordo com o Esquema IV.1.

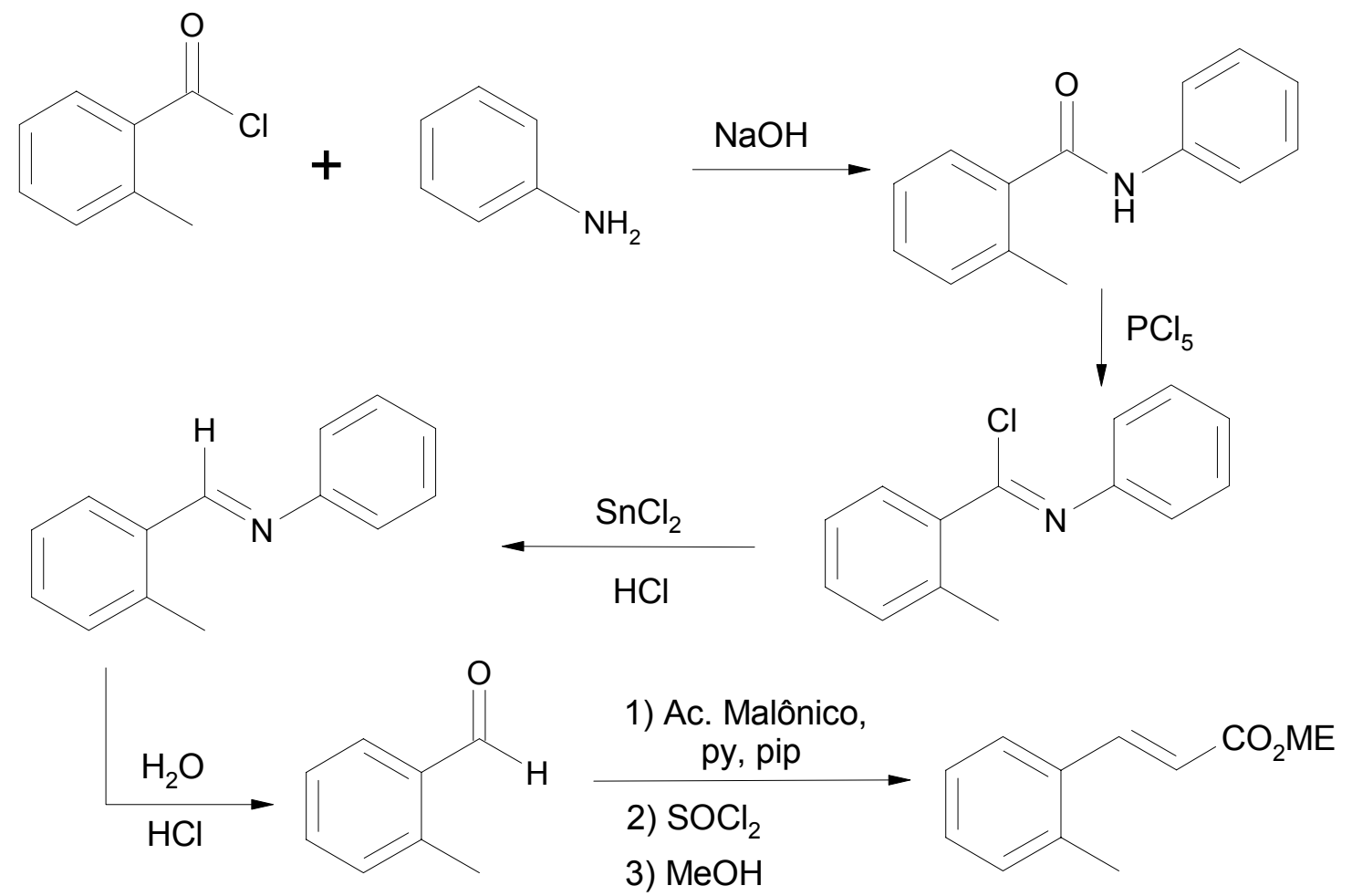

Esquema IV.1 Preparação do o-metilcinamato de metila (1) 
Nesta preparação a o-toluanilida obtida por procedimento descrito para a benzanilida ${ }^{31}$, foi utilizada para a síntese do o-tolualdeído (o-metilbenzaldeído) ${ }^{32}$. Este foi transformado no ácido o-metilcinâmico (1a) empregando a modificação de Doebner da reação de Knoevenagel ${ }^{31 b}$. Como a esterificação do ácido (1a) por meio de metanol na presença de ácido sulfúrico concentrado como relatado para o ácido cinâmico ${ }^{31 c}$, conduziu ao produto desejado (1) em rendimento apenas regular, resolveu-se preparar o cloreto de $\mathbf{1 a}$, o qual foi feito reagir com excesso de metanol anidro fornecendo $1 \mathrm{com}$ $82 \%$ de rendimento.

A preparação do o-nitrocinamato de metila (3) está resumida no Esquema IV.2.

${ }^{31}$ (a) A. I. Vogel, "Textbook of Practical Organic Chemistry", 4" ed., Longman Groups, 1978. p. 683. (b) A. I. Vogel, "Textbook of Practical Organic Chemistry", 5a ed., Longman Groups, 1989, p. 1040, (c) Idem, p. 1078.

32 J. W. Williams, C. H. Witten, J. A. Krynitsky, Org. Synth., 1955, Coll. Vol. III, p 818. 
<smiles>O=Cc1ccccc1[N+](=O)[O-]</smiles><smiles>CC(=O)OCc1ccncn1</smiles><smiles>O=C(O)/C=C/c1ccccc1[N+](=O)[O-]</smiles><smiles>COC(=O)/C=C/c1ccccc1[N+](=O)[O-]</smiles><smiles>COCCO</smiles><smiles>O=C(Cl)/C=C/c1ccccc1[N+](=O)[O-]</smiles>

Esquema IV.2 Preparação do o-nitrocinamato de metila (3) através do método 1.

As reações do o-nitrobenzaldeído com ácido malônico de acordo com o procedimento descrito ${ }^{31 b}$ para obter o ácido o-nitrocinâmico (3a) e de sua transformação no éster metílico (3) empregando a metodologia usada na preparação do o-metilcinamato de metila foram realizados com sucesso ( $74 \%$ de rendimento).

Dois métodos foram utilizados para a preparação do onitrobenzaldeído. No primeiro partiu-se de o-nitrotolueno que, reagido com N-bromosuccinimida (NBS) e piridina resultou no brometo de o-nitrobenzilpiridinio ${ }^{33}$. Este foi feito reagir com o cloreto de p-nitroso- $N, N$-dimetilanilínio previamente preparado a partir da

${ }^{33}$ A. Kalir, Org. Synth., 1973 Coll. Vol. V p. 825. 
$\overline{N, N \text {-dimetilanilina }{ }^{34} \text { levando a } N \text {-oxi-imina cuja hidrólise com ácido }}$ sumfírico aquoso resultou no o-nitrobenzaldeído. o-nitrobenzilpiridina que então com ácido sulfúrico e água resultou no 0 -nitrobenzaldeído ${ }^{33}$ (Esquema IV.2.a).

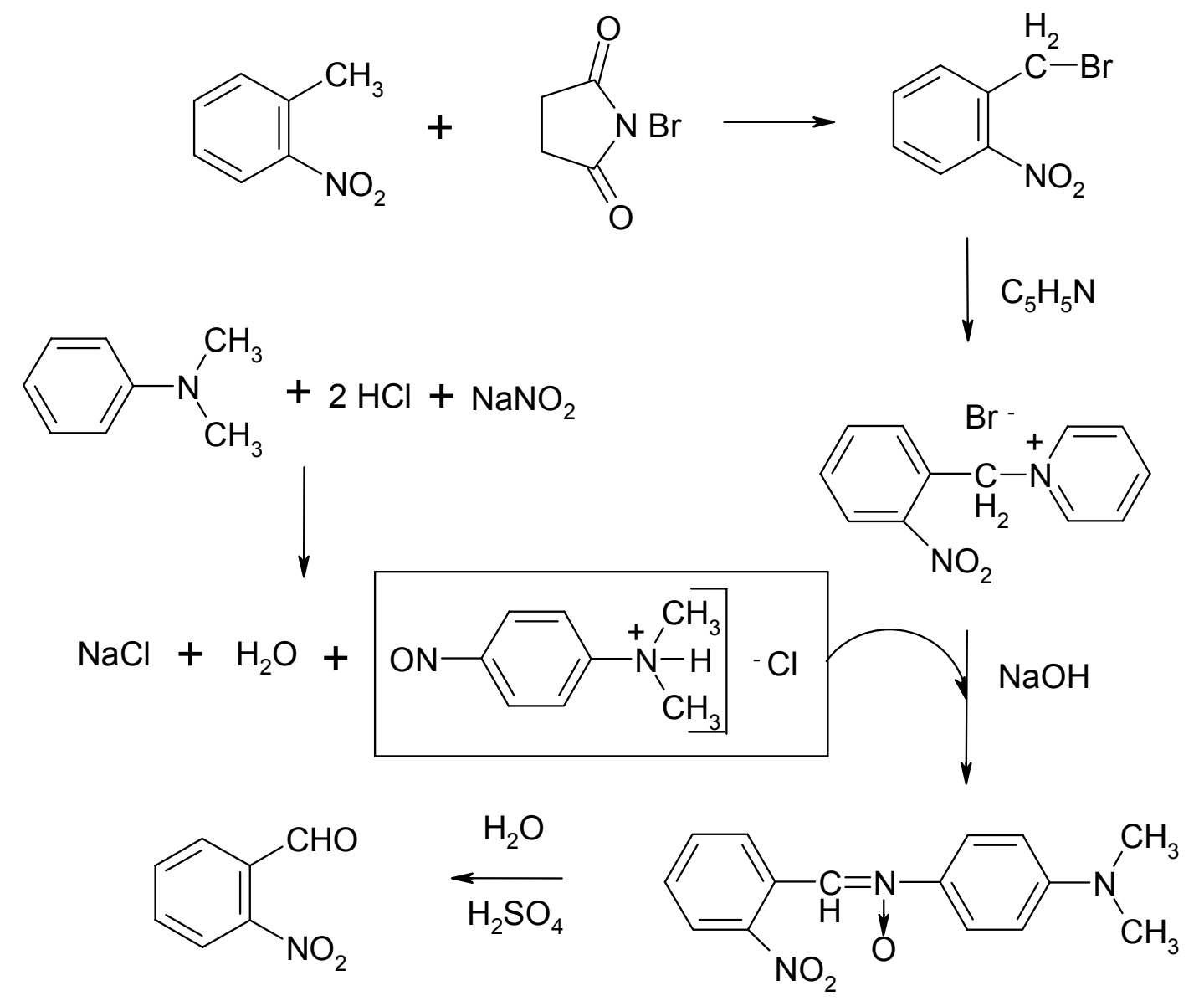

Esquema IV.2.a Preparação do o-nitrocinamato de metila (3) através do método 1 .

${ }^{34}$ G. M. Bennett, E. V. Bell, Org. Synth. Coll. Vol. II , 1943 p. 223. 
No segundo procedimento, o-nitrobenzaldeído foi preparado a partir da oxidação do álcool o-nitrobenzílico comercial com $\mathrm{PCC}^{35}$ (Esquema IV.2.b)<smiles>O=Cc1ccccc1[N+](=O)[O-]</smiles>

Esquema IV.2.b Preparação do o-nitrocinamato de metila (3) através do método 2 .

Analogamente à preparação do o-nitrocinamato de metila (3), o $m$-nitrocinamato de metila (7) foi obtido a partir do $m$-nitrobenzaldeído comercial com rendimento de $77 \%$ (Esquema IV.3).

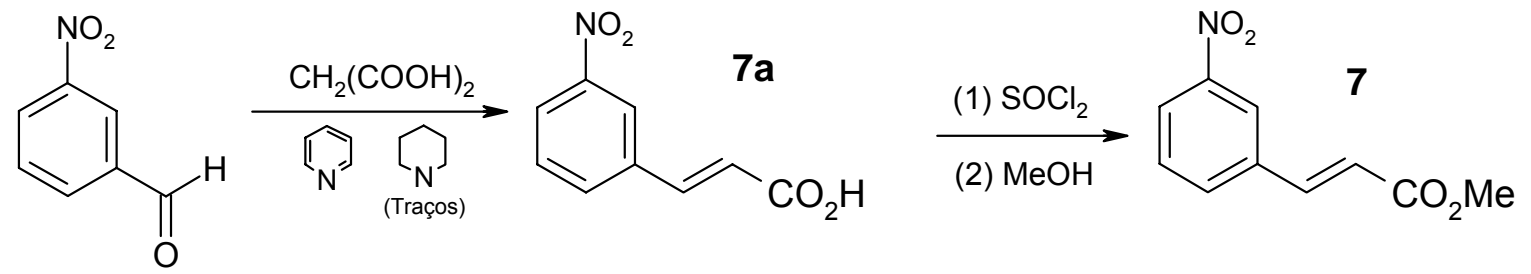

Esquema IV.3 Preparação do $m$-nitrocinamato de metila (7).

${ }^{35}$ E. J. Corey, W. Suggs, Tetrahedron. Lett., 1975, 31, 2647. 
Os o-cloro- (2), $m, p$-dicloro- (4), $m$-cloro- (5) e $p$-cloro- cinamatos de metila (6) foram preparados utilizando clorobenzaldeídos correspondentes como substratos de partida, na reação de DoebnerKnoevenagel para a síntese dos ácidos cinâmicos. Os ácidos assim obtidos foram esterificados com metanol contendo ácido sulfúrico concentrado (ésteres 5 e 6) ou por meio da obtenção prévia do cloreto de ácido e a deste com metanol (ésteres 2 e 4) apresentando rendimentos globais de 60 a $85 \%$.<smiles>[R]c1ccc(C=O)c([R])c1[R]</smiles><smiles>CC(=O)OCc1cccnc1</smiles><smiles>[R]c1ccc(/C=C/C(=O)O)c([R])c1[R]</smiles>

\begin{tabular}{|c|c|c|c|c|c|c|}
\hline Éster & Ácido & $\mathrm{R}^{1}$ & $\mathrm{R}^{2}$ & $\mathrm{R}^{3}$ & \multirow{5}{*}{$\begin{array}{l}\text { (1) } \mathrm{SOCl}_{2} \\
\text { (2) } \mathrm{MeOH}\end{array}$} & \multirow{5}{*}{$\begin{array}{l}\mathrm{MeOH} \\
\mathrm{H}_{2} \mathrm{SO}_{4} \text { conc. } \\
\text { e } 6\end{array}$} \\
\hline 2 & $2 a$ & $\mathrm{Cl}$ & $\mathrm{H}$ & $\mathrm{H}$ & & \\
\hline 4 & $4 a$ & $\mathrm{H}$ & $\mathrm{Cl}$ & $\mathrm{Cl}$ & & \\
\hline 5 & $5 a$ & $\mathrm{H}$ & $\mathrm{Cl}$ & $\mathrm{H}$ & & \\
\hline 6 & $6 a$ & $\mathrm{H}$ & $\mathrm{H}$ & $\mathrm{Cl}$ & & \\
\hline
\end{tabular}

Esquema IV.4 Preparação dos cinamatos de metila clorados $(\mathbf{2}, \mathbf{4 - 6})$. 
As etapas da síntese do o-metoxicarbonilcinamato de metila (8) encontram-se detalhadas no Esquema IV.5.

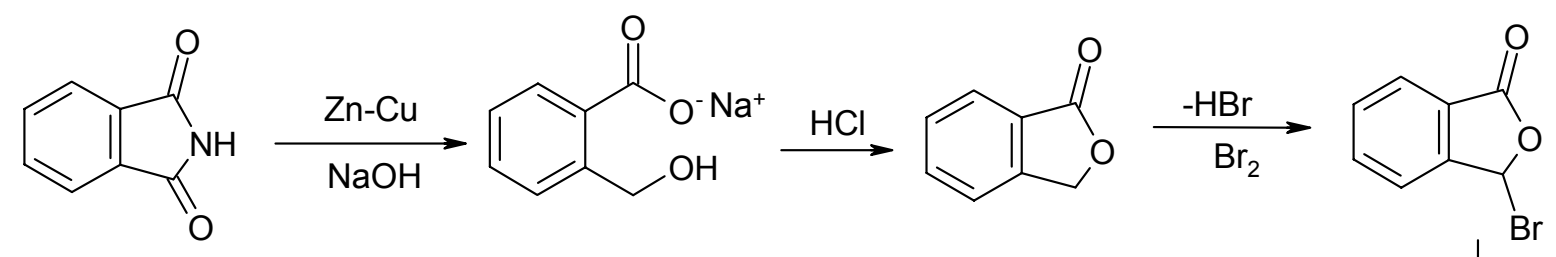<smiles>O=C(O)CC1OC(=O)c2ccccc21</smiles><smiles>COC(=O)/C=C/c1ccccc1C(=O)OCC(=O)O</smiles>

Esquema IV.5 Preparação do o-metoxicarbonilcinamato de metila (8).

O o-carboxibenzaldeído foi preparado a partir da ftalimida. Esta foi reduzida com zinco ativado por cobre em meio alcalino $(\mathrm{NaOH})$ conduzindo ao o-hidroximetilbenzoato de sódio que foi lactonizaado com ácido clorídrico formando a ftalida ${ }^{36}$. A reação da ftalida com bromo forneceu a bromoftalida que, foi hidrolizada ao o-

${ }^{36}$ J. H. Gardner e C. A. Naylor, Org. Synth. Coll. Vol II 1943,, 526. 
carboxibenzaldeído ${ }^{37}$. Este aldeído pode se transformar com o tempo na 3-hidroxiftalida através do equilíbrio existente entre estas duas formas ${ }^{38}$. A posição deste equilíbrio depende do $\mathrm{pH}$ do meio, sendo a forma aberta favorecida em meio alcalino ou fortemente ácido ${ }^{39}$. No caso de ser adquirido comercialmente, o benzaldeído estará provavelmente está na forma de 3-hidroxiftalida ${ }^{39}$, que pode ser transformada novamente no o-carboxibenzaldeído através do seu aquecimento em solução de hidróxido de sódio.<smiles>O=Cc1ccccc1C(=O)O</smiles>

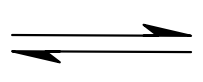<smiles>O=C1OC(O)c2ccccc21</smiles>

Esquema IV.6 Equilíbrio entre o o-carboxibenzaldeído. e a 3-hidroxiftalida.

A reação de Doebner-Knoevenagel do o-carboxibenzaldeído com ácido malônico não conduziu ao ácido o-carboxicinâmico (8a), mas á lactona (8'a). Para obter o ácido cinâmico $(\mathbf{8 a})^{40}$ a lactona foi hidrolizasa em meio alcalino e, após acidular o meio, o ácido $\mathbf{8 a}$ foi isolado. É

${ }^{37}$ R. L. Shriner e F. J. Wolf, Org. Synth. Coll. Vol III, 1955, 737.

${ }^{38}$ D. D. Wheeler, D. C. Young, D. S. Erley, J. Org. Chem., 1957, 22, 547.

39 J. Kagan, J. Org. Chem., 1967, 32, 4060.

${ }^{40}$ A. F. Titley, J. Chem. Soc., 1928, 2571. 
digno de nota, que 8a transforma-se rapidamente na lactona 8'a ao ser fundido ${ }^{41}$.

O ácido foi secado, feito reagir com cloreto de tionila e o cloreto de acila foi trtansformado no produto com metanol em excesso. A análise do produto de reação revelou ser constituído de uma mistura de cinamato (8) e o éster metílico da lactona (8'). Os dois compostos foram separados em coluna cromatográfica de sílica gel e 8', quando submetido à hidrólise alcalina, permitiu obter novamente o ácido cinâmico 8a empregado para preparar mais do produto desejado, o ometoxicarbonilcinamato de metila (8).

\section{Experimentos eletroquímicos}

\subsection{Voltametria Cíclica}

As experiências de voltametria cíclica foram realizadas com o objetivo principal de determinar os potenciais de redução dos substratos, para que pudessem servir de orientação para o potencial a ser aplicado nas eletrólises preparativas. Os potenciais de pico registrados para os substratos estudados são os apresentados na Tabela IV.1 e os voltamogramas registrados nas Figura IV.1Figura IV.8.

${ }^{41}$ F. M. Rowe, A. S. Haigh e A. T. Peters, J. Chem. Soc., 1936, 1098. 
Tabela IV.1 Potenciais dos picos de redução dos cinamatos de metila 1 - 8 obtidos por voltametria cíclica.

\begin{tabular}{cc|cc}
\hline Subst. & -Epc (V) & Subst. & -Epc (V) \\
\hline 1 & 1,37 & 5 & 1,24 \\
2 & 1,24 e 1,42 & 6 & 1,26 e 1,36 \\
3 & 0,$52 ; 1,00$ e 1,61 & 7 & 0,$68 ; 1,32$ e 1,65 \\
4 & 1,16 e 1,27 & 8 & 1,25 e 1,54 \\
& & $9 *$ & 1,38 \\
\hline
\end{tabular}

*9 - cinamato de metila.

Condições experimentais: DMF / 0,1 $\mathrm{mol} \mathrm{L}^{-1}$ TEAP; eletrodo de trabalho: mercúrio depositado em platina; eletrodo de referência: fio de prata em solução de DMF / 0,1 mol L-1, TEAP 0,05 mol L-1, iodeto de tetrabutilamônio (TBAl); velocidade de varredura: $200 \mathrm{mVs}^{-1}$; substrato: $10^{-3} \mathrm{~mol} \mathrm{~L}^{-1}$. 


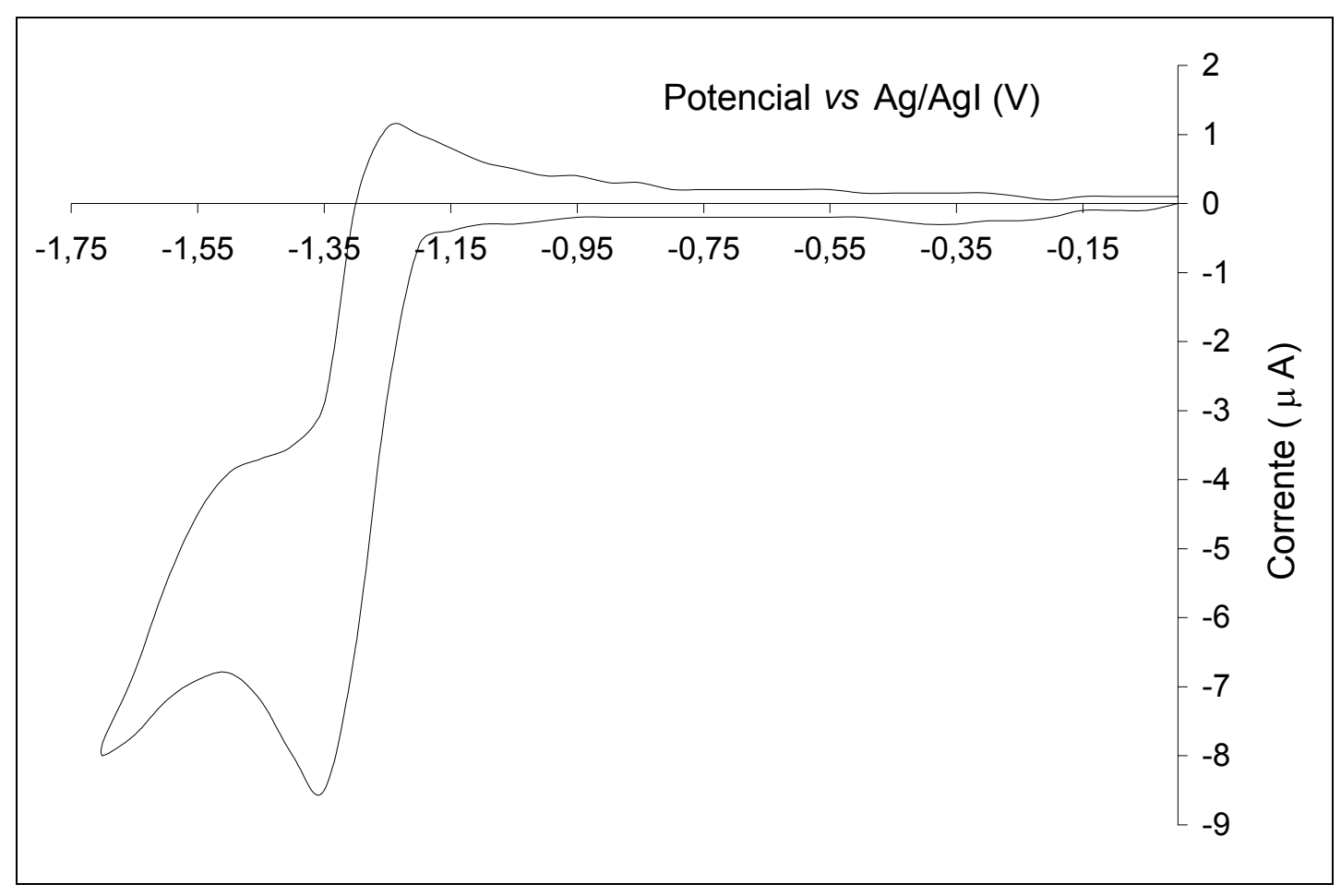

Figura IV.1 Voltamograma do o-metilcinamato de metila (1)

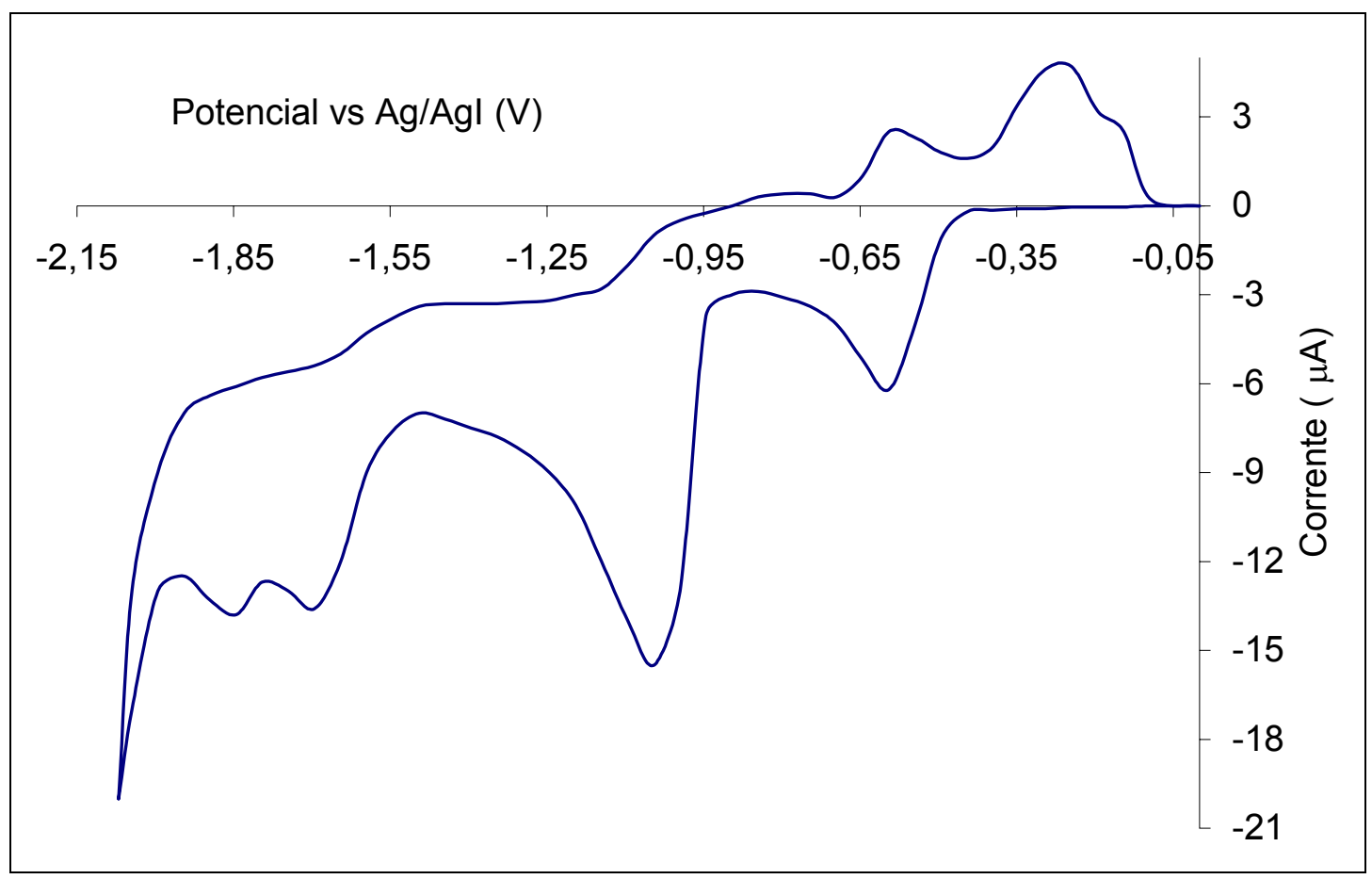

Figura IV.2 Voltamograma do o-nitrocinamato de metila (3) 


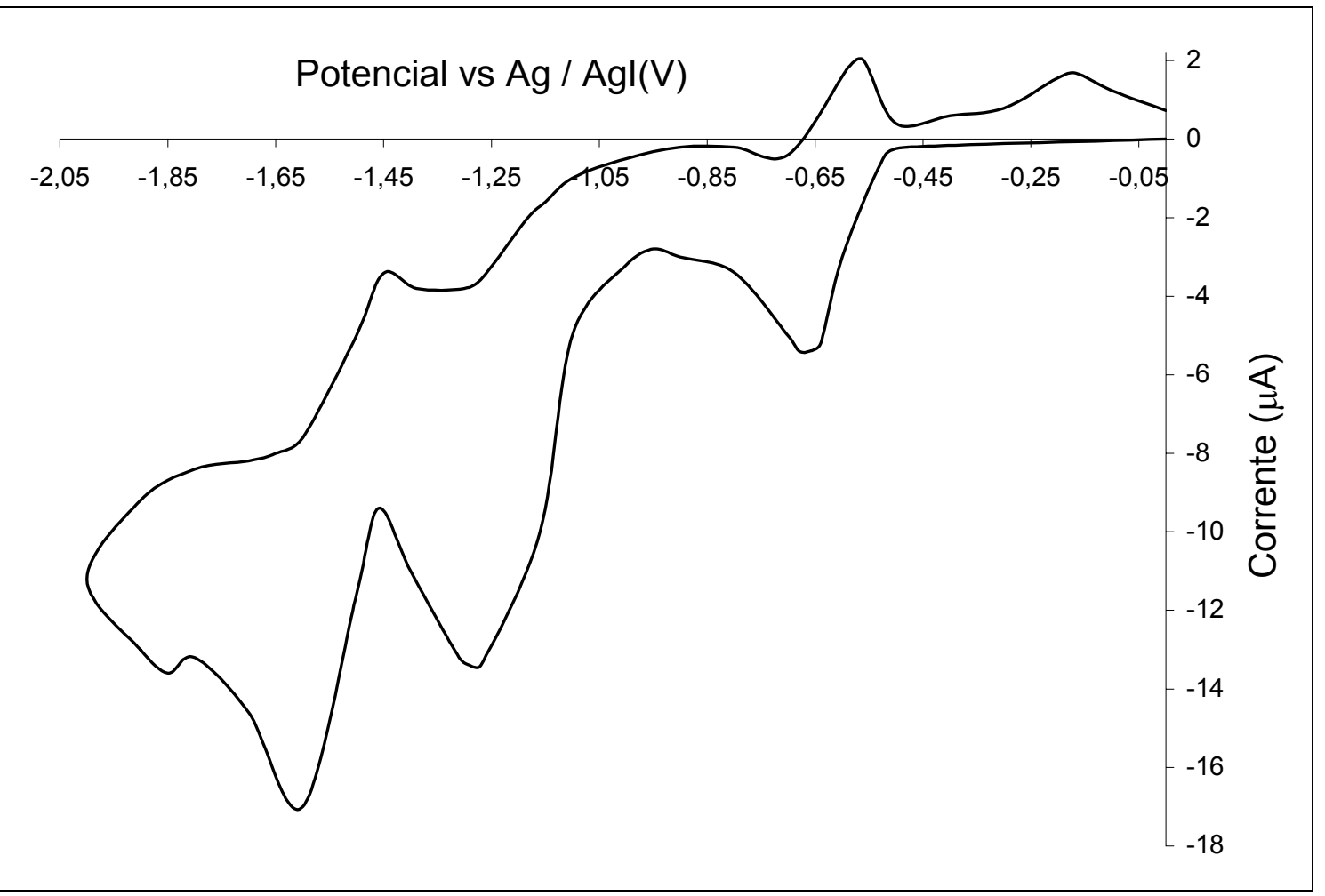

Figura IV.3 Voltamograma do $m$-nitrocinamato de metila (7)

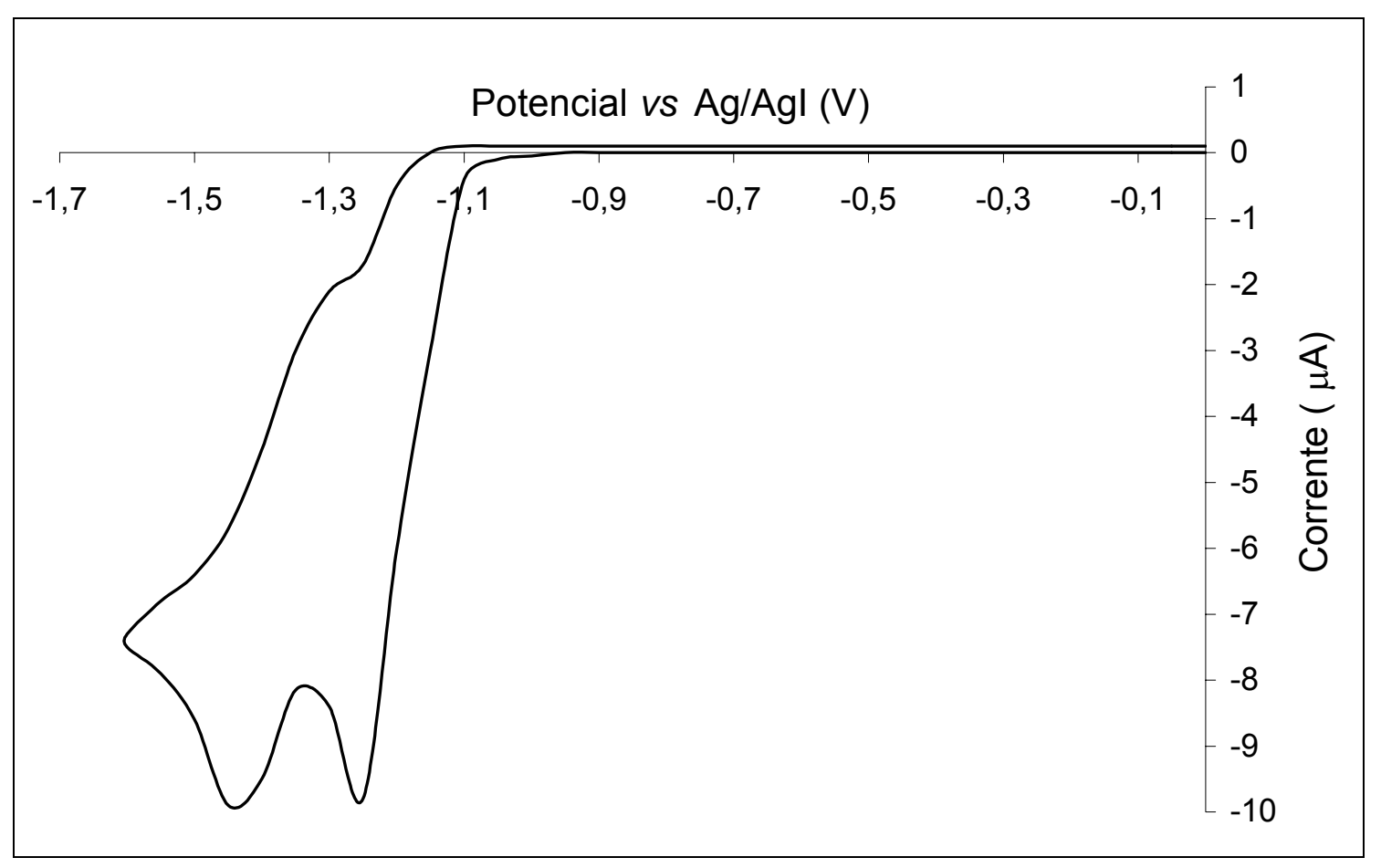

Figura IV.4 Voltamograma do o-clorocinamato de metila (2) 


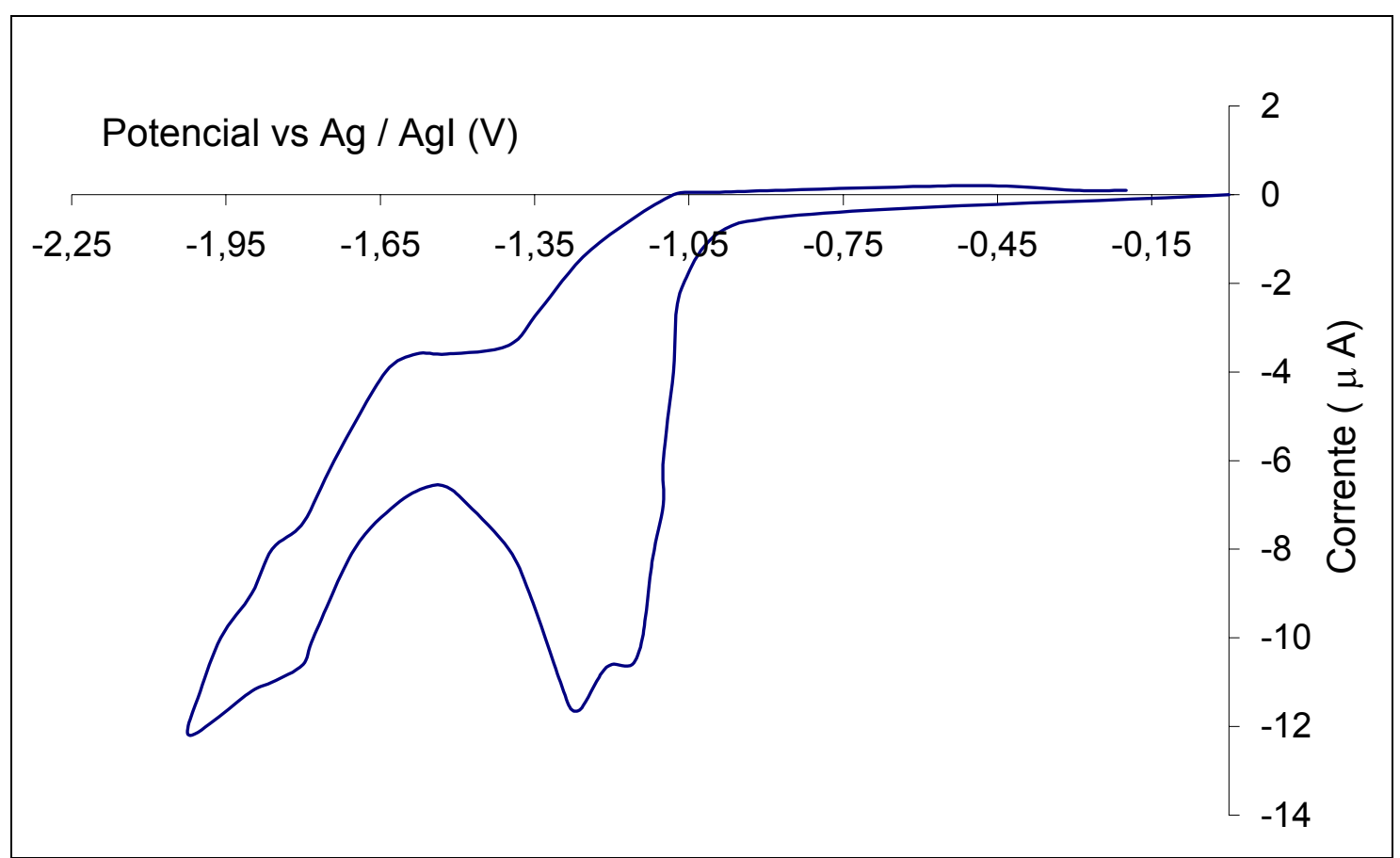

Figura IV.5 Voltamograma do $m, p$-diclorocinamato de metila (4)

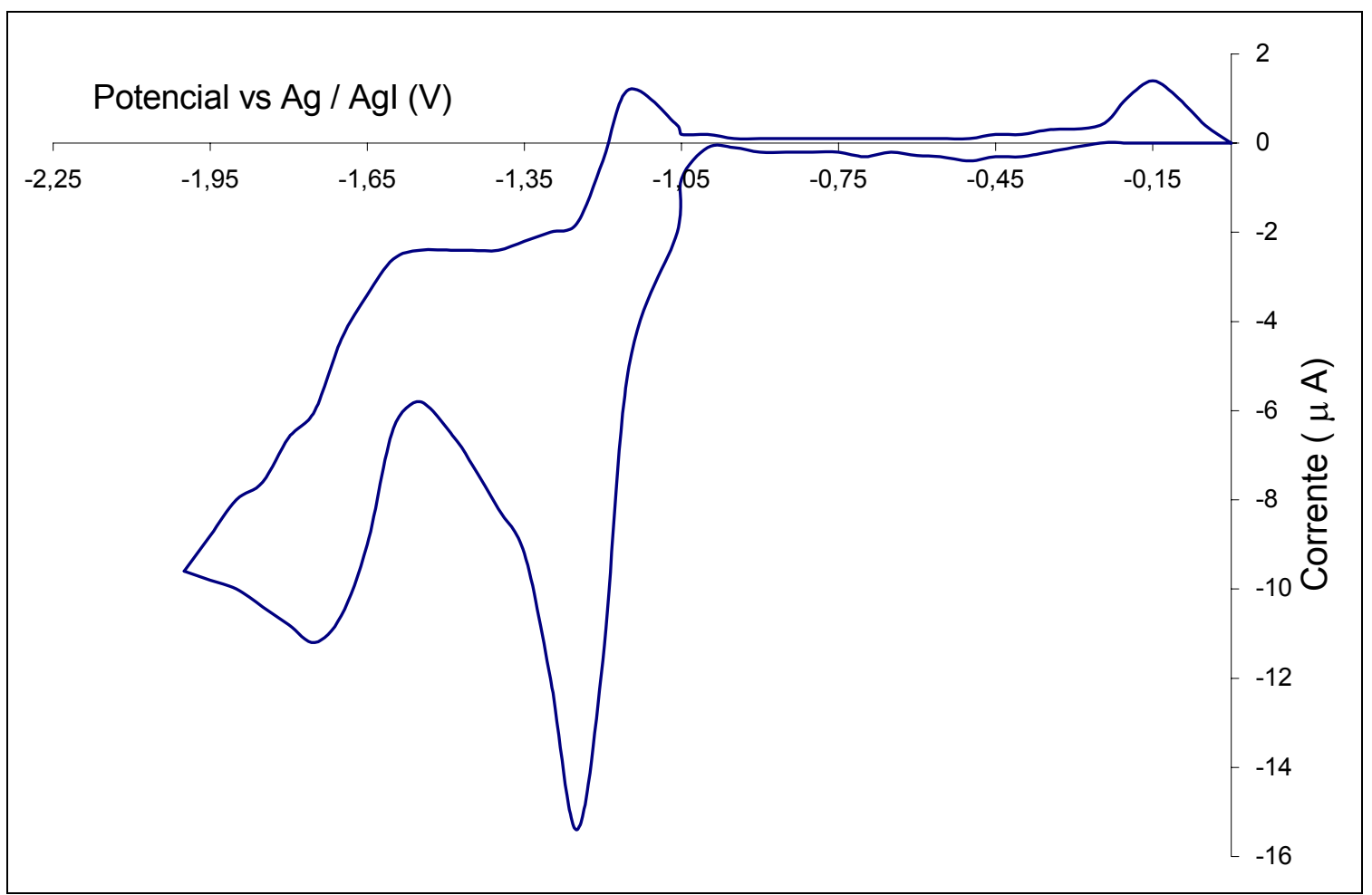

Figura IV.6 Voltamograma do $m$-clorocinamato de metila (5) 


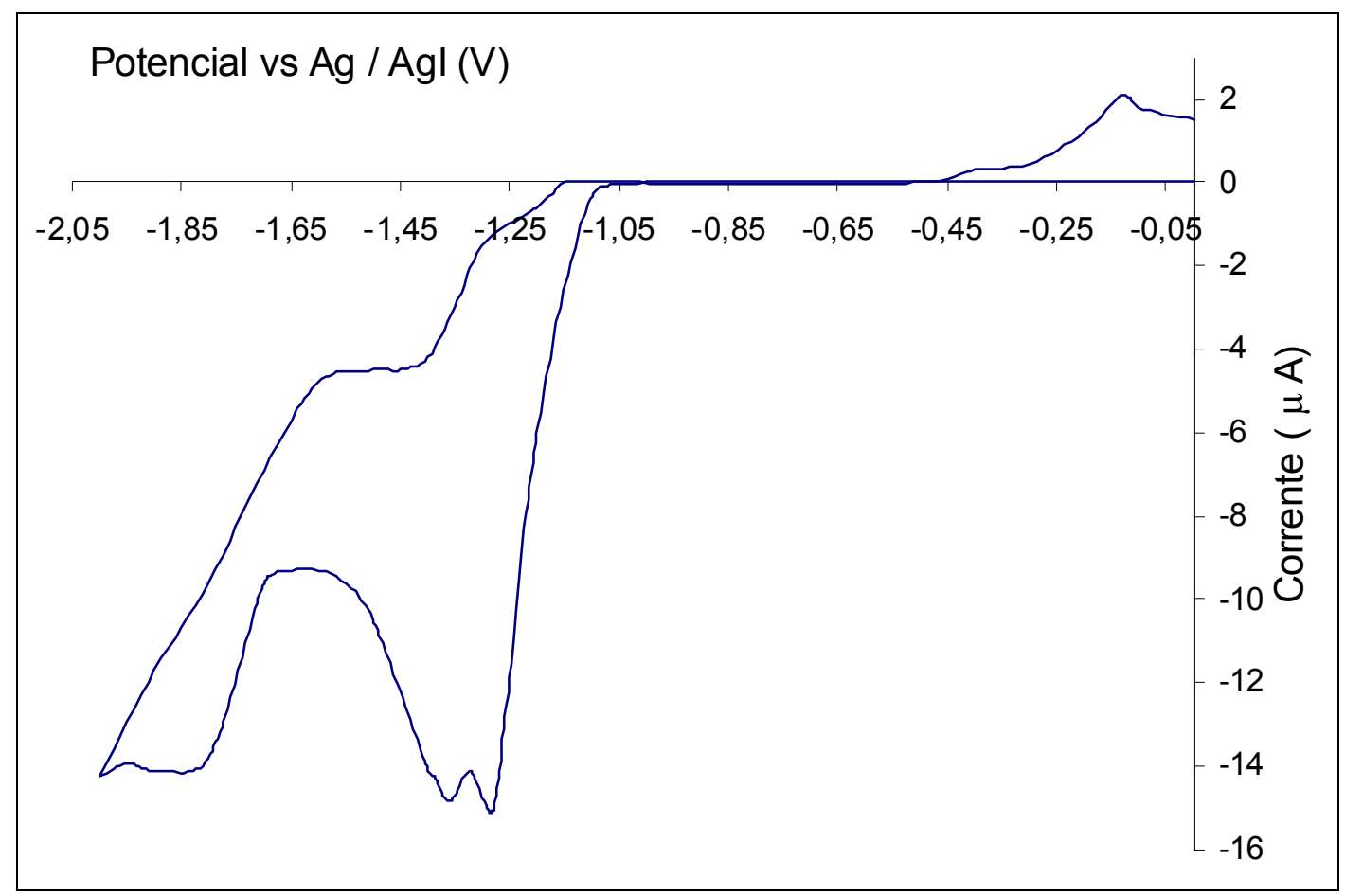

Figura IV.7 Voltamograma do $p$-clorocinamato de metila (6)

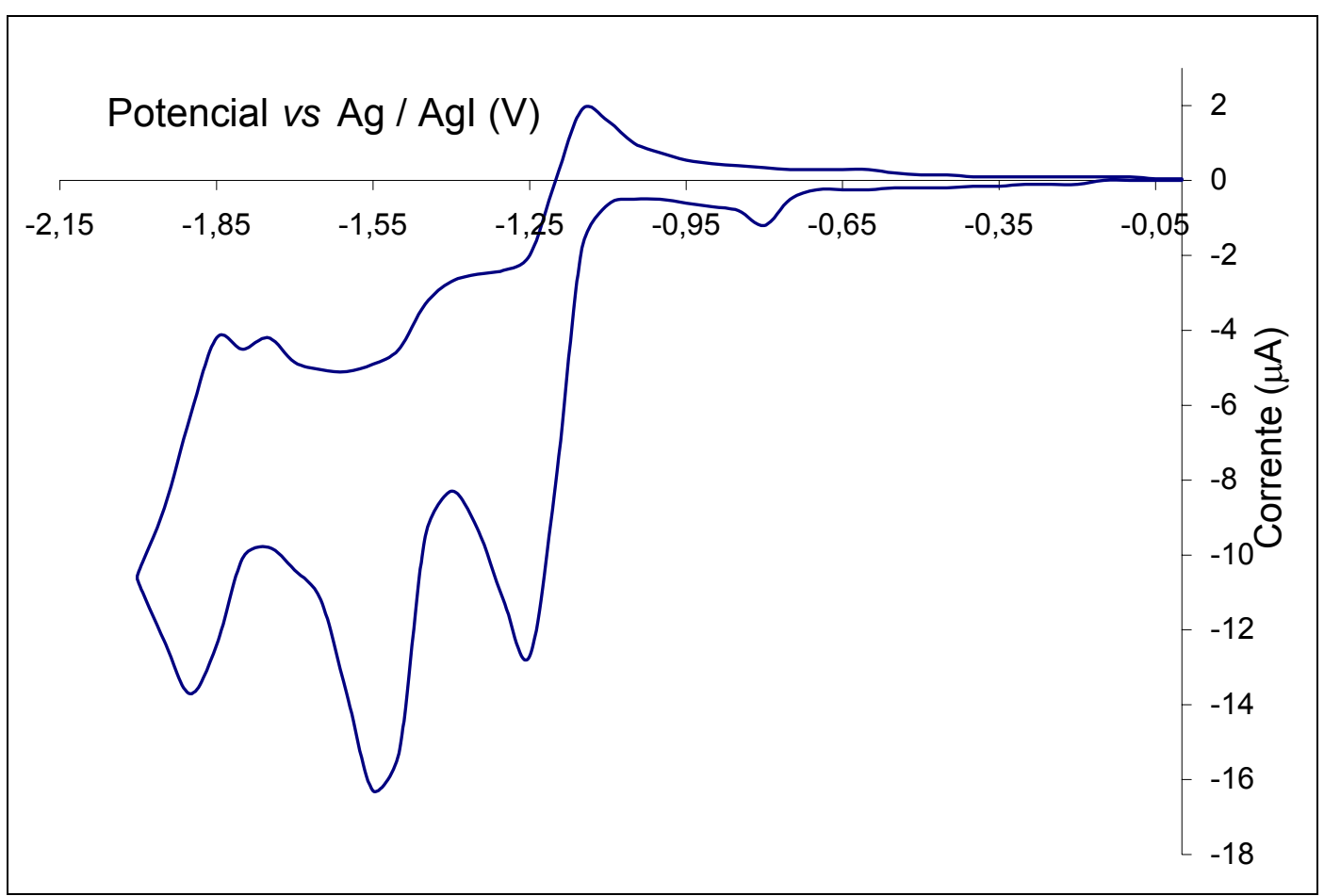

Figura IV.8 Voltamograma do o-metoxicarbonilcimanato de metila (8) 
No estudo do substrato 1 , observou-se pouca interferência do grupo metila no potencial de redução ao comparar este voltamograma àquele obtido para o cinamato de metila, portanto é provável que ocorra a redução da dupla ligação carbono - carbono.

Por outro lado, para os compostos nitro-substituídos (3 e 7), foi possível observar três picos de redução. O primeiro pico de redução provavelmente corresponde a uma transferência de elétron reversível envolvendo o grupo nitro ${ }^{42}$. Também foi possível determinar que espécies formadas nos $2^{\text {os }}$ picos de redução de 3 e 7 eram reoxidadas em $-0,3 \vee$ e $-0,2 \vee$ respectivamente.

Uma análise dos voltamogramas dos clorocinamatos de metila revela:

(a) Para o o-clorocinamato de metila (2) dos picos de redução foram registrados separados por cerca de $200 \mathrm{mV}$, sendo que o primeiro pico mostrou corresponder a um processo irreversível.

(b) Um pico de redução em -1,24 V vs. Ag / Agl foi registrado para o $m$-clorocinamato de metila (5).

42 (a) L. J. Núñez-Vergara, M. Bonta, P. A. Navarrete-Encina, J. A. Squella. Electrochim. Acta, 2001, 6, 4289. (b) J. Cabajo, S. Bollo, L. J. Núñez-Vergara, P. Navarrete e J. A. Squella, J. Electroanal. Chem. 2000, $\underline{494}, 69$. 
(c) Dois picos de redução no caso do $p$-clorocinamato de metila (6) como para o substrato 2 , porém a diferença dos potenciais é de apenas ca. $100 \mathrm{mV}$.

(d) Para o m,p-diclorocinamato de metila (4) também são observados dois picos de redução em -1,16 V e -1,27 V vs. Ag / Agl. Comparando estes potenciais com aqueles registrados para os substratos mono-clorados verifica-se que são menos negativos, possivelmente indicando que a presença dos dois cloros torna o substrato mais suscetível à redução eletroquímica.

A existência de um único pico de redução nos voltamogramas do m-clorocinamato de metila (5) e de dois picos de redução para os outros substratos clorados na mesma região de potenciais chamou a nossa atenção e alguns ensaios de voltametria foram feitos. A reversão do ciclo após o primeiro pico de redução dos substratos 2 e 6 revelou que esta redução correspondia a um processo irreversível, enquanto que no caso do substrato 5 houve indícios de tratar-se de uma transferência de elétron reversível acoplada a uma reação química. Esta diferença parecia indicar a ocorrência de dois processos eletroquímicos diferentes, mas para confirmar esta hipótese era necessário examinar as eletrólises preparativas a potencial controlado com isolamento e caracterização dos produtos.

Os resultados dos experimentos de voltametria cíclica do composto 8 revelaram a existência de dois picos de redução em $-1,25 \mathrm{~V}$ e $-1,54 \mathrm{~V}$ vs. Ag / Agl com uma diferença de potenciais de 
cerca de $300 \mathrm{mV}$. O primeiro pico de redução voltamétrica mostraou corresponder a uma transferência de elétron reversível acoplada a uma reação química.

\subsection{Eletrólises preparativas a potencial controlado}

\section{a - Cinamato de metila (9)}

As eletrólises foram inicialmente realizadas com o cinamato de metila (9) verificando-se a formação do hidrodímero cíclico (9b) com rendimentos de 41 - $48 \%$. Estas eletrólises foram efetuadas para exploração inicial do método, e para obter o composto $\mathbf{9 b}$ (hidrodímero cíclico) a ser utilizado como padrão de comparação analítico (Figura IV.9, Tabela IV.2).<smiles>O=C(O)/C=C/c1ccccc1</smiles>

$9 a$<smiles>CC(=O)C1C(=O)C[C@H](c2ccccc2)[C@H]1c1ccccc1</smiles>

$9 b$

Figura IV.9 Produtos da eletrólise do cinamato de metila (9). 
Tabela IV.2 Resultados das eletrólises preparativas de $\mathbf{9}$.

\begin{tabular}{|c|c|c|c|c|}
\hline \multirow[b]{2}{*}{ Eletrólises $^{a}$} & \multirow[b]{2}{*}{ Potencial (V) } & \multirow[b]{2}{*}{ Carga $(F)$} & \multicolumn{2}{|c|}{ Rendimento dos Produtos (\%) ${ }^{b}$} \\
\hline & & & $9 b$ & $9 a$ \\
\hline 1 & 1,47 & 0,93 & 41 & 24 \\
\hline 2 & 1,47 & 0,88 & 45 & 23 \\
\hline 3 & 1,47 & 0,93 & 48 & 20 \\
\hline
\end{tabular}

compartimento de trabalho); eletrodo de trabalho: poço de mercúrio; eletrodo de referência: Ag / Agl.

${ }^{b}$ Porcentagens calculadas a partir da massa inicial de substrato.

b - o-metilcinamato de metila (1)

As eletrólises preparativas com os substratos propostos foram iniciadas com o o-metilcinamato de metila (1), estudo no qual foi possível verificar que este tem um comportamento semelhante ao do o-metoxicinamato de metila frente à redução eletroquímica ${ }^{28}$. Houve a formação do hidrodímero cíclico cis, trans $\mathbf{1 b}$ ao lado do trans, trans 1c, com a razão $\mathbf{1 b} / \mathbf{1 c} \leq 1$ (Figura IV.10, Tabela IV.3).

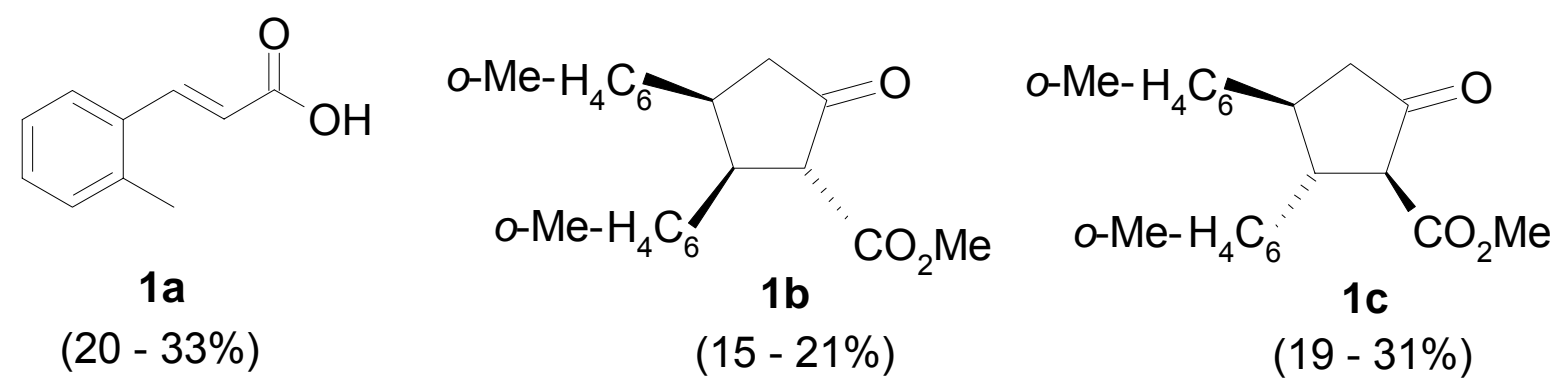

Figura IV.10 Produtos da eletrólise do o-metilcinamato de metila (1). 
Tabela IV.3 Resultados das eletrólises preparativas de 1.

\begin{tabular}{|c|c|c|c|c|c|}
\hline \multirow[b]{2}{*}{ Eletrólises $^{a}$} & \multirow[b]{2}{*}{ Potencial (V) } & \multirow[b]{2}{*}{ Carga $(F)$} & \multicolumn{3}{|c|}{ Rendimento dos Produtos (\%) } \\
\hline & & & 1b & 1c & $1 a$ \\
\hline 1 & 1,38 & 0,82 & 15 & 31 & 21 \\
\hline 2 & 1,45 & 0,85 & 21 & 21 & 30 \\
\hline 3 & 1,45 & 0,84 & 16 & 19 & 20 \\
\hline 4 & 1,45 & 0,67 & 17 & 20 & 25 \\
\hline 5 & 1,45 & 0,69 & 17 & 27 & 26 \\
\hline 6 & 1,45 & 0,90 & 10 & 25 & 33 \\
\hline
\end{tabular}

compartimento de trabalho); eletrodo de trabalho: poço de mercúrio; eletrodo de referência: Ag / Agl.

b Produtos isolados, porcentagens calculadas a partir da massa inicial de substrato.

O primeiro indício para a formação dos dois estereoisômeros $\mathbf{1 b}$ e 1c foi a existência de dois sinais com tempos de retenção bastante parecidos nos cromatogramas do produto bruto. Assim, foi feita uma separação em coluna cromatográfica de sílica destes estereoisômeros que foram analisados por RMN e espectrometria de massas.

Ao analisar os diastereômeros por $\mathrm{cg} / \mathrm{ms}$, os $\mathrm{m} / \mathrm{z}$ dos íons moleculares eram 264, o que correspondia a $\mathrm{M}^{+}-\mathrm{CO}_{2} \mathrm{Me}$.

Os íons moleculares obtidos na espectrometria de massas por injeção direta, para ambos os compostos, indicou resultados coerentes com a massa molar do hidrodímero cíclico esperado usualmente obtido em eletrólises de cinamatos (Tabela IV.4). A 
caracterização e estereoquímica destes isômeros foi feita através dos espectros de RMN de ${ }^{1} \mathrm{H}$ e ${ }^{13} \mathrm{C}$.

Tabela IV.4 Resultados do espectro de massas de 1b e 1c.

\begin{tabular}{|c|c|c|c|}
\hline $\mathrm{m} / \mathrm{z}$ & $\begin{array}{c}\text { Intens. } \\
\text { cis (1b) (\%) }\end{array}$ & $\begin{array}{c}\text { Intens. } \\
\text { trans (1c) }(\%)\end{array}$ & Fragmentos \\
\hline 323 & 6 & 4 & $\mathrm{M}+1$ \\
\hline 322 & 23 & 15 & $\left.\mathrm{M}=\left[\begin{array}{c}\text { o-Me- } \mathrm{H}_{4} \mathrm{C}_{6} \\
\text { o-Me- } \mathrm{H}_{4} \mathrm{C}_{6}\end{array}\right]^{+} \mathrm{CO}_{2} \mathrm{Me}\right]$ \\
\hline 145 & 25 & 25 & {$\left[0-{\mathrm{Me}-\mathrm{C}_{6} \mathrm{H}_{4}}_{\mathrm{O}}\right]^{+}$} \\
\hline 118 & 100 & 100 & {$\left[\mathrm{C}_{9} \mathrm{H}_{10}\right]$} \\
\hline 91 & 26 & 22 & {$\left[\mathrm{C}_{7} \mathrm{H}_{7}\right]$} \\
\hline
\end{tabular}

Nos espectros de RMN de ${ }^{13} \mathrm{C}$ e DEPT foram encontrados 21 sinais para o composto trans e 20 para o composto cis, pois dois sinais de carbonos aromáticos possuem deslocamentos químicos idênticos. Como esperado, no espectro de DEPT do composto cis foram encontrados 14 sinais e sendo um deles o sinal invertido para o carbono secundário da ciclopentanona. Já para o espectro de DEPT do estereoisômero trans foram observados 15 sinais sendo os mesmos do cis, porém acrescentando o sinal que não está sobreposto nos carbonos quaternários aromáticos(Tabela IV.5). 
Tabela IV.5 Resultados dos espectros de RMN ${ }^{1} \mathrm{H},{ }^{13} \mathrm{C}$ e DEPT dos compostos $\mathbf{1 b}$ e $\mathbf{1 c}$.

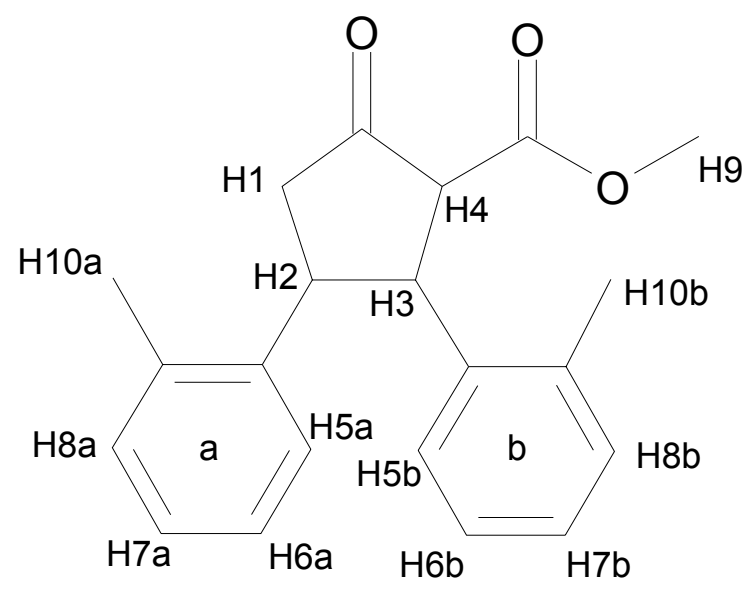

\begin{tabular}{|c|c|c|c|c|c|c|}
\hline Hidrogênio & Cis (1) & Multiplic & $\mathrm{J}(\mathrm{Hz})$ & Trans (1c) & Multiplic. & $\mathrm{J}(\mathrm{Hz})$ \\
\hline $\mathrm{H} 10 \mathrm{a}$ & 1,67 & $3 \mathrm{H}, \mathrm{s}$ & & 1,93 & $3 \mathrm{H}, \mathrm{s}$ & \\
\hline $\mathrm{H} 10 \mathrm{~b}$ & 2,37 & $3 \mathrm{H}, \mathrm{s}$ & & 2,01 & $3 \mathrm{H}, \mathrm{s}$ & \\
\hline H1 & 2,90 & $1 \mathrm{H}, \mathrm{dd}$ & $\begin{array}{c}4,5 \text { (cis H2) } \\
19,0 \text { (geminal) }\end{array}$ & 2,72 & $1 \mathrm{H}, \mathrm{dd}$ & $\begin{array}{l}11,7 \text { (trans } \mathrm{H} 2) \\
18,6 \text { (geminal) }\end{array}$ \\
\hline $\mathrm{H} 1$ & 2,98 & $1 \mathrm{H}, \mathrm{dd}$ & $\begin{array}{l}\text { 7,5 (trans } \mathrm{H} 2 \text { ) } \\
18,7 \text { (geminal) }\end{array}$ & 2,98 & $1 \mathrm{H}, \mathrm{dd}$ & $\begin{array}{c}\text { 7,8 } \text { (cis H2) } \\
18,9 \text { (geminal) }\end{array}$ \\
\hline $\mathrm{H} 9$ & 3,68 & $3 \mathrm{H}, \mathrm{s}$ & & 3,71 & $3 \mathrm{H}, \mathrm{s}$ & \\
\hline $\mathrm{H} 4$ & 3,83 & $1 \mathrm{H}, \mathrm{d}$ & 11,4 (trans H3) & 3,68 & $1 \mathrm{H}, \mathrm{d}$ & 11,7 (trans H3) \\
\hline $\mathrm{H} 2$ & 4,18 & $1 \mathrm{H}, \mathrm{ddd}$ & $\begin{array}{c}\text { 4,5 (cis H1) } \\
6,5(\text { cis H3) } \\
7,5 \text { (trans H1) }\end{array}$ & 3,80 & $1 \mathrm{H}, \mathrm{ddd}$ & $\begin{array}{c}\text { 8,0 (cis H1) } \\
11,7 \text { (trans H1) } \\
11,7 \text { (trans H3) }\end{array}$ \\
\hline H3 & 4,55 & $1 \mathrm{H}, \mathrm{dd}$ & $\begin{array}{c}\text { 6,5 (cis H2) } \\
11,4 \text { (trans H4) }\end{array}$ & 4,33 & $1 \mathrm{H}, \mathrm{dd}$ & $\begin{array}{l}\text { 11, } 7 \text { (trans } \mathrm{H} 2) \\
11,8(\text { trans } \mathrm{H} 4)\end{array}$ \\
\hline Har & 6,12 & $1 \mathrm{H}, \mathrm{d}$ & 7,8 & 6,95 & $1 \mathrm{H}, \mathrm{s}$ & \\
\hline Har & $6,76-6,83$ & $2 \mathrm{H}, \mathrm{m}$ & & 6,97 & $1 \mathrm{H}, \mathrm{s}$ & \\
\hline Har & $6,89-6,92$ & $1 \mathrm{H}, \mathrm{m}$ & & $7,03-7,09$ & $2 \mathrm{H}, \mathrm{m}$ & \\
\hline Har & $7,03-7,05$ & $2 \mathrm{H}, \mathrm{m}$ & & 7,20 & $2 \mathrm{H}, \mathrm{m}$ & \\
\hline Har & $7,08-7,11$ & $2 \mathrm{H}, \mathrm{m}$ & & 7,37 & $1 \mathrm{H}, \mathrm{d}$ & 7,8 \\
\hline & & & & 7,49 & $1 \mathrm{H}, \mathrm{d}$ & 7,8 \\
\hline
\end{tabular}


(1b) $\mathrm{RMN}^{13} \mathrm{C}$ (75 MHz): $\delta$ em ppm ( $\left.\mathrm{CDCl}_{3} / \mathrm{TMS}\right)$ 18,9; 19,7; 38,6; 45,$6 ; 45,7 ; 52,7 ; 58,7 ; 125,5 ; 125,9 ; 126,0 ; 126,2 ; 126,9 ; 130,1 ; 130,4$; 135,6; 136,9; 137,8; 137,9; 168,9; 221,4. (1b) DEPT 135 (75 MHz): $\delta$ em ppm ( $\left.\mathrm{CDCl}_{3} / \mathrm{TMS}\right) 18,9 ; 19,7 ; 38,5 ; 45,6$ ( $\mathrm{p} /$ baixo $\left.-\mathrm{CH}_{2}\right) ; 45,7$; 52,$7 ; 58,7 ; 125,4 ; 126,0 ; 125,9 ; 126,1 ; 126,9 ; 130,1 ; 130,4$.

(1c) RMN ${ }^{13}$ C (75 MHz): $\delta$ em ppm ( $\left.\mathrm{CDCl}_{3} / \mathrm{TMS}\right)$ 19,4; 19,5; 43,$3 ; 46,9 ; 48,7 ; 52,6 ; 64,0 ; 125,4 ; 125,6 ; 126,3 ; 126,4 ; 126,7 ; 126,9$; 130,$4 ; 130,5 ; 136,5 ; 137,2 ; 137,7 ; 138,4 ; 168,8 ; 208,7$. (1c) DEPT $135^{\circ}$ (75 MHz): $\delta$ em ppm ( $\left.\mathrm{CDCl}_{3} / \mathrm{TMS}\right)$ 19,5; 19,6; 43,3; 46,9 ( $\mathrm{p} /$ baixo $\left.\mathrm{CH}_{2}\right) ; 48,7 ; 52,6 ; 64,0 ; 125,4 ; 125,6 ; 126,3 ; 126,4 ; 126,7 ; 126,9 ; 130,4$; 130,5

No aspecto estereoquímico, o espectro mais interessante a ser analisado é o de $R M N{ }^{1} \mathrm{H}$, assim como COSY e HETCOR, que confirmaram as observações feitas através dos dados do primeiro.

Como já mencionado, os resultados obtidos com o substrato 1 são semelhantes aos da redução eletroquímica do o-metoxicinamato de metila ${ }^{28}$. Os grupos metoxila e metila ligados ao anel aromático são doadores de elétrons e, portanto, parece ser razoável afirmar que a sua presença é essencial para a formação do hidrodímero cis. É provável que a presença destes grupos mude a energia do estado de transição da dimerização que leva ao diânion com estereoquímica meso tornando-a semelhante àquela do estado de transição da dimerização dos radicais ânions que conduz ao diânion ( \pm ). 
Também foi isolado nesta eletrólise o ácido correspondente ao substrato de partida. Esta hidrólise parcial do substrato também foi observada com outros compostos estudados mesmo com os solventes e eletrólitos de suporte secados previamente. A hidrólise dos substratos deve ter ocorrido durante o processo eletroquímico com o aumento do $\mathrm{pH}$ da solução do compartimento de trabalho (cátodo) da cela. Esta hipótese é fundamentada pela observação de que a redução eletroquímica do sal do ácido o-metilcinâmico (1a) formado na hidrólise somente ocorre em potencial bem mais negativo do que a do éster, consequentemente o ácido 1a não seria reduzido. Uma outra evidência que reforça o argumento anterior são as cargas usadas nas eletrólises (Tabela IV.3), todas menores do que $1 \mathrm{~F}$, o valor teórico esperado para a transformação de um mol do substrato no hidrodímero cíclico correspondente. Em experimentos descritos na literatura $^{23}$ as cargas variam entre 1,1 e 1,2 F sem a ocorrência da hidrólise dos cinamatos.

\section{c - Nitrocinamatos (3 e 7)}

No caso do composto 3 , o qual possui o grupo nitro na posição orto, os produtos recuperados em qualquer dos potenciais empregados nas eletrólises preparativas foram o próprio éster de partida e o ácido 3a em diferentes proporções (Figura IV.11, Tabela IV.6). 
<smiles>COC(=O)/C=C/c1ccccc1[N+](=O)[O-]</smiles>

3

$(23-50 \%)$<smiles>O=C(O)/C=C/c1ccccc1[N+](=O)[O-]</smiles>

$3 a$

$(15-44 \%)$

Figura IV.11 Produtos da eletrólise do o-nitrocinamato de metila (3).

Tabela IV.6 Resultados das eletrólises preparativas de 3.

\begin{tabular}{|c|c|c|c|c|}
\hline \multirow[b]{2}{*}{ Eletrólises $^{a}$} & \multirow[b]{2}{*}{ Potencial (V) } & \multirow[b]{2}{*}{ Carga $(F)$} & \multicolumn{2}{|c|}{ Rendimento dos Produtos (\%) ${ }^{b}$} \\
\hline & & & 3 & $3 a$ \\
\hline 1 & 0,64 & 1,60 & 27 & 43 \\
\hline 2 & 0,66 & 1,82 & 23 & 44 \\
\hline 3 & 0,83 & 1,52 & 50 & 32 \\
\hline 4 & 1,20 & 1,62 & 40 & 15 \\
\hline
\end{tabular}
compartimento de trabalho); eletrodo de trabalho: poço de mercúrio; eletrodo de referência: Ag / Agl.

b Produtos isolados, porcentagens calculadas a partir da massa inicial de substrato.

Tal observação nos levou a estudar o $m$-nitrocinamato de metila (7), que apresentou um comportamento semelhante ao de 3 , porém mostrando um aumento da proporção de ácido recuperado com o aumento do potencial aplicado durante a redução (Figura IV.12). Esta observação pode ser explicada pela transferência preferencial de elétrons ao grupo nitro, porém não foi possível isolar nenhum composto resultante da redução do grupo nitro. Pode se concluir, no entanto que, nas condições experimentais de eletrólise, a ligação dupla carbonocarbono não é reduzida (Figura IV.12,Tabela IV.7). 


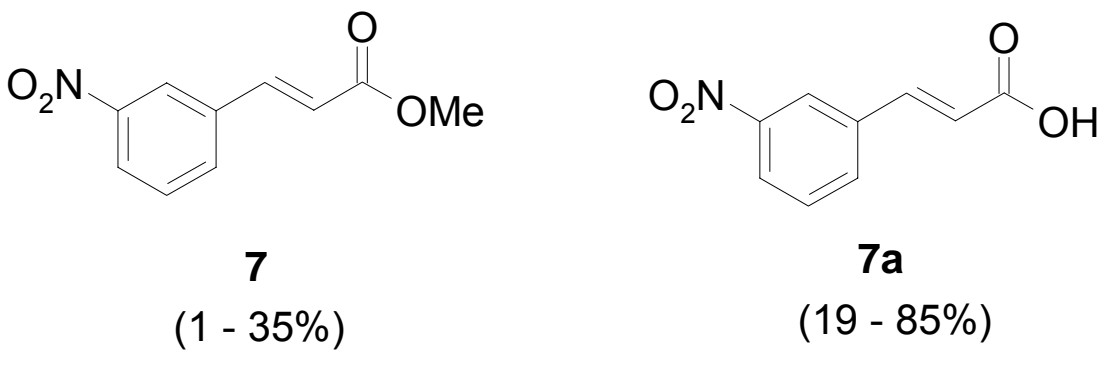

Figura IV.12 Produtos da eletrólise do $m$-nitrocinamato de metila (7).

Tabela IV.7 Resultados das eletrólises preparativas de 7.

\begin{tabular}{|c|c|c|c|c|}
\hline \multirow[b]{2}{*}{ Eletrólises $^{a}$} & \multirow[b]{2}{*}{ Potencial (V) } & \multirow[b]{2}{*}{ Carga $(F)$} & \multicolumn{2}{|c|}{ Rendimento dos Produtos (\%) } \\
\hline & & & 7 & $7 a$ \\
\hline 1 & 0,68 & 0,72 & 35 & 29 \\
\hline 2 & 0,68 & 0,78 & 25 & 52 \\
\hline 3 & 1,32 & 2,04 & 9 & 19 \\
\hline 4 & 1,32 & 3,36 & 3 & 85 \\
\hline 5 & 1,32 & 3,86 & 1 & 62 \\
\hline
\end{tabular}

compartimento de trabalho); eletrodo de trabalho: poço de mercúrio; eletrodo de referência: Ag / Agl.

${ }^{b}$ Produtos isolados, porcentagens calculadas a partir da massa inicial de substrato.

Este resultado pode ser justificado através de estudos que mostram que, em meio aprótico, os ânions-radicais nitroaromáticos são bastante estáveis ${ }^{42 a}$. Isso ocorre, pois a velocidade de protonação em qualquer ponto deste intermediário é bastante diminuída neste meio reacional ${ }^{42 b}$. 


\section{d - Cinamatos clorados $(2,4-6)$}

Os estudos foram iniciados com o substrato clorado na posição orto (2). Para este verificou-se que no potencial de redução menos negativo $(-1,24 \mathrm{~V})$ não ocorria a dimerização e sim a saída de cloreto, conduzindo à formação do cinamato de metila (9). Este resultado foi inicialmente comprovado através da cromatografia a gás comparando o substrato 2 , o produto e uma amostra padrão de cinamato de metila (9) e corroborado através de espectrometria de massas e RMN ${ }^{1} \mathrm{H}$.

No potencial mais negativo $(-1,48 \mathrm{~V})$ houve a formação de um hidrodímero cujos espectros de massas e de $\mathrm{RMN}{ }^{1} \mathrm{H}$ quando comparados com os do produto de eletrólise obtido para o cinamato de metila não substituído, mostraram tratar-se do composto 9b (Figura IV.13, Tabela IV.8).<smiles>COC(=O)/C=C/c1ccccc1</smiles>

9<smiles>CC(=O)C1C(=O)C[C@@H](C)[C@H]1C(C)(C)C</smiles>

9b<smiles>O=C(O)/C=C/c1ccccc1Cl</smiles>

$2 a$

$(5-51 \%)$

$(0-53 \%)$

$(20-30 \%)$

Figura IV.13 Produtos da eletrólise do o-clorocinamato de metila (2). 
Tabela IV.8 Resultados das eletrólises preparativas de 2.

\begin{tabular}{|c|c|c|c|c|c|}
\hline \multirow[b]{2}{*}{ Eletrólises $^{a}$} & \multirow[b]{2}{*}{ Potencial (V) } & \multirow[b]{2}{*}{ Carga $(F)$} & \multicolumn{3}{|c|}{ Rendimento dos Produtos $(\%)^{\mathrm{b}}$} \\
\hline & & & 9 & $9 b$ & $2 a$ \\
\hline 1 & 1,24 & 0,85 & 47 & --- & 20 \\
\hline 2 & 1,24 & 0,85 & 51 & --- & 30 \\
\hline 3 & 1,45 & 1,39 & 5 & 40 & 26 \\
\hline 4 & 1,50 & 1,52 & 6 & 53 & 22 \\
\hline
\end{tabular}

compartimento de trabalho); eletrodo de trabalho: poço de mercúrio; eletrodo de referência: Ag / Agl.

${ }^{b}$ Produtos isolados, porcentagens calculadas a partir da massa inicial de substrato.

A fim de verificar se este comportamento, isto é a saída de cloreto, seria observado para outros substratos clorados, foi investigado 0 composto 4. A sua redução forneceu o composto $5 \mathrm{com}$ a saída do cloro na forma de cloreto da posição para e manutenção do da posição meta quando eletrolisado no potencial de $-1,16 \vee$ (Figura IV.14,Tabela IV.9).<smiles>COC(=O)/C=C/c1cccc(Cl)c1</smiles>

5<smiles>O=C(O)/C=C/c1ccc(Cl)c(Cl)c1</smiles>

$4 a$

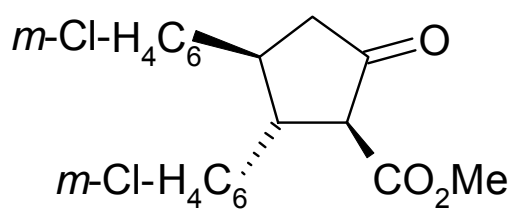

$5 b$
$(37-56 \%)$
$(1-40 \%)$

Figura IV.14 Produtos da eletrólise do $m, p$-diclorocinamato de metila. 
Tabela IV.9 Resultados das eletrólises preparativas de 4.

\begin{tabular}{|c|c|c|c|c|}
\hline \multirow[b]{2}{*}{ Eletrólises $^{a}$} & \multirow[b]{2}{*}{ Potencial (V) } & \multirow[b]{2}{*}{ Carga (F) } & \multicolumn{2}{|c|}{ Rendimento dos Produtos ( $\%)^{b}$} \\
\hline & & & $5 b$ & $4 a$ \\
\hline 1 & 1,16 & 0,94 & 37 & 1 \\
\hline 2 & 1,16 & 1,11 & 42 & 15 \\
\hline 3 & 1,20 & 1,14 & 56 & 40 \\
\hline & & & Mistura $^{\mathrm{C}}$ & $4 a$ \\
\hline 4 & 1,26 & 0,76 & 23 & 19 \\
\hline 5 & 1,26 & 1,10 & 37 & 14 \\
\hline 6 & 1,26 & 0,76 & 30 & 10 \\
\hline 7 & 1,30 & 0,81 & 38 & 14 \\
\hline
\end{tabular}
compartimento de trabalho); eletrodo de trabalho: poço de mercúrio; eletrodo de referência: Ag / Agl.

b Produtos isolados, porcentagens calculadas a partir da massa inicial de substrato.

${ }^{\mathrm{c}}$ Mistura rica no composto $5 \mathbf{b}(62-73 \%)$, porém contendo outros dímeros.

Uma comparação do tempo de retenção na cromatografia a gás e dos espectros de massas e RMN ${ }^{1} \mathrm{H}$ do produto com o do formado nas eletrólises do m-clorocinamato de metila (5) confirmaram sua identidade.

Quando as eletrólises foram feitas em potencial mais negativo $(-1,26 \mathrm{~V})$, obteve-se uma mistura de produtos na qual $\mathbf{5 b}$ mostrou ser 0 principal na análise por CG (Tabela IV.9). Não foi possível isolá-lo por cromatografia em coluna de sílica devido à existência de outros componentes na mistura cujo comportamento era muito semelhante ao 
do produto principal. Desta maneira a análise foi feita por meio de CG/EM.

Com base nos espectros de massas de outros dois componentes da mistura de produtos, pode-se sugerir tratar-se de hidrodímeros com 3 e 4 cloros.

O espectro de massas registrado para o produto principal em experimento CG/EM revelou a existência de íons moleculares $\mathrm{M}^{+}\left(-\mathrm{CO}_{2} \mathrm{Me}\right) \mathrm{m} / \mathrm{z}=304 ; \mathrm{M}^{+}+2\left(-\mathrm{CO}_{2} \mathrm{Me}\right) \mathrm{m} / \mathrm{z}=306 ; \mathrm{M}^{+}+4$ $\left(-\mathrm{CO}_{2} \mathrm{Me}\right) \mathrm{m} / \mathrm{z}=308$, concordante com os espectros de massas registrados em experimento CG/EM do hidrodímero 5b (Figura IV.14). A identidade de $\mathbf{5 b}$ também foi confirmada pela comparação dos tempos de retenção na $C G$ e espectros de RMN ${ }^{1} \mathrm{H}$ com os do produto formado na eletrólise do $m$-clorocinamato de metila (5)

Pelos resultados obtidos nas eletrólises do composto 4, ficou evidente que a presença de dois cloros ligados ao anel aromático era responsável pela complexidade da mistura dos produtos de eletrólise.

Deve-se registrar que o composto 4 foi escolhido em nosso estudo devido à disponibilidade do $m, p$-diclorobenzaldeído, matéria prima na preparação deste substrato. Os $m$ - e $p$-clorobenzaldeídos foram cedidos por colegas do IQ-USP, permitindo o preparo dos substratos 5 e 6 e estudar a sua redução eletroquímica.

As eletrólises de $\mathbf{5}$ (meta-substituído) conduziram ao hidrodímero cíclico $\mathbf{5 b}$ que foi isolado e teve sua estrutura estabelecida (Figura IV.15,Tabela IV.10). 
<smiles>O=C(O)/C=C/c1cccc(Cl)c1</smiles>

$5 a$

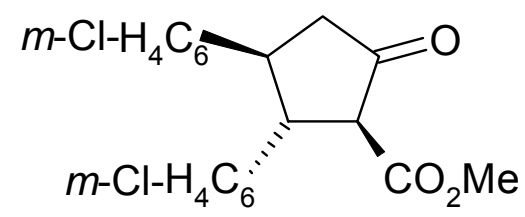

$5 \mathbf{b}$

$(21-26 \%)$

$(46-48 \%)$

Figura IV.15 Produtos da eletrólise do $m$-clorocinamato de metila.

Tabela IV.10 Resultados das eletrólises preparativas de $\mathbf{5}$.

\begin{tabular}{|c|c|c|c|c|}
\hline \multirow[b]{2}{*}{ Eletrólises $^{a}$} & \multirow[b]{2}{*}{ Potencial (V) } & \multirow[b]{2}{*}{ Carga $(F)$} & \multicolumn{2}{|c|}{ Rendimento dos Produtos $(\%)^{b}$} \\
\hline & & & $5 b$ & $5 a$ \\
\hline 1 & 1,30 & 0,89 & 48 & 26 \\
\hline 2 & 1,30 & 0,86 & 46 & 21 \\
\hline
\end{tabular}
compartimento de trabalho); eletrodo de trabalho: poço de mercúrio; eletrodo de referência: Ag / Agl.

b Produtos isolados, porcentagens calculadas a partir da massa inicial de substrato.

Através de espectrometria de massas foi verificada a presença dos íons moleculares $\mathrm{M}^{+}, \mathrm{M}^{+}+2, \mathrm{M}^{+}+4$ e um perfil de fragmentação coerente com a estrutura do dímero 5b (Tabela IV.11).

O espectro de $\mathrm{RMN}{ }^{1} \mathrm{H}$ confirmou a estereoquímica trans, trans entre os substituintes do anel da ciclopentanona, com base nas constantes de acoplamento e sua comparação com as obtidas para o composto 1c (Tabela IV.5). 
Tabela IV.11 Resultados principais para o espectro de massas de $\mathbf{5 b}$.

\begin{tabular}{|c|c|c|}
\hline $\mathbf{m} / \mathbf{z}$ & Intens. (\%) & Fragmentos \\
\hline 366 & 2 & $\mathrm{M}^{+}+4$ \\
\hline 364 & 9 & $\mathrm{M}^{+}+2$ \\
\hline 362 & 12 & $\left.\mathrm{M}=\left[\begin{array}{c}m-\mathrm{Cl}_{-} \mathrm{H}_{4} \mathrm{C}_{6} \\
m-\mathrm{Cl}_{-} \mathrm{H}_{4} \mathrm{C}_{6}\end{array}\right]^{+} \mathrm{CO}_{2} \mathrm{Me}\right]$ \\
\hline 165 & 26 & {$\left[m-\mathrm{Cl}_{6} \mathrm{C}_{4}\right.$} \\
\hline 139 & 33 & $\left.\left[\mathrm{C}_{8} \mathrm{H}_{9} \mathrm{Cl}\right]^{37}\right]$ \\
\hline 137 & 100 & {$\left[\mathrm{C}_{8} \mathrm{H}_{9}\right]^{+}$} \\
\hline
\end{tabular}

Tabela IV.12 Constantes de acoplamento dos hidrogênios da ciclopentanona $\mathbf{5 b}$ apresentando estereoquímica trans.

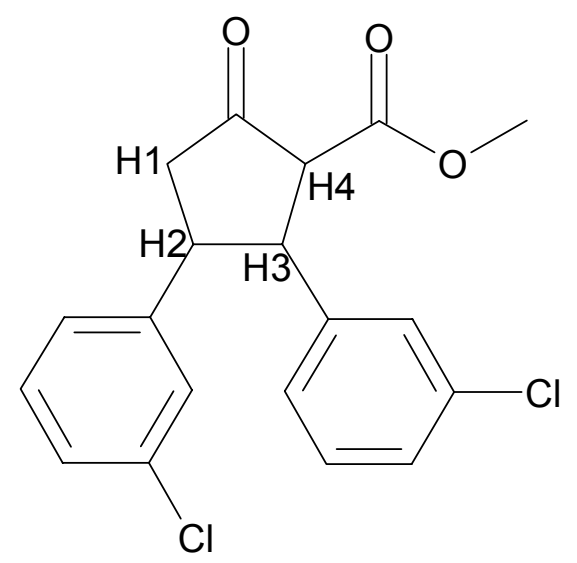

\begin{tabular}{|c|c|c|c|}
\hline Hidrogênio & Trans (5b) & Multiplic. & $\mathrm{J}(\mathrm{Hz})$ \\
\hline $\mathrm{H} 1$ & 2,67 & $1 \mathrm{H}, \mathrm{dd}$ & $\begin{array}{c}12(\text { trans H2) } \\
18(\mathrm{gem})\end{array}$ \\
\hline $\mathrm{H} 1$ & 2,97 & $1 \mathrm{H}, \mathrm{dd}$ & $\begin{array}{c}8(\text { cis H2) } \\
18(\mathrm{gem})\end{array}$ \\
\hline $\mathrm{H} 2$ & 3,45 & $1 \mathrm{H}, \mathrm{ddd}$ & $\begin{array}{c}8,0(\text { cis H1) } \\
12(\text { trans H1) } \\
12(\text { trans H3) }\end{array}$ \\
\hline $\mathrm{H} 4$ & 3,56 & $1 \mathrm{H}, \mathrm{d}$ & $12($ trans H3) \\
\hline $\mathrm{H} 3$ & 3,87 & $1 \mathrm{H}, \mathrm{dd}$ & $\begin{array}{c}12(\text { trans H2) } \\
12(\text { trans H4) }\end{array}$ \\
\hline
\end{tabular}


No estudo do composto 6 (para-substituido), os resultados apontam para a ocorrência de uma competição entre a saída de cloreto e a dimerização dependendo do potencial aplicado (Figura IV.16, Tabela IV.13).<smiles>COC(=O)/C=C/c1ccccc1</smiles>

9<smiles>O=C(O)/C=C/c1ccc(Cl)cc1</smiles>

$6 a$

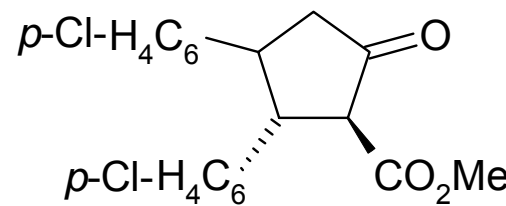

$6 b$

$(5-53 \%)$

$(21-26 \%)$

$(12-53 \%)$

Figura IV.16 Produtos da eletrólise do $p$-clorocinamato de metila (6).

Tabela IV.13 Resultados das eletrólises preparativas de 6.

\begin{tabular}{|c|c|c|c|c|c|}
\hline \multirow[b]{2}{*}{ Eletrólises ${ }^{\circledR}$} & \multirow[b]{2}{*}{ Potencial (V) } & \multirow[b]{2}{*}{ Carga (F) } & \multicolumn{3}{|c|}{ Rendimento dos Produtos (\%) } \\
\hline & & & 9 & $6 b$ & $6 a$ \\
\hline 1 & 1,20 & 0,95 & $38^{b}$ & $12^{b}$ & $26^{b}$ \\
\hline 2 & 1,25 & 0,86 & $53^{c}$ & $17^{c}$ & $21^{b}$ \\
\hline 3 & 1,35 & 1,04 & $5^{c}$ & $40^{c}$ & $26^{b}$ \\
\hline 4 & 1,36 & 1,06 & $6^{c}$ & $53^{b}$ & $22^{b}$ \\
\hline
\end{tabular}

compartimento de trabalho); eletrodo de trabalho: poço de mercúrio; eletrodo de referência: Ag / Agl.

${ }^{b}$ Produtos isolados, porcentagens calculadas a partir da massa inicial de substrato.

${ }^{\mathrm{C}}$ Produtos de eletrólise analisados através de CG/EM e não isolados. 
Em potenciais menos negativos foi obtida maior quantidade do composto 9, rapidamente identificado através da cromatografia a gás comparativa. Para eletrólises de 6 em potenciais mais negativos obtémse bons rendimentos de $\mathbf{6 b}$, que foi isolado e teve sua estrutura e estereoquímica determinadas por EM e RMN ${ }^{1} \mathrm{H}$. O resultado destas análises é a comprovação da presença de dois cloros na molécula e a estereoquímica trans, trans dos substituintes da ciclopentanona como em $5 \mathbf{b}$.

Uma análise dos resultados obtidos nas reduções eletroquímicas dos clorocinamatos revela que a desalogenação é observada nos substratos em que o cloro está ligado nas posições orto ou para do anel aromático e não ocorre quando este ocupa a posição meta. Com base nestes resultados é sugerido um mecanismo para a desalogenação de 2 (Esquema IV.7) e 6 (Esquema IV.8).

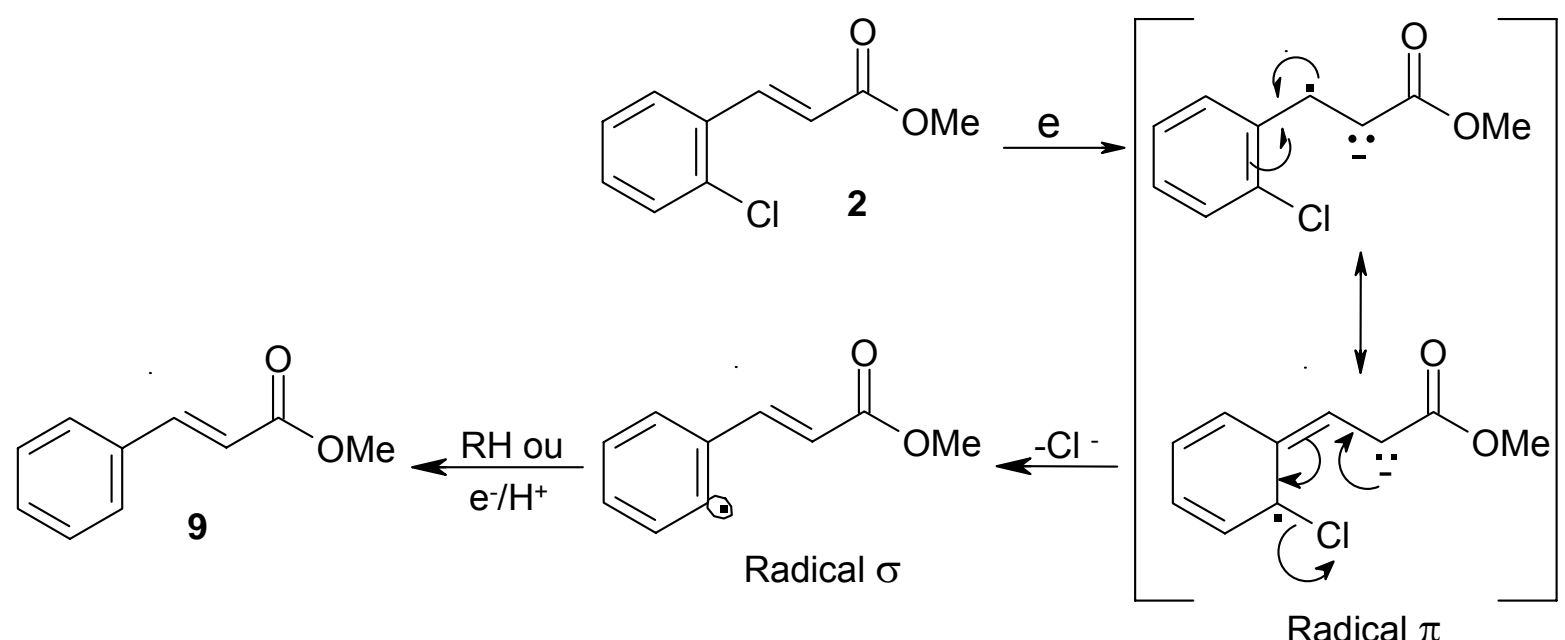

Esquema IV.7 Mecanismo proposto para saída de cloreto da posição orto do composto 2 . 


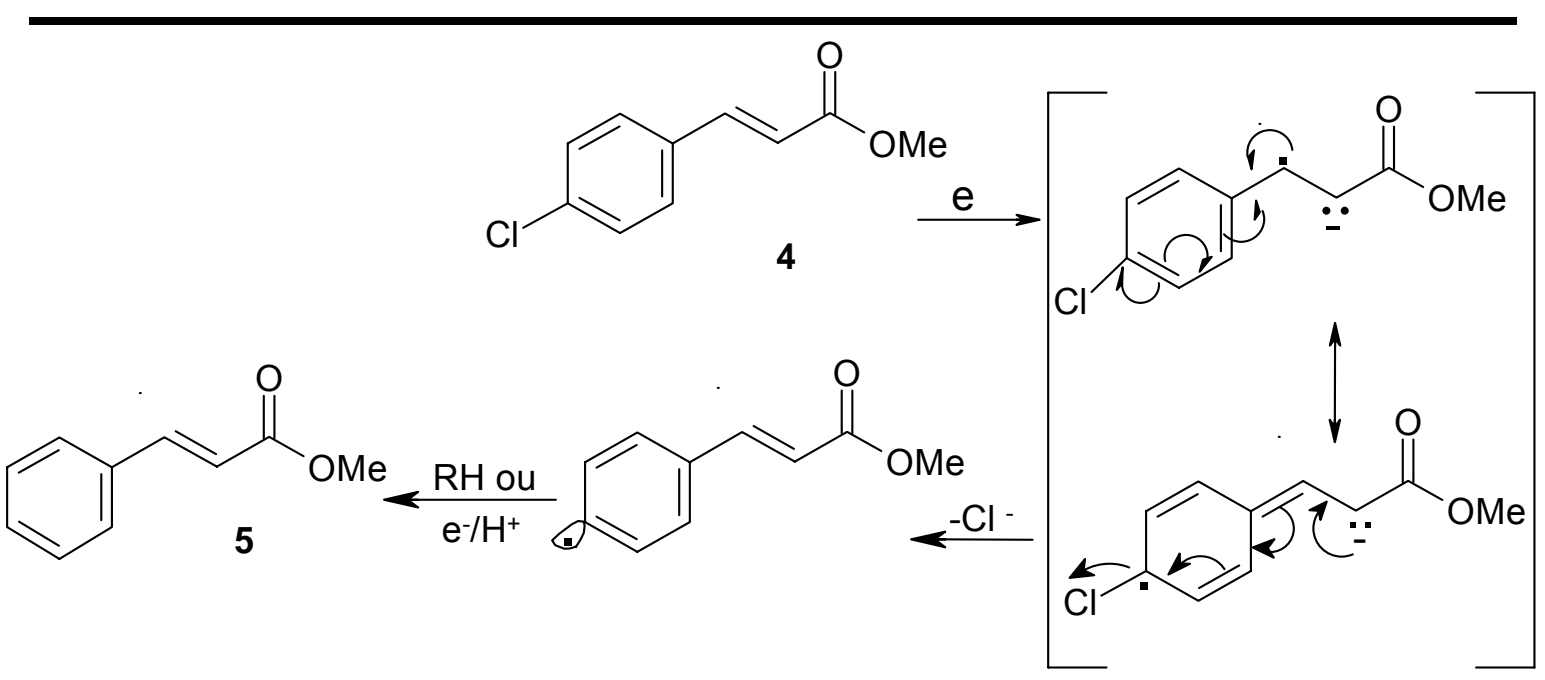

Esquema IV.8 Mecanismo proposto para saída de cloreto da posição para do composto 6 .

O Esquema IV.9 mostra que a deslocalização de elétrons no radical-ânion de 5 não favorece a saída do cloreto na posição meta.<smiles>CCCc1cc(Cl)cc(C=CC(=O)OC)c1C=CC(=O)OC</smiles>

Esquema IV.9 Deslocalização de elétrons no ânion-radical de $\mathbf{5}$. 
Comparando os o-clorocinamato de metila (2) e $p$-clorocinamato de metila (6) verifica-se que a desalogenação em (2) ocorre independentemente do potencial de redução (Tabela IV.8), enquanto que no substrato (6) esta etapa é preferencial em potencial menos negativo, porém a dimerização prevalece em potenciais mais negativos.

A literatura oferece uma diversidade de estudos que justificam os fatos observados na redução eletroquímica destes cinamatos clorados. Em estudos eletroquímicos de compostos haloaromáticos observou-se que a perda do halogênio é uma das reações mais freqüentes para os ânions-radicais ${ }^{43}$.

O mecanismo estabelecido para a ocorrência da desalogenação em solventes orgânicos ${ }^{44}$ ocorre através da formação do ânion-radical, que sofre uma clivagem formando um ânion haleto e um radical arila que após ser reduzido ao ânion correspondente é protonado.

Em estudos cinéticos sobre a clivagem da ligação carbono halogênio do ânion-radical feitos com diversos substratos haloaromáticos foi observado que a posição do halogênio no anel

${ }^{43}$ I. Gallardo, G. Guirado, J. Marquet, J. Electroanal. Chem. 2000, $\underline{448}, 64$.

44 (a) C. P. Andrieux, J. M. Savéant, K. B. Su, J. Phys. Chem. 1986, 90, 3815; (b) D. O. Wipf, R. M. Wightman, J. Phys. Chem. 1989, 93, 4286; (c) R. J. Enemaerke, T. B. Christensen, H. Jensen, K. Daasbjerg, J. Chem. Soc. Trans 2, 2001, 1620. 
aromático influencia a estabilidade do ânion-radical ${ }^{45 a}$. Assim, a velocidade de clivagem desta ligação seria menor para um substituinte em meta, e maior para os substituintes em orto e para, sendo a posição orto a mais reativa. Esta observação foi explicada pela distribuição de densidade de elétron desemparelhado no estudo por orbitais moleculares ${ }^{45 b}$.

Um bom exemplo bastante estudado foi a decomposição de ânions-radicais gerados através da redução eletroquímica de acetofenonas halogenadas ${ }^{44 \mathrm{~b}}$. Neste trabalho foram calculadas as constantes de velocidade da clivagem da ligação carbono - halogênio para os compostos clorados em orto, para e meta iguais a $3 \times 10^{5}, 3 \times$ $10^{3}$ e 15 , respectivamente. Estes resultados mostram que a clivagem para o composto halogenado na posição meta é muito mais lenta do que aquelas das posições orto e para.

45 (a) F. M'Halla, J. Pinson, J. M. Savéant, J. Electroanal. Chem. 1978, 89, 347; (b) K. Alwair, J. Grimshaw, J. Chem. Soc. Trans 2, 1973, 1151. 
e - $\quad$ o-metoxicarbonilcinamato de metila (8)

Durante o estudo da redução eletroquímica do o-metoxicarbonilcinamato de metila (8), sob condições experimentais semelhantes às utilizadas para os demais compostos, não foi observada a formação de nenhum dos produtos usuais de redução de cinamatos, mas das moléculas policíclicas $8 \mathbf{b}$ - 8d (Figura IV.17, Tabela IV.14).

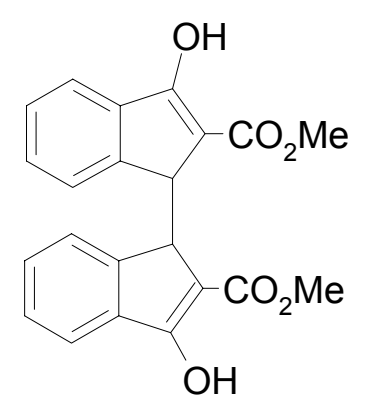

8b

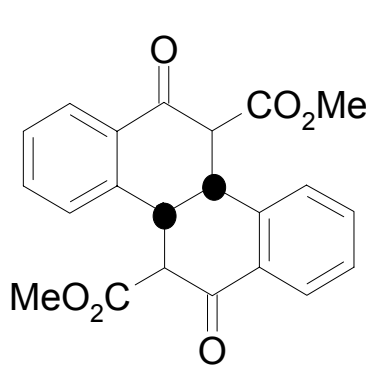

$8 c$

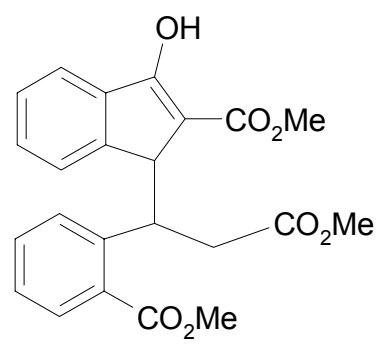

8d

$(20-31 \%)$

$(19-22 \%)$

$(5-9 \%)$

Figura IV.17 Produtos da eletrólise do o-metoxicarbonilcinamato de metila (8).

A elucidação das estruturas dos produtos isolados foi complicada, por serem bastante diferentes dos produtos usualmente obtidos na redução eletroquímica de cinamatos. Os compostos $\mathbf{8 b}$ e $\mathbf{8 c}$ são isômeros estruturais inéditos e sua caracterização foi feita utilizando RMN ${ }^{1} \mathrm{H}$, RMN ${ }^{13} \mathrm{C}$, DEPT $135^{\circ}$, HETCOR, COSY, espectrometria de massas e análise elementar. 
Tabela IV.14 Resultados das eletrólises preparativas de 8.

\begin{tabular}{|c|c|c|c|c|c|}
\hline \multirow[b]{2}{*}{ Eletrólises $^{a}$} & \multirow[b]{2}{*}{ Potencial (V) } & \multirow[b]{2}{*}{ Carga $(F)$} & \multicolumn{3}{|c|}{ Rendimento dos Produtos (\%) ${ }^{b, c}$} \\
\hline & & & $8 b$ & 8c & $8 a$ \\
\hline 1 & 1,26 & 0,93 & 28 & 22 & 16 \\
\hline 2 & 1,25 & 0,91 & 31 & 19 & 14 \\
\hline 3 & 1,26 & 0,49 & 31 & 21 & 20 \\
\hline 4 & 1,26 & 0,86 & 20 & 16 & 14 \\
\hline
\end{tabular}
compartimento de trabalho); eletrodo de trabalho: poço de mercúrio; eletrodo de referência: Ag / Agl.

${ }^{\mathrm{b}}$ Produtos isolados, porcentagens calculadas a partir da massa inicial de substrato.

c Alem dos presentes produtos foi isolado o composto $\mathbf{8 d}$ em quantidades de 5 - $9 \%$.

O espectro de RMN ${ }^{1} \mathrm{H}$ do composto 8 b não apresentava os sinais esperados para a ciclopentanona substituída ou para o dímero acíclico (Figura IV.18), produto usualmente formados nas EHD dos cinamatos.<smiles>COC(=O)c1ccccc1C1CC(=O)C(C(C)=O)C1c1ccccc1C(C)=O</smiles><smiles>CC(=O)CC(c1ccccc1C(C)=O)C(CC(C)=O)c1ccccc1C(C)=O</smiles>

Figura IV.18 Produtos esperados para a eletrólise do o-metoxicarbonilcinamato de metila (8). 
Tabela IV.15 Resultados dos espectros de $\mathrm{RMN}{ }^{1} \mathrm{H},{ }^{13} \mathrm{C}$ e DEPT para $\mathbf{8 b}$.

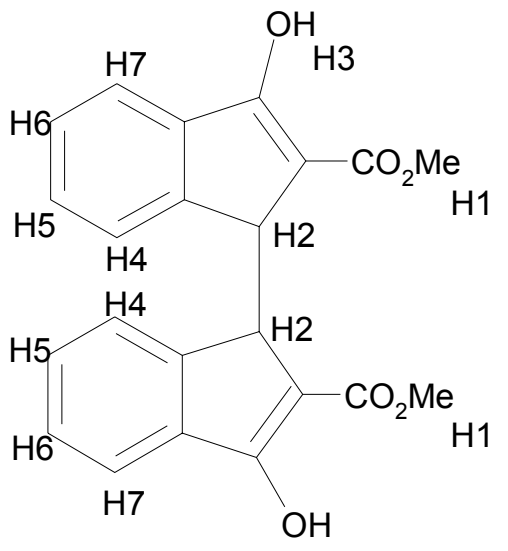

H3

\begin{tabular}{|c|c|c|}
\hline Hidrogênio & $\delta(\mathrm{ppm})$ & Multiplic. $(\mathrm{J})$ \\
\hline $\mathrm{H} 1$ & 3,84 & $6 \mathrm{H}, \mathrm{s}$ \\
\hline $\mathrm{H} 2$ & 4,25 & $4 \mathrm{H}, \mathrm{s}$ \\
\hline $\mathrm{H} 7$ & 6,94 & $2 \mathrm{H}, \mathrm{d}(8.8 \mathrm{~Hz})$ \\
\hline $\mathrm{H} 5 \mathrm{e} \mathrm{H} 6$ & 7,23 & $4 \mathrm{H}, \mathrm{m}$ \\
\hline $\mathrm{H} 4$ & 7,76 & $2 \mathrm{H}, \mathrm{d}(8.8 \mathrm{~Hz})$ \\
\hline $\mathrm{H} 3^{*}$ & 12,77 & $2 \mathrm{H}, \mathrm{s}$ \\
\hline
\end{tabular}

Solvente: d6-DMSO / TMS

${ }^{*}$ Troca com $\mathrm{D}_{2} \mathrm{O}$

(8b) RMN ${ }^{13} \mathrm{C}$ (75 MHz): $\delta$ em ppm (d6-DMSO / TMS) 35,4; 51,9; 97,1; 124,$6 ; 126,19 ; 126,8 ; 129,9 ; 131,3 ; 139,5 ; 166,4 ; 173,4$. DEPT $1^{\circ} 5^{\circ}$ (75 MHz): $\delta$ em ppm (d6-DMSO / TMS) 35,4; 51,9; 124,6; 126,19; 126,8; 131,3 .

No RMN ${ }^{13} \mathrm{C}$ foram observados 11 sinais, dos quais nenhum correspondia a $\mathrm{CH}_{2}$, o que foi verificado no espectro de DEPT. Para o derivado da ciclopentanona (Figura IV.18) seriam esperados pelo menos 15 sinais considerando 8 sinais para os dois substituintes o-metoxicarbonilfenila. Estas evidências espectroscópicas excluíram definitivamente o produto usual de eletroidrodimerização e seu precursor de cadeia aberta.

Com base na hipótese de que os ânions radicais formados na transferência de elétrons conduziriam a um dímero dianiônico e que os grupos metoxicarbonila ligados aos anéis aromáticos são 
eletrofílicos, foi considerada a possibilidade de ocorrer uma ciclização de Dieckmann conforme pode ser visto no Esquema IV.10 (p.89). Esta reação seria competitiva com a ciclização de Dieckmann que fornece o derivado da ciclopentanona (Figura IV.18).

Os dados da espectrometria de massas (Tabela IV.16) e de RMN reunidos na Tabela IV.15 dão suporte à estrutura do composto 8b, ainda não descrito na literatura.

Tabela IV.16 Resultados principais para o espectro de massas de $\mathbf{8 b}$.

\begin{tabular}{|c|c|c|}
\hline $\mathrm{m} / \mathrm{z}$ & Intens. (\%) & Fragmentos \\
\hline 346 & 4 & $\mathrm{M}=$ \\
\hline 189 & 73 & {$\left[\mathrm{CO}_{2} \mathrm{CO}_{2} \mathrm{OH}\right.$} \\
\hline 157 & 18 & {$\left[\mathrm{CO}_{10} \mathrm{H}_{9} \mathrm{O}_{2}\right]$} \\
\hline 130 & 33 & {$\left[\mathrm{C}_{9} \mathrm{H}_{8} \mathrm{O}\right]$} \\
\hline
\end{tabular}

A análise elementar do composto $\mathbf{8 b}$ revelou $66,50 \%$ de $\mathrm{C}$ e $5,15 \%$ de $\mathrm{H}$, valores muito distintos dos calculados para $\mathrm{C}_{22} \mathrm{H}_{18} \mathrm{O}_{6}$ (C $69,89 \% ; H 4,76 \%$ ). Surpreendentemente ao refazer os cálculos para $\mathrm{C}_{22} \mathrm{H}_{18} \mathrm{O}_{6} \bullet \mathrm{H}_{2} \mathrm{O}(\mathrm{C} 66,67 \% ; \mathrm{H} \mathrm{5,05 \% )}$ os resultados da análise 
elementar foram concordantes. Assim, foi feita uma secagem deste produto sob vácuo a $96^{\circ} \mathrm{C}$ em um Abderhalden e refeita a análise elementar cujo resultado (C $69,30 \% ; \mathrm{H} \mathrm{4,73 \% )} \mathrm{se} \mathrm{mostrou} \mathrm{compatível}$ com os valores para o composto $\mathbf{8 b}$.

Um fato que merece ser comentado é a estabilidade da forma enolica, sendo que nos espectros de $\mathrm{RMN}{ }^{1} \mathrm{H}$ não foi observado sinal correspondente à forma cetônica. No espectro de $\mathrm{RMN}{ }^{1} \mathrm{H}$ registrado para a 2-(metoxicarbonil)-1-indanona em $\mathrm{CDCl}_{3}{ }^{46}$, a presença da forma cetônica $(\delta 3,2-3,8,3 \mathrm{H} ; \mathrm{m})$ é preponderante, com apenas $10 \%$ da forma enólica $(\delta 10,3,0,1 \mathrm{H} ; \mathrm{sl})$.

Esta diferença de comportamento de $\mathbf{8 b}$ e da indanona pode ser atribuída à maior estabilidade do enol $\mathbf{8 b}$, pois as interações estéricas dos hidrogênios e do grupo substituinte ligados aos carbonos $s p^{3}$ do anel de 5 membros da forma cetônica da indanona seriam menores do que na forma cetônica da espécie dimérica. O substituinte volumoso no grupo metínico de $\mathbf{8 b}$ aumenta sensivelmente a tensão torcional na forma cetônica e o alívio torcional que ocorre na forma enólica é bem maior do que no caso da indanona.

Assim como houve problemas para a determinação da estrutura 8b, a estrutura 8c devido à sua simetria também apresentou

${ }^{46} \mathrm{~K}$. Umemura; H, Matsuyama; N. Watanabe; M. Kobayashi; N. Kamigata J. Org. Chem. 1989, 노, 2374. 
dificuldades, porém menores, pois este composto era solúvel em clorofórmio, o que não ocorria com $\mathbf{8 b}$.

A análise dos dados de espectrometria de massas e de RMN permitiram, como anteriormente, concluir que não se tratava de nenhum dos produtos usualmente esperados na redução dos cinamatos. Pelo o espectro de massas (Tabela IV.17) começou a ser proposta a estrutura 8c, que foi confirmada pelos dados de RMN ${ }^{1} \mathrm{H},{ }^{13} \mathrm{C}$ e DEPT (Tabela IV.18).

Tabela IV.17 Resultados principais para o espectro de massas de 8c.

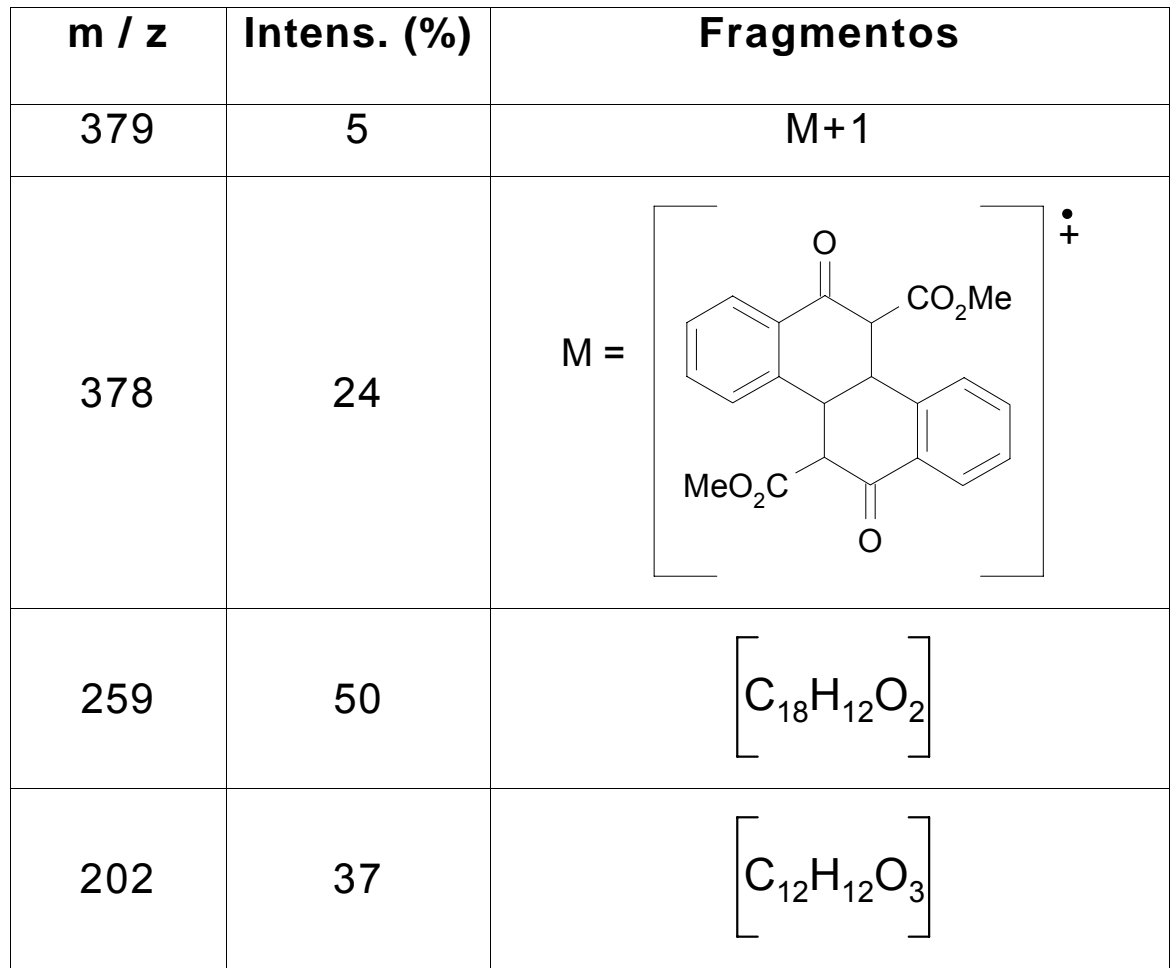


Tabela IV.18 Resultados dosespéctrosde RMN ${ }^{1} \mathrm{H}^{13} \mathrm{C}$ e DEPT para 8c.

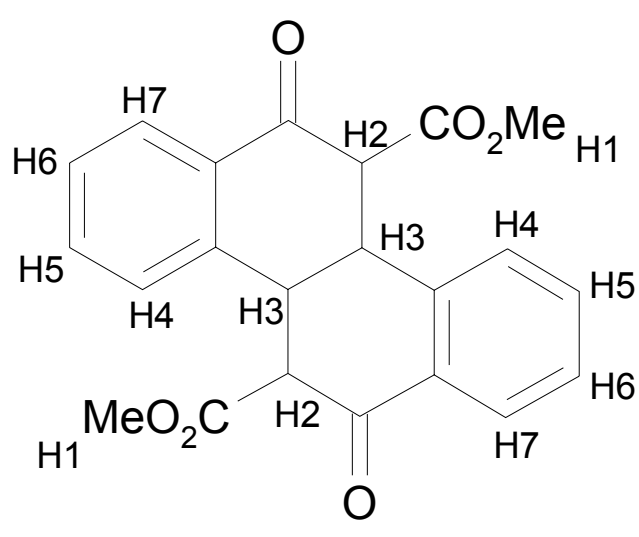

\begin{tabular}{|c|c|c|}
\hline Hidrogênio & $\delta$ (ppm) & Multiplic. (J) \\
\hline $\mathrm{H} 2$ & 2,93 & $2 \mathrm{H}, \mathrm{d}(4,4 \mathrm{~Hz})$ \\
\hline $\mathrm{H} 1$ & 3,55 & $6 \mathrm{H}, \mathrm{s}$ \\
\hline $\mathrm{H} 3$ & 4,77 & $2 \mathrm{H}, \mathrm{d},(3,9 \mathrm{~Hz})$ \\
\hline $\mathrm{H} 4$ & $7,44-7,52$ & $2 \mathrm{H}, \mathrm{m}$ \\
\hline $\mathrm{H} 5$ e H6 & $7,60-7,70$ & $4 \mathrm{H}, \mathrm{m}$ \\
\hline $\mathrm{H} 7$ & 7,80 & $2 \mathrm{H}, \mathrm{d},(8 \mathrm{~Hz})$ \\
\hline
\end{tabular}

(8c) RMN ${ }^{13} \mathrm{C}$ (75 MHz): $\delta$ em ppm ( $\left.\mathrm{CDCl}_{3} / \mathrm{TMS}\right)$ 197,2; 168,8; 153,$7 ; 135,7 ; 135,6 ; 129,0 ; 125,5 ; 125,1 ; 55,5 ; 52,7 ; 44,6$. DEPT $135^{\circ}$ (75 MHz): $\delta$ em ppm ( $\left.\mathrm{CDCl}_{3} / \mathrm{TMS}\right) 135,7 ; 129,0 ; 125,5 ; 125,1 ; 55,5$; 52,$7 ; 44,6$.

A análise elementar de $\mathbf{8 c}$ apresentou um resultado coerente com a estrutura proposta: C22H18O6 - Calc: C 69,84\%, H 4,79\%. Observado: C 70,21\%, H 4,66 \%.

Com os dados espectroscópicos disponíveis não foi possível determinar a estereoquímica dos compostos $\mathbf{8 b}$ e $\mathbf{8 c}$ devido à simetria apresentada por estas moléculas. Considerando que a dimerização dos ânions-radicais intermediários na redução de cinamatos geralmente conduz ao dímero racêmico, os compostos $\mathbf{8 b}$ e $\mathbf{8 c}$ provavelmente serão os estereoisômeros racêmicos. Caso esta hipótese seja verdadeira a junção dos anéis em $\mathbf{8 c}$ deve ser cis, o que 
parece ser confirmado pelas constantes de acoplamento de 3,9 Hz e 4,4 Hz (Tabela IV.18).

O isolamento de uma pequena quantidade do produto $\mathbf{8 d}$ serviu como uma evidência para o mecanismo proposto, já que a sua ciclização de Dieckmann conduz a um dos compostos principais, o $\mathbf{8 b}$.

No Esquema IV.10 é apresentado o mecanismo de reação proposto para a EHD de 8.

2
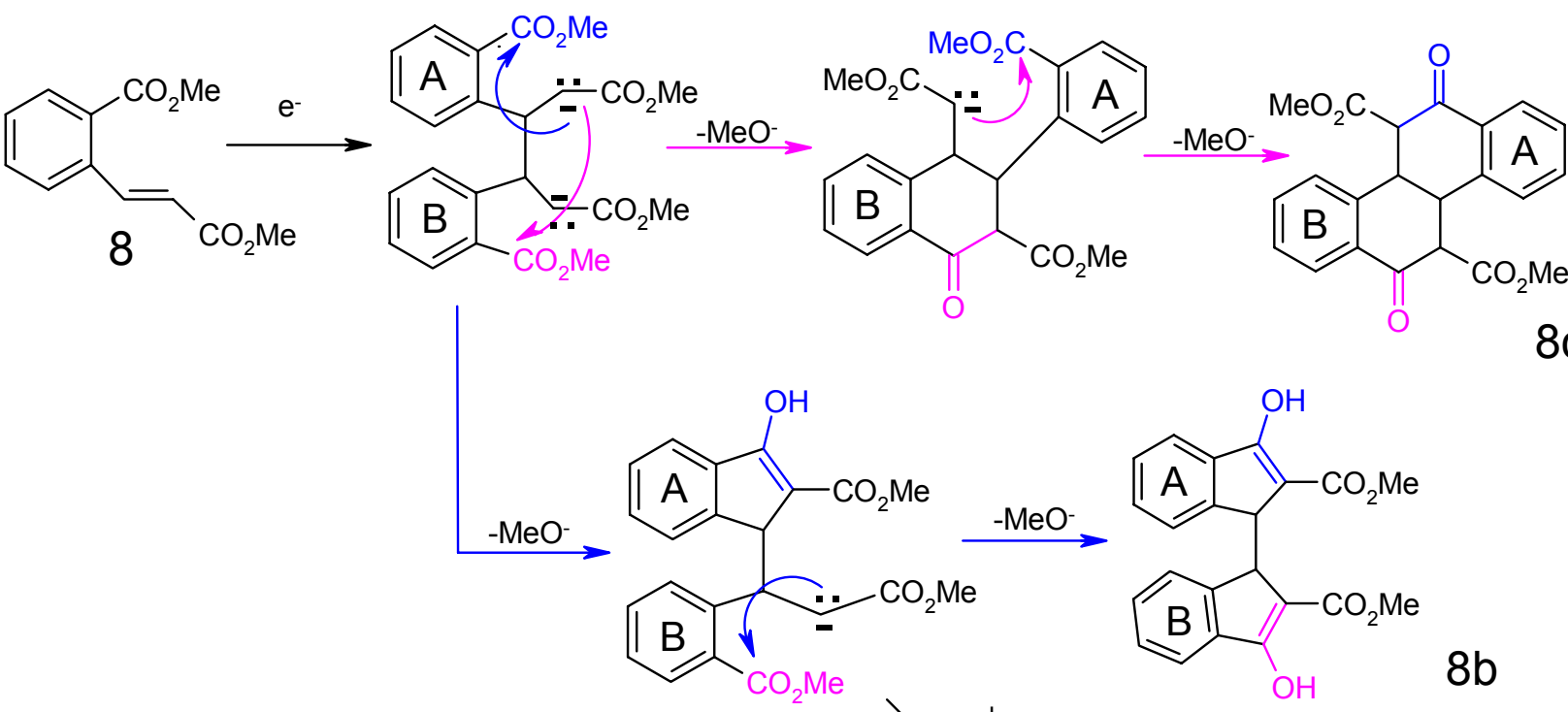

$8 c$

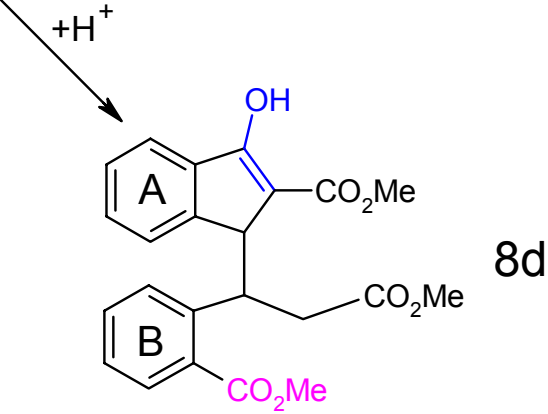

Esquema IV.10 Mecanismo proposto para a formação dos compostos policíclicos. 


\subsection{Cálculos $A b$ Initio}

Com o objetivo de obter embasamento teórico para as verificações experimentais obtidas através da redução eletroquímica de alguns cinamatos substituídos, cálculos ab initio (Hartree-Fock não restrito) utilizando a base STO-3g foram feitos para a aquisição dos coeficientes de contribuição atômica dos orbitais moleculares e densidades de $\operatorname{carga}^{47}$ e de $\operatorname{spin}^{48}$ de Mülliken dos ânions-radicais gerados através destes compostos. A densidade de spin considerada pelo calculo é a dos elétrons com o spin de menor energia, o $\alpha$.

Anteriormente foi feita a otimização da estrutura chegando à conformação de menor energia utilizando a mesma base de dados e então foram feitos os cálculos utilizando o programa Gaussian $03^{49} \mathrm{e}$ a representação gráfica com o Chem 3D Ultra 8.0 (CambridgeSoft).

${ }^{47}$ Densidade de carga: distribuição da carga total da molécula nesta indicando indicando cargas parciais positivas e negativas em seus átomos.

${ }^{48}$ Densidade de spin: densidade de elétron desemparelhado em uma posição do substrato.

${ }^{49}$ Gaussian 03, Revision B.04, M. J. Frisch, G. W. Trucks, H. B. Schlegel, G. E. Scuseria, M. A. Robb, J. R. Cheeseman, J. A. Montgomery, Jr., T. Vreven, K. N. Kudin, J. C. Burant, J. M. Millam, S. S. lyengar, J. Tomasi, V. Barone, B. Mennucci, M. Cossi, G. Scalmani, N. Rega, G. A. Petersson, H. Nakatsuji, M. Hada, M. Ehara, K. Toyota, R. Fukuda, J. Hasegawa, M. Ishida, T. Nakajima, Y. Honda, O. Kitao, H. Nakai, M. Klene, X. Li, J. E. Knox, H. P. Hratchian, J. B. Cross, C. Adamo, J. Jaramillo, R. Gomperts, R. E. Stratmann, O. Yazyev, A. J. Austin, R. Cammi, C. Pomelli, J. W. Ochterski, P. Y. Ayala, K. Morokuma, G. A. Voth, P. Salvador, J. J. Dannenberg, V. G. Zakrzewski, S. Dapprich, A. D. Daniels, M. C. Strain, O. Farkas, D. K. Malick, A. D. Rabuck, K. Raghavachari, J. B. Foresman, J. V. Ortiz, Q. Cui, A. G. Baboul, S. Clifford, J. Cioslowski, B. B. Stefanov, G. Liu, A. Liashenko, P. Piskorz, I. Komaromi, R. L. Martin, D. J. Fox, T. Keith, M. A. AlLaham, C. Y. Peng, A. Nanayakkara, M. Challacombe, P. M. W. Gill, B. Johnson, W. Chen, M. W. Wong, C. Gonzalez, and J. A. Pople, Gaussian, Inc., Pittsburgh PA, 2003. 
a - Nitro-derivados

Como discutido anteriormente, não foi observada a formação de produtos procedentes de dimerização em nenhuma eletrólise dos cinamatos nitro-substituidos estudados ( 3 e 7 ), fato que como discutido anteriormente ocorre devido à estabilidade do ânion-radical gerado (Item 2.2.c - ).

Observando os coeficientes de contribuição dos orbitais moleculares obtidos para os ânions-radicais de $\mathbf{3}$ e 7, foram verificados menores coeficientes no carbono benzílico (C5) e no $\alpha$-carbonílico (C4) para o SOMO (single occupied molecular orbital) destas espécies quando comparadas à contribuição observada para o ânion-radical do cinamato não substituído, além de ser observada também a contribuição dos átomos do nitro grupo para este orbital, o que causaria a estabilidade da espécie(Tabela IV.19/Figura IV.19).

No entanto estas observações não justificam a não ocorrência da dimerização, já que a diminuição dos coeficientes de contribuição no SOMO dos carbonos C4 e C5 citados acima é muito pequena, sendo até imperceptível na representação gráfica, podendo ser observada na tabela com os valores de coeficientes de $p_{y}$ para estes átomos. Estes valores de $p_{y}$ foram selecionados entre os demais obtidos, já que são os que possuem maior coeficiente de contribuição atômica no orbital em questão, o SOMO. 
Tabela IV.19 Coeficientes de contribuição atômica de $p_{z}$ para o SOMO dos ânions-radicais do cinamato de metila (9) e dos nitrocinamatos (3 e 7).

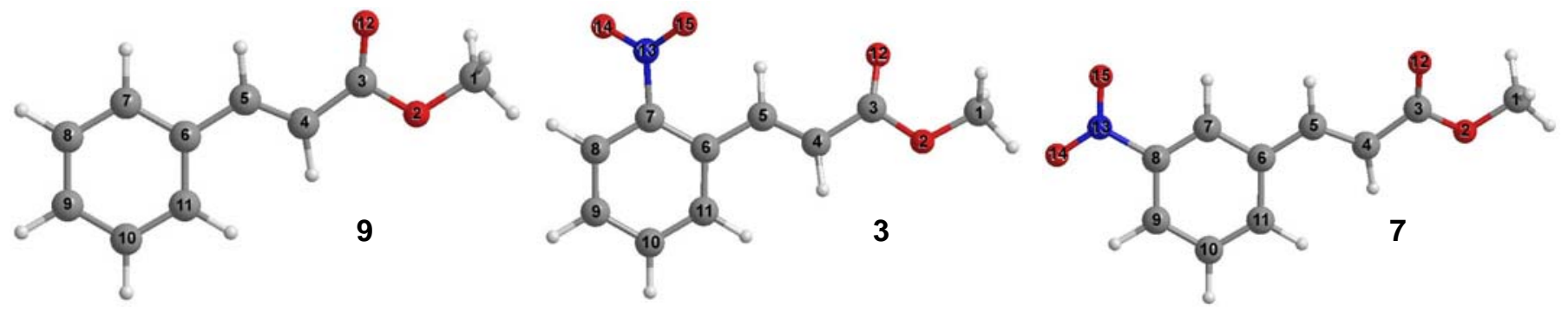

\begin{tabular}{|c|c|c|c|c|c|c|c|c|c|c|c|c|c|c|c|}
\hline 9 & C1 & O2 & C3 & C4 & C5 & C6 & C7 & C8 & C9 & C10 & C11 & 012 & & & \\
\hline SOMO & $-0,01$ & $-0,21$ & 0,32 & 0,55 & $-0,52$ & $-0,34$ & 0,22 & 0,10 & $-0,19$ & 0,09 & 0,22 & $-0,30$ & & & \\
\hline 3 & C1 & O2 & C3 & C4 & C5 & C6 & C7 & $\mathrm{C} 8$ & C9 & C10 & C11 & 012 & N13 & O14 & 015 \\
\hline SOMO & 0,00 & 0,13 & $-0,18$ & $-0,41$ & 0,42 & 0,53 & $-0,33$ & $-0,99$ & 0,28 & $-0,17$ & $-0,33$ & 0,17 & 0,10 & 0,17 & 0,17 \\
\hline 7 & $C$ & $\mathrm{O} 2$ & $\mathrm{C3}$ & $\mathrm{C} 4$ & C5 & C6 & 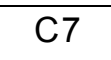 & C8 & 80 & 10 & C11 & 2 & N13 & 014 & 015 \\
\hline OMO & 0,00 & 0,12 & $-0,16$ & $-0,39$ & 0,40 & 0,49 & $-0,26$ & $-0,24$ & 0,33 & $-0,11$ & $-0,35$ & 0,16 & $-0,08$ & 0,15 & 0,15 \\
\hline
\end{tabular}

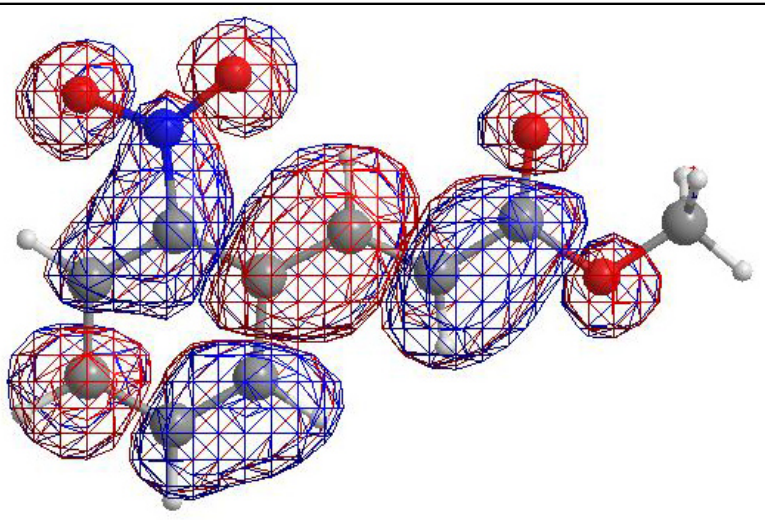

o-nitrocinamato de metila (3)

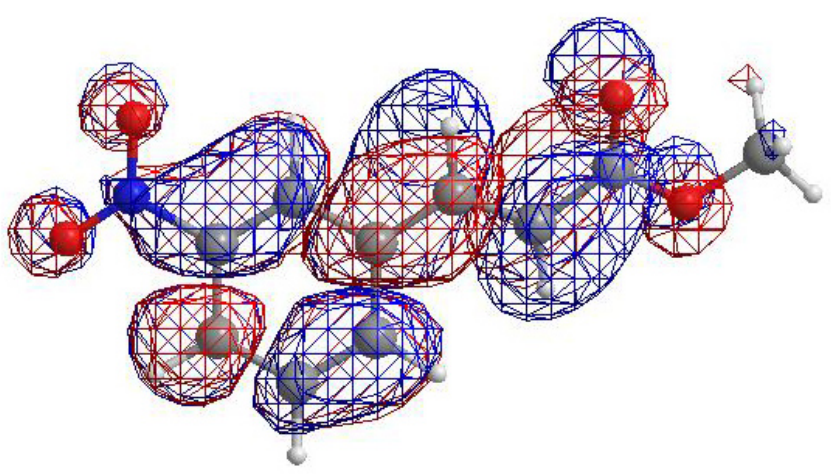

m-nitrocinamato de metila (7)

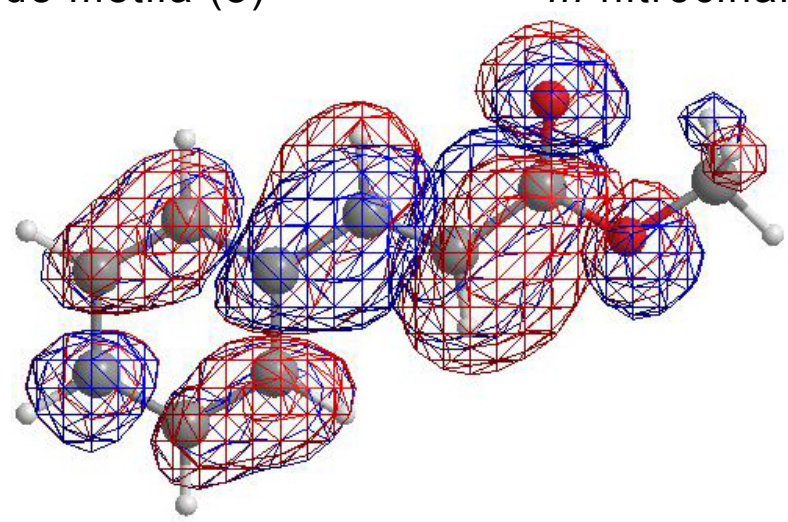

cinamato de metila (9)

Figura IV.19 Representação gráfica dos coeficientes de contribuição atômica do orbital SOMO dos substratos 3,7 e 9. 
Tabela IV.20 Densidades de carga e densidade de spin $\alpha$ de Mülliken dos ânions-radicais do cinamato de metila (9) e dos nitrocinamatos (3 e 7).

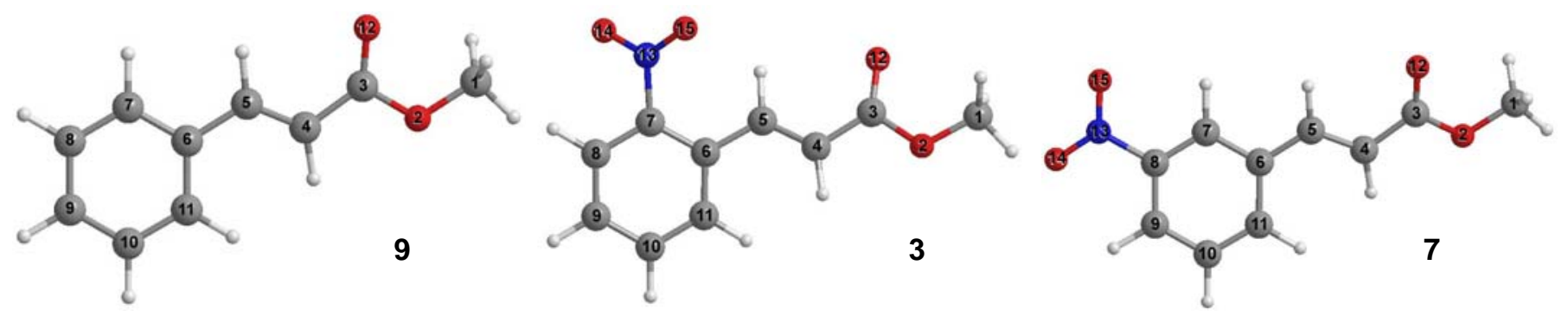

\begin{tabular}{|c|c|c|c|c|c|c|c|c|}
\hline 9 & Carga & Spin & 3 & Carga & Spin & 7 & Carga & Spin \\
\hline $\mathrm{C} 1$ & $-0,04$ & 0 & C1 & $-0,06$ & 0 & C1 & $-0,04$ & 0 \\
\hline $\mathrm{O} 2$ & $-0,30$ & 0 & $\mathrm{O} 2$ & $-0,27$ & 0 & $\mathrm{O} 2$ & $-0,28$ & 0 \\
\hline C3 & 0,21 & 0 & C3 & 0,20 & 0 & C3 & 0,25 & 0 \\
\hline $\mathrm{C} 4$ & $-0,19$ & 0,19 & C4 & $-0,13$ & 0,62 & C4 & $-0,15$ & 0,51 \\
\hline C5 & $-0,13$ & 0,42 & C5 & $-0,13$ & 0 & C5 & $-0,11$ & 0 \\
\hline C6 & $-0,04$ & 0 & $\mathrm{C} 6$ & $-0,06$ & 0 & C6 & $-0,07$ & 0 \\
\hline $\mathrm{C} 7$ & $-0,08$ & 0,75 & $\mathrm{C} 7$ & 0,03 & 0,49 & C7 & $-0,07$ & 0,42 \\
\hline $\mathrm{C} 8$ & $-0,08$ & 0 & C8 & $-0,07$ & 0 & C8 & 0,04 & 0 \\
\hline C9 & $-0,09$ & 0,80 & C9 & $-0,10$ & 0,75 & C9 & $-0,09$ & 0,81 \\
\hline C10 & $-0,08$ & 0 & C10 & $-0,08$ & 0 & C10 & $-0,08$ & 0 \\
\hline C11 & $-0,08$ & 0,75 & C11 & $-0,08$ & 0,66 & C11 & $-0,08$ & 0,69 \\
\hline 012 & $-0,37$ & 0,46 & 012 & $-0,24$ & 0,73 & 012 & $-0,32$ & 0,46 \\
\hline $\mathrm{H} 1 \mathrm{a}$ & 0,04 & 0,05 & N13 & 0,10 & 0 & N13 & 0,18 & 0,06 \\
\hline $\mathrm{H} 1 \mathrm{~b}$ & 0,04 & 0 & O14 & $-0,23$ & 0,09 & O14 & $-0,25$ & 0,01 \\
\hline $\mathrm{H} 1 \mathrm{C}$ & 0,04 & 0 & O15 & $-0,26$ & 0,10 & O15 & $-0,25$ & 0 \\
\hline $\mathrm{H} 4$ & $-0,01$ & 0 & $\mathrm{H} 8$ & 0,06 & 0,05 & H9 & 0,04 & $-0,06$ \\
\hline $\mathrm{H} 5$ & 0,00 & 0 & H9 & 0,03 & 0 & $\mathrm{H} 10$ & 0,02 & 0,05 \\
\hline $\mathrm{H} 7$ & 0,02 & 0,06 & H10 & 0,03 & 0,05 & $\mathrm{H} 11$ & 0,03 & 0 \\
\hline $\mathrm{H} 8$ & 0,02 & 0 & H11 & 0,03 & 0 & $\mathrm{H} 7$ & 0,05 & 0 \\
\hline $\mathrm{H} 9$ & 0,02 & 0 & H5 & 0,05 & 0,02 & H5 & 0,01 & 0,01 \\
\hline H10 & 0,04 & 0 & $\mathrm{H} 4$ & 0,03 & 0 & $\mathrm{H} 4$ & 0,02 & 0 \\
\hline \multirow[t]{3}{*}{ H11 } & 0,03 & 0 & $\mathrm{H} 1 \mathrm{a}$ & 0,05 & 0 & $\mathrm{H} 1 \mathrm{a}$ & 0,05 & 0 \\
\hline & & & $\mathrm{H} 1 \mathrm{~b}$ & 0,05 & 0 & $\mathrm{H} 1 \mathrm{~b}$ & 0,05 & 0 \\
\hline & & & $\mathrm{H} 1 \mathrm{c}$ & 0,05 & 0 & $\mathrm{H} 1 \mathrm{c}$ & 0,05 & 0 \\
\hline
\end{tabular}


Tendo em vista estas observações, foram então verificadas as densidades de carga e de spin de Mülliken para estes ânions-radicais. Verifica-se que parte da carga negativa está localizada nos oxigênios do nitro grupo (014 e 015), e que a densidade de spin é nula no carbono benzílico (C5). Esta ausência de densidade de spin pode justificar a não dimerização desta espécie, pois sem a probabilidade de existir um elétron desemparelhado no C5, a dimerização não seria possível ( Tabela IV.20).

\section{b - $\quad$ Cloro-derivados}

Os cinamatos clorados apresentam um comportamento eletroquímico bastante curioso caracterizado pela competição entre o processo de desalogenação e o de dimerização. Estes processos são mais ou menos favorecidos dependendo da posição do substituinte no anel aromático (Item 2.2.d - ).

Uma comparação dos coeficientes de contribuição do SOMO destes ânions-radicais halogenados, com os do ânion-radical do cinamato de metila (9) mostra qua não são muito diferente. É interessante ressaltar a verificação de contribuições do $p_{z}$ dos cloros com valores que variam entre 0,01 e 0,25 , sendo que o maior coeficiente corresponde ao cloro do substrato 2 , e o menor ao cloro do substrato 5. Isto é facilmente observado nas representações gráficas 
destes SOMOs (Tabela IV.21/Figura IV.20). Assim como no caso dos nitrocinamatos, o $p_{z}$ foi utilizado, pois possui os maiores coeficientes de contribuição no SOMO destes ânions-radicais.

Tabela IV.21 Coeficientes de contribuição atômica de $p_{z}$ para o SOMO dos ânions-radicais do cinamato de metila (9) e dos cinamatos clorados $(2,4-6)$.

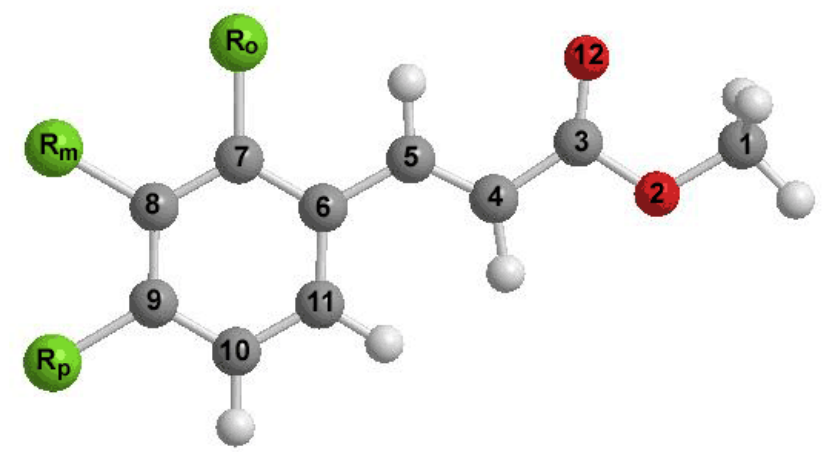

\begin{tabular}{|cc|cc|cc|cc|cc|}
\hline $\mathbf{9}$ & Coef. & $\mathbf{2}$ & Coef. & $\mathbf{5}$ & Coef. & $\mathbf{6}$ & Coef. & $\mathbf{7}$ & Coef. \\
\hline $\mathrm{C} 1$ & $-0,01$ & $\mathrm{C} 1$ & $-0,01$ & $\mathrm{C} 1$ & 0,01 & $\mathrm{C} 1$ & 0,01 & $\mathrm{C} 1$ & 0,01 \\
$\mathrm{O} 2$ & $-0,21$ & $\mathrm{O} 2$ & $-0,18$ & $\mathrm{O} 2$ & 0,15 & $\mathrm{O} 2$ & 0,15 & $\mathrm{O} 2$ & 0,17 \\
$\mathrm{C} 3$ & 0,32 & $\mathrm{C} 3$ & 0,27 & $\mathrm{C} 3$ & $-0,24$ & $\mathrm{C} 3$ & $-0,25$ & $\mathrm{C} 3$ & $-0,26$ \\
$\mathrm{C} 4$ & 0,55 & $\mathrm{C} 4$ & 0,51 & $\mathrm{C} 4$ & $-0,46$ & $\mathrm{C} 4$ & $-0,46$ & $\mathrm{C} 4$ & $-0,50$ \\
\hline $\mathrm{C} 5$ & $-0,58$ & $\mathrm{C} 5$ & $-0,38$ & $\mathrm{C} 5$ & 0,55 & $\mathrm{C} 5$ & 0,49 & $\mathrm{C} 5$ & 0,40 \\
\hline $\mathrm{C} 6$ & $-0,34$ & $\mathrm{C} 6$ & $-0,42$ & $\mathrm{C} 6$ & 0,36 & $\mathrm{C} 6$ & 0,36 & $\mathrm{C} 6$ & 0,44 \\
$\mathrm{C} 7$ & 0,22 & $\mathrm{C} 7$ & 0,27 & $\mathrm{C} 7$ & $-0,22$ & $\mathrm{C} 7$ & $-0,22$ & $\mathrm{C} 7$ & $-0,27$ \\
$\mathrm{C} 8$ & 0,10 & $\mathrm{C} 8$ & 0,11 & $\mathrm{C} 8$ & $-0,10$ & $\mathrm{C} 8$ & $-0,10$ & $\mathrm{C} 8$ & $-0,15$ \\
$\mathrm{C} 9$ & $-0,19$ & $\mathrm{C} 9$ & $-0,23$ & $\mathrm{C} 9$ & 0,20 & $\mathrm{C} 9$ & 0,19 & $\mathrm{C} 9$ & 0,26 \\
$\mathrm{C} 10$ & 0,09 & $\mathrm{C} 10$ & 0,12 & $\mathrm{C} 10$ & $-0,11$ & $\mathrm{C} 10$ & $-0,11$ & $\mathrm{C} 10$ & $-0,13$ \\
$\mathrm{C} 11$ & 0,22 & $\mathrm{C} 11$ & 0,27 & $\mathrm{C} 11$ & $-0,23$ & $\mathrm{C} 11$ & $-0,22$ & $\mathrm{C} 11$ & $-0,27$ \\
$\mathrm{O} 12$ & $-0,30$ & $\mathrm{O} 12$ & $-0,25$ & $\mathrm{O} 12$ & 0,22 & $\mathrm{O} 12$ & 0,22 & $\mathrm{O} 12$ & 0,23 \\
\cline { 3 - 8 } & & $\mathrm{Cl}(\mathrm{Ro})$ & $-0,25$ & $\mathrm{Cl}(\mathrm{Rm})$ & $-0,01$ & $\mathrm{Cl}(\mathrm{Rp})$ & $-0,18$ & $\mathrm{Cl}(\mathrm{Rp})$ & $-0,16$ \\
\cline { 3 - 8 } & & & & & & & $\mathrm{Cl}(\mathrm{Rm})$ & 0,03 \\
\hline
\end{tabular}

Buscando mais indicações sobre a reatividade destes compostos foram verificadas as densidades de carga e de spin de Mülliken destes compostos halogenados frente ao composto não substituído (Tabela IV.22). 


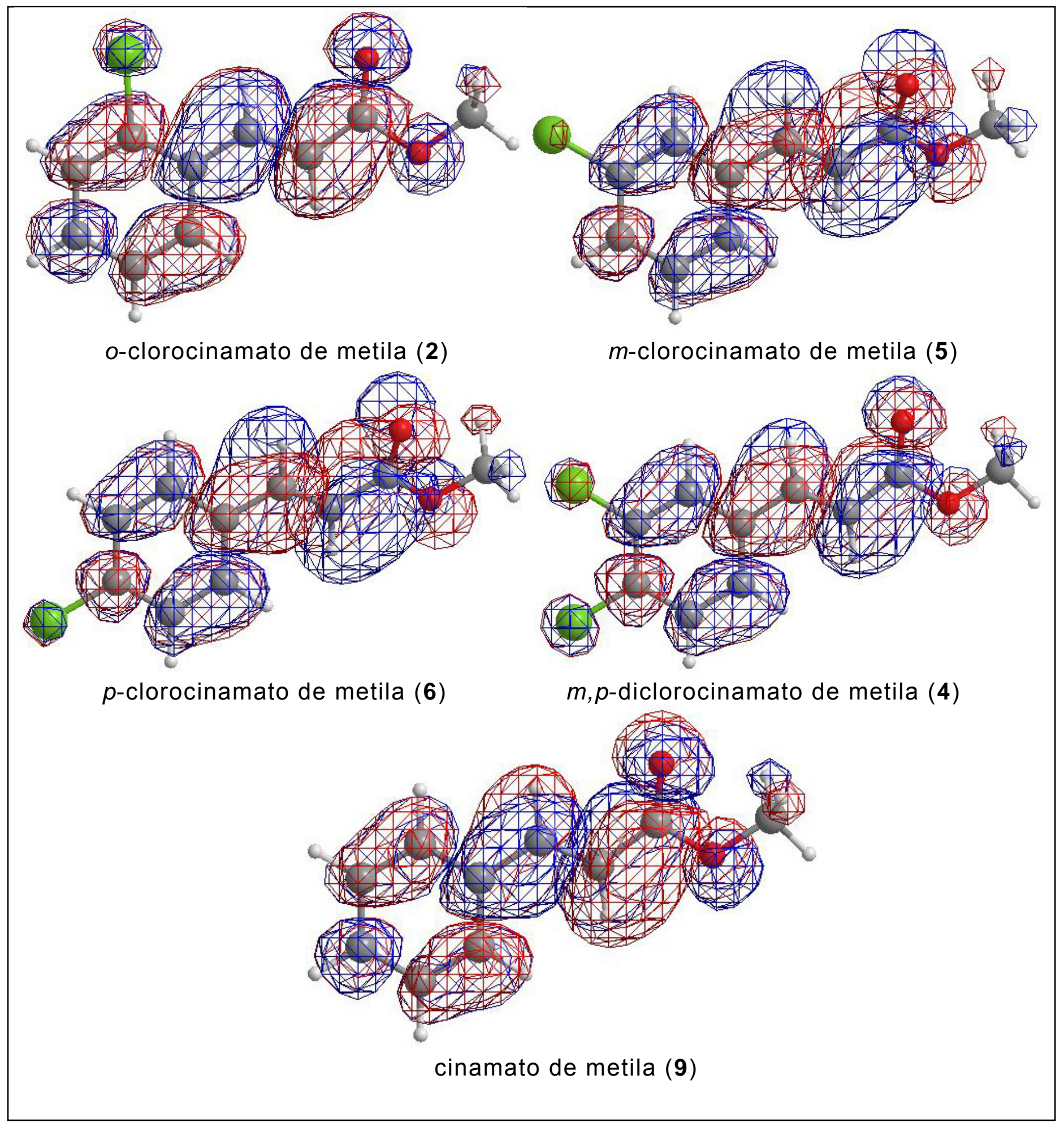

Figura IV.20 Representação gráfica dos coeficientes de contribuição atômica do orbital SOMO dos substratos 2,4-6 e 9. 
Tabela IV.22 Densidades de carga e densidade de spin $\alpha$ de Mülliken dos ânions-radicais do cinamato de metila (9) e dos cinamatos clorados $(2,4-6)$.

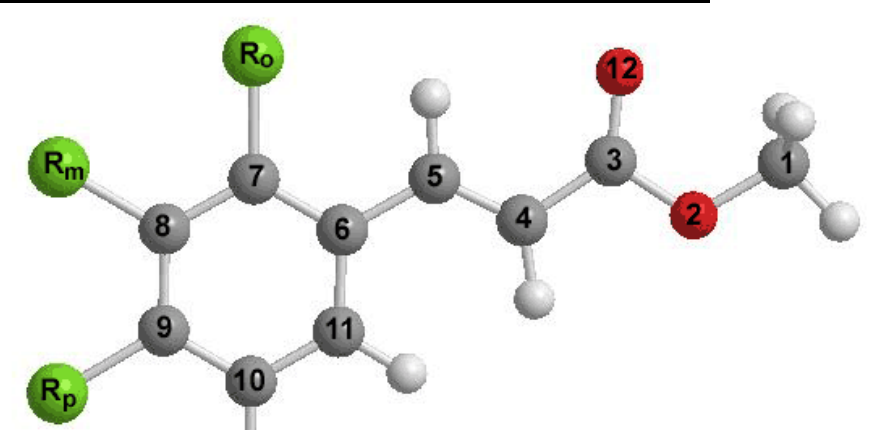

\begin{tabular}{|c|c|c|c|c|c|c|c|c|c|c|c|c|c|c|}
\hline 9 & arga & Spin & 2 & Carga & Spin & 5 & Carga & Spin & 6 & Carga & Spin & 4 & Carga & Spin \\
\hline C1 & $-0,04$ & 0 & C1 & $-0,06$ & 0 & C1 & $-0,04$ & 0 & C1 & $-0,04$ & 0 & C1 & $-0,04$ & 0 \\
\hline $\mathrm{O} 2$ & $-0,30$ & 0 & $\mathrm{O} 2$ & $-0,28$ & 0 & $\mathrm{O} 2$ & $-0,30$ & 0 & $\mathrm{O} 2$ & $-0,30$ & 0 & $\mathrm{O} 2$ & $-0,29$ & 0 \\
\hline C3 & 0,21 & 0 & C3 & 0,19 & 0 & C3 & 0,22 & 0 & C3 & 0,22 & 0 & C3 & 0,23 & 0 \\
\hline C4 & $-0,19$ & 0,19 & C4 & $-0,17$ & 0,31 & C4 & $-0,18$ & 0,26 & C4 & $-0,18$ & 0,25 & C4 & $-0,17$ & 0,37 \\
\hline C5 & $-0,13$ & 0,42 & C5 & $-0,13$ & 0,18 & C5 & $-0,13$ & 0,36 & C5 & $-0,13$ & 0,37 & C5 & $-0,12$ & 0,15 \\
\hline C6 & $-0,04$ & 0 & C6 & $-0,05$ & 0 & C6 & $-0,04$ & 0 & $\mathrm{C} 6$ & $-0,04$ & 0 & $\mathrm{C} 6$ & $-0,06$ & 0 \\
\hline $\mathrm{C} 7$ & $-0,08$ & 0,75 & C7 & 0,04 & 0,75 & $\mathrm{C} 7$ & $-0,07$ & 0,72 & $\mathrm{C} 7$ & $-0,07$ & 0,74 & C7 & $-0,07$ & 0,65 \\
\hline C8 & $-0,08$ & 0 & C8 & $-0,07$ & 0 & C8 & 0,03 & 0 & C8 & $-0,06$ & 0 & $\mathrm{C} 8$ & 0,02 & 0 \\
\hline C9 & $-0,09$ & 0,80 & C9 & $-0,08$ & 0,84 & C9 & $-0,08$ & 0,78 & C9 & 0,02 & 0,76 & C9 & 0,01 & 0,75 \\
\hline C10 & $-0,08$ & 0 & C10 & $-0,08$ & 0 & C10 & $-0,07$ & 0 & C10 & $-0,07$ & 0 & C10 & $-0,06$ & 0 \\
\hline C11 & $-0,08$ & 0,75 & C11 & $-0,08$ & 0,77 & C11 & $-0,07$ & 0,73 & C11 & $-0,07$ & 0,72 & C11 & $-0,08$ & 0,68 \\
\hline 012 & $-0,37$ & 0,46 & 012 & $-0,30$ & 0,62 & 012 & $-0,35$ & 0,47 & 012 & $-0,35$ & 0,48 & 012 & $-0,33$ & 0,51 \\
\hline $\mathrm{H} 1 \mathrm{a}$ & 0,04 & 0,05 & Ro & $-0,24$ & 0 & $\mathrm{Rm}$ & $-0,21$ & 0,04 & $\mathrm{Rp}$ & $-0,21$ & 0 & $\mathrm{Rm}$ & $-0,17$ & 0 \\
\hline $\mathrm{H} 1 \mathrm{~b}$ & 0,04 & 0 & $\mathrm{H} 1 \mathrm{a}$ & 0,04 & 0 & $\mathrm{H} 1 \mathrm{a}$ & 0,04 & 0 & $\mathrm{H} 1 \mathrm{a}$ & 0,04 & 0 & $\mathrm{Rp}$ & $-0,17$ & 0,03 \\
\hline $\mathrm{H} 1 \mathrm{c}$ & 0,04 & 0 & $\mathrm{H} 1 \mathrm{~b}$ & 0,05 & 0 & $\mathrm{H} 1 \mathrm{~b}$ & 0,04 & 0 & $\mathrm{H} 1 \mathrm{~b}$ & 0,04 & 0 & $\mathrm{H} 1 \mathrm{a}$ & 0,04 & 0 \\
\hline $\mathrm{H} 4$ & $-0,01$ & 0 & $\mathrm{H} 1 \mathrm{c}$ & 0,05 & 0 & $\mathrm{H} 1 \mathrm{c}$ & 0,05 & 0 & $\mathrm{H} 1 \mathrm{c}$ & 0,04 & 0 & $\mathrm{H} 1 \mathrm{~b}$ & 0,05 & 0 \\
\hline $\mathrm{H} 5$ & 0,00 & 0 & $\mathrm{H} 4$ & 0,01 & 0 & $\mathrm{H} 4$ & 0,00 & 0 & $\mathrm{H} 4$ & 0,00 & 0 & $\mathrm{H} 1 \mathrm{C}$ & 0,05 & 0 \\
\hline $\mathrm{H} 7$ & 0,02 & 0,06 & $\mathrm{H} 5$ & 0,03 & 0 & H5 & 0,00 & 0 & H5 & 0,00 & 0 & $\mathrm{H} 4$ & 0,01 & 0 \\
\hline $\mathrm{H} 8$ & 0,02 & 0 & $\mathrm{H} 8$ & 0,05 & 0,06 & $\mathrm{H} 7$ & 0,04 & 0 & $\mathrm{H} 7$ & 0,03 & 0 & $\mathrm{H} 5$ & 0,01 & 0 \\
\hline $\mathrm{H} 9$ & 0,02 & 0 & $\mathrm{H} 9$ & 0,03 & 0 & $\mathrm{H} 9$ & 0,04 & 0 & H8 & 0,04 & 0,05 & $\mathrm{H} 7$ & 0,05 & 0 \\
\hline H10 & 0,04 & 0 & $\mathrm{H} 10$ & 0,03 & 0,05 & H10 & 0,03 & 0,05 & $\mathrm{H} 10$ & 0,04 & 0 & $\mathrm{H} 10$ & 0,04 & 0,05 \\
\hline H11 & 0,03 & 0 & $\mathrm{H} 11$ & 0,04 & 0 & $\mathrm{H} 11$ & 0,05 & 0 & $\mathrm{H} 11$ & 0,05 & 0,06 & $\mathrm{H} 11$ & 0,04 & 0 \\
\hline
\end{tabular}

Quando se observa a densidade de spin no ânion-radical do cinamato de metila, verifica-se que o carbono benzílico C5 apresenta um valor de 0,42 , os carbonos do anel aromático possuem, também, densidade de spin elevada devido à deslocalização ocasionada pela conjugação das ligações $\pi$. Quando observamos o cinamato clorado 
em posição orto (2), verifica-se que a densidade de spin neste carbono diminui significantemente, o que concorda com dados experimentais da dificuldade de dimerização deste composto.

Com base nos dados da tabela, se pode observar que quando existe um átomo de cloro em posição orto ou para, existe uma densidade de spin relativamente alta no carbono ao qual ele está ligado, e o carbono onde ocorreria a dimerização possui uma densidade de spin menor do que o mesmo carbono no cinamato não substituído, o que nos leva a correlacionar este fato com as observações experimentais dos substratos clorados em orto e para sofrerem a desalogenação mais facilmente que a dimerização, havendo casos como o de 2 que esta nem ocorre.

Por outro lado, no cinamato com cloro em meta (5), a densidade de spin do carbono C5 é quase a mesma do substrato não substituído, e, no entanto é observada a ausência de elétrons desemparelhados no carbono C8, explicando o fato experimental deste substrato (5) dimerizar normalmente sem a saída do substituinte, ao contrário dos outros exemplos.

A ausência de elétrons desemparelhados no carbono C8, também é observada para o ânion-radical do substrato 4, embasando a verificação experimental da saída somente do substituinte da posição para, sendo que o carbono C9 possui uma grande densidade de spin que justifica tal correlação. 


\section{Conclusão}

Neste trabalho foi possível verificar que os substratos ortosubstituídos têm efetivamente uma reatividade diferenciada. A partir da variação dos grupos nesta posição, diferentes produtos são obtidos desde os hidrodímeros cíclicos geralmente observados nas reduções eletroquímicas de cinamatos até moléculas policíclicas, como no caso dos produtos obtidos na redução eletroquímica de $\mathbf{8}$.

É fácil perceber que a natureza do substituinte tem grande influência sobre o curso da reação, tendo em vista que, dependendo de sua natureza, pode influenciar a diastereosseletivadade da ciclização (composto 1), ser removido do substrato (compostos clorados em orto e para) ou agir como eletrófilo (composto 8).

No estudo do o-metilcinamato de metila (1), verificou-se que este tem um comportamento semelhante ao do o-metoxicinamato de metila frente à redução eletroquímica ${ }^{28}$, a formação do hidrodímero cíclico cis,trans $\mathbf{1 b}$ ao lado de trans, trans $\mathbf{1 c}$ (neste caso $\mathbf{1 b} / \mathbf{1} \mathbf{c} \leq 1$ ).

Estes resultados mostram que a presença dos grupos metoxila e metila doadores de elétrons ligados à posição orto do anel aromático é essencial para a formação do hidrodímero cíclico com os anéis aromáticos em cis. É provável que a presença destes grupos mude a energia do estado de transição da dimerização que leva ao diânion com estereoquímica meso tornando-a semelhante àquela do estado de 
transição da dimerização dos ânions-radicais que conduz ao diânion \pm $(d, I)$.

Uma análise dos resultados obtidos nas reduções eletroquímicas dos clorocinamatos revela a ocorrência da desalogenação nos substratos em que o cloro está ligado nas posições orto (2) ou para (6) do anel aromático e não ocorre quando este ocupa a posição meta.

Comparando os resultados dos estudos do o-clorocinamato de metila (2) e do p-clorocinamato de metila (6) verifica-se que a desalogenação de 2 ocorre independentemente do potencial de redução, enquanto que no substrato (6) esta etapa é preferencial em potencial menos negativo porém a dimerização prevalece em potenciais mais negativos.

A literatura oferece uma diversidade de estudos que justificam os fatos observados na redução eletroquímica destes cinamatos clorados. Em estudos eletroquímicos de compostos haloaromáticos observou-se que a perda do halogênio é uma das reações mais freqüentes para os ânions-radicais destes ${ }^{43}$.

O mecanismo estabelecido para a ocorrência da desalogenação em solventes orgânicos ${ }^{44}$ ocorre através da formação do ânionradical, que sofre uma clivagem formando um ânion haleto e um radical arila que é protonado rapidamente. Com base nestas informações e nos resultados obtidos foram sugeridos mecanismos para a desalogenação de 2 (Esquema IV.7, p. 78) e 6 (Esquema IV.8, p. 79).

Os cálculos através da teoria de orbitais moleculares forneceram embasamento para os dados empírico, observando-se os 
coeficientes de contribuições do $p_{z}$ dos cloros, o maior coeficiente corresponde ao cloro do ânion-radical do substrato 2, e o menor ao cloro do ânion-radical do substrato 5. Podendo ser verificado também que quando há um átomo de cloro em posição orto ou para dos ânions-radicais, existe uma densidade de spin relativamente alta no carbono ao qual ele está ligado e o carbono onde ocorreria a dimerização possui uma densidade de spin menor do que o mesmo carbono no cinamato não substituído, o que nos leva a correlacionar este fato com às observações experimentais dos substratos clorados em orto e para sofrerem a desalogenação mais facilmente que a dimerização e no caso de 2 esta nem ocorre.

Por outro lado, no estudo do ânion-radical do cinamato com cloro em meta (5), a densidade de spin do carbono benzílico é quase a mesma da observada para o ânion-radical do substrato não substituído e, no entanto, é observada a ausência de elétrons desemparelhados no carbono ao qual o cloro está ligado, explicando o fato experimental deste substrato dimerizar normalmente sem a saída do substituinte, ao contrário dos demais substratos halogenados.

No caso dos nitrocinamatos de metila ( 3 e 7 ) o ânion-radical formado envolvendo o grupo nitro parece ser bastante estável (nas experiências de voltametria cíclica a primeira transferência de elétron é reversível). Considerando os produtos isolados, pode-se concluir que a ligação dupla carbono-carbono não foi reduzida e o elétron transferido ao substrato parece ficar localizado no grupo nitro. 
A reduzida reatividade dos ânions radicais formados é um fator determinante para o curso da reação de dimerização que não foi observada. É possível que os intermediários estejam envolvidos em reações de transferência de elétrons sem reações químicas acopladas, o que justificaria a recuperação dos substratos de partida e dos ácidos correspondentes, resultantes da hidrólise dos ésteres. Durante 0 isolamento dos produtos de eletrólise, a redução da água causada pela transferência de elétrons dos ânions-radicais não pode ser excluída. Esta reatividade diferenciada também pode ser embasada pelos cálculos feitos para os ânions radicais dos substratos nitro-substituídos (3 e 7), que apresentam coeficientes de contribuição atômica, densidades de carga e spin de Mülliken diferenciados em relação aos demais substratos que sofreriam dimerização, pois os coeficientes nos carbonos benzílicos dos anions radicais de 3 e 7 são menores do que os observados para os ânions-radicais do substrato não substituído, além de não haver densidade de spin neste carbono para os ânions-radicais destes substratos, diferentemente de $\mathbf{9}$.

Durante o estudo da redução eletroquímica do o-metoxicarbonilcinamato de metila (8), não foi observada a formação de nenhum dos produtos usuais de redução de cinamatos, mas das moléculas policíclicas $\mathbf{8 b} \mathbf{-} \mathbf{8 d}$ (Figura IV.17, Tabela IV.14).

$\mathrm{O}$ isolamento de uma pequena quantidade do produto $\mathbf{8 d}$ serviu como uma evidência para o mecanismo proposto (Esquema IV.10), já que a sua ciclização de Dieckmann conduziria a um dos compostos principais, o $8 \mathbf{b}$. 
Com os dados espectroscópicos disponíveis não foi possível a determinação da estereoquímica dos compostos $\mathbf{8 b}$ e $\mathbf{8 c}$ devido à simetria apresentada por estas moléculas. Considerando que a dimerização dos ânions-radicais intermediários na redução de cinamatos geralmente conduz ao dímero racêmico, os compostos $\mathbf{8 b}$ e 8c provavelmente serão os estereoisômeros racêmicos. Caso esta hipótese seja verdadeira a junção dos anéis em 8c deve ser cis, o que parece ser confirmado pelas constantes de acoplamento de $3,9 \mathrm{~Hz}$ e $4,4 \mathrm{~Hz}$ verificados no espectro de $\mathrm{RMN}{ }^{1} \mathrm{H}$ deste envolvendo os hidrogênios da junção dos anéis e dos carbonos ligados aos grupos metoxicarbonila. 


\section{Parte Experimental A - Preparação dos substratos}

\section{Métodos Gerais}

1.1. As análises cromatográficas foram realizadas em cromatógrafo a gás HP modelo $5890 \mathrm{~A}$, equipado com um detector de ionização de chama e um integrador HP 3339 A, utilizando uma coluna HP - 17 (crosslinked $50 \%$ PhMeSilicone, $10 \mathrm{~m} \times 0,53 \mathrm{~mm}$, 2,0 $\mu \mathrm{m}$ filme) e como gás de arraste nitrogênio.

1.2. Os espectros de Ressonância Magnética Nuclear foram obtidos nos aparelhos Brucker AC-200, DPX-300 e DPX-500, tendo sido usado como padrão interno o tetrametilsilano (TMS) e como solvente o $\mathrm{CDCl}_{3}$ ou o d6-DMSO.

1.3. Os espectros de Infravermelho foram obtidos em um aparelho Perkin - Elmer - FT-IR modelo 1750.

1.4. Nas cromatografias em coluna foi utilizada Silicagel 60 (70-230 mesh) da Merck e os solventes hexano, acetato de etila e metanol devidamente purificados. 
1.5. Para a cromatografia em placa preparativa foi utilizada sílica gel PF254 tipo 60 / E da Aldrich.

1.6. Para a cromatografia em camada delgada (TLC) foram utilizadas placas de sílica gel sobre alumínio da Merck.

1.7. Os pontos de fusão (pf) foram determinados em um aparelho Kofler e apresentados sem correção.

\section{Solventes e Reagentes}

2.1. Os seguintes solventes diclorometano, éter etílico, acetato de etila, n-hexano, metanol anidro e éter de petróleo foram purificados segundo métodos descritos na literatura ${ }^{50 a}$.

2.2. A $N, N$-dimetilformamida $(D M F)^{51}$ para as voltametrias cíclicas e eletrólises foi purificada a partir da agitação deste

50 (a) A. I. Vogel, "Textbook of Practical Organic Chemistry", 5 ed., Longman Groups, 1989, p. 395 - 413, (b) Idem, p. 1040, (c) Ibid., p. 1078.

51 (a) N. Tanaka em J. Jullard, "Recommended Methods for Purification of Solvents and Test for Purities", J. F. Coetzee, editos, Pergamon Press, 1983, 33. (b) R. E. Visco em C. K. Mann "Non-Aquous Solvents for Electrochemical Use", Electroanalytical Chemistry, vol. 3 A. J. Bard, editor, Marcel Dekker Inc., 1969, 57. 
solvente com $\mathrm{CuSO}_{4}$ anidro por, pelo menos, 48 horas, em seguida

o sulfato foi decantado e o solvente destilado a pressão reduzida.

2.3. Todos os reagentes utilizados, com exceção dos que têm sua preparação descrita, eram comerciais e foram purificados quando necessário através de métodos convencionais.

\section{Procedimentos padrão de preparação}

3.1. Ácido cinâmico $50 \mathrm{~b}$

O ácido cinâmico foi preparado utilizando $0,20 \mathrm{~mol}$ de benzaldeído, 0,44 mol de ácido malônico, $90 \mathrm{~mL}$ de piridina e $1,5 \mathrm{~mL}$ de piperidina, todos previamente purificados e secos.

Estes reagentes foram colocados em um balão de 3 bocas equipado com condensador de refluxo protegido por tubo secante contendo $\mathrm{CaCl}_{2}$ e com 1 termômetro, e aquecidos a $90^{\circ}$ a $100{ }^{\circ} \mathrm{C}$ em uma manta elétrica equipada com agitação magnética. Após o término do desprendimento de $\mathrm{CO}_{2}$, a mistura de reação foi aquecida sob refluxo durante 5 minutos para completar a reação. A mistura foi então passada para um erlenmeyer contendo uma solução de $\mathrm{HCl}$ 1:1 em quantidade suficiente para reagir com a piridina e o ácido precipitado foi separado por filtração em um funil de Büchner ou de vidro 
sinterizado, lavado com água e colocado em dessecador contendo ácido sulfúrico concentrado sob vácuo até massa constante. Determinou-se o ponto de fusão e a partir deste se verificou a necessidade de ser feita uma recristalização com o solvente adequado.

3.2. Cinamato de metila

3.2.a Esterificação de Fischer-Speier ${ }^{50 c}$

Em um balão, acoplado a um condensador de refluxo protegido por tubo secante, foram adicionados $0,1 \mathrm{~mol}$ de ácido cinâmico, $0,4 \mathrm{~mol}$ de metanol anidro e então $1,5 \mathrm{~mL}$ de $\mathrm{H}_{2} \mathrm{SO}_{4}$ (conc.). Aqueceu-se a refluxo durante 5 horas.

Ao final da reação, o excesso de metanol foi removido à pressão reduzida, o resíduo da destilação adicionado a $125 \mathrm{~mL}$ de água e a mistura foi extraída com éter $(3 \times 30 \mathrm{~mL})$. Os extratos etéreos reunidos foram lavados com solução saturada de $\mathrm{NaHCO}_{3}$, água e solução saturada de $\mathrm{NaCl}$. Após secagem com sulfato de magnésio anidro, o éter foi evaporado e o éster cinâmico obtido. 
3.2.b Esterificação através do cloreto de ácido.

Em um balão de três bocas, equipado com condensador de refluxo protegido com tubo secante, foi colocado $0,1 \mathrm{~mol}$ de ácido cinâmico e adicionado, lentamente, $0,2 \mathrm{~mol}$ de cloreto de tionila, através de um funil de adição, sob agitação. A mistura foi deixada sob refluxo até o término da saída de gases e então resfriada em banho de gelo para a adição lenta de $0,5 \mathrm{~mol}$ de metanol anidro. Em seguida o aquecimento foi reiniciado e mantido por $1 \mathrm{~h}$.

A mistura de reação resfriada foi colocada em água e extraiu-se com diclorometano (3 $\times 20 \mathrm{~mL})$. A fase orgânica foi lavada com solução saturada de bicarbonato de sódio (1 x $20 \mathrm{~mL})$, água ( 3 x $20 \mathrm{~mL}$ ) e solução saturada de cloreto de sódio. Após secagem com sulfato de magnésio, o secante foi filtrado e o diclorometano rotoevaporado resultando no cinamato de metila seco.

A fase aquosa obtida após a lavagem com bicarbonato foi acidificada com ácido clorídrico concentrado e extraída com o diclorometano para recuperar o ácido cinâmico residual.

Algumas vezes, quando o ácido de partida era sólido, a preparação do cloreto de ácido foi feita na presença de benzeno seco a fim de que a reação ocorresse num meio mais homogêneo. 


\section{4. o-metilcinamato de metila (1)}

(Esquema IV.1, p. 46)

\section{1. o-metilbenzaldeído}

\section{a - cloreto de o-metilbenzoíla}

Nesta preparação o ácido o-metilbenzóico comercial $(68 \mathrm{~g}-$ $500 \mathrm{mmol}$ ) e o cloreto de tionila destilado (em proporção molar de $1: 1,5)$ foram adicionados a um balão de três bocas, equipado com agitação magnética e condensador de refluxo protegido por tubo secante, e a mistura foi refluxada até cessar o desprendimento de gases. Em seguida foi adicionado benzeno seco e rotoevaporou-se a pressão reduzida para retirar o excesso de cloreto de tionila.

O cloreto de ácido foi destilado obtendo-se $66 \mathrm{~g}$ na fração principal a $88-90{ }^{\circ} \mathrm{C} / 12 \mathrm{mmHg}$, com rendimento de $86 \%$.

b - o-toluanilida (N-fenil-o-metilbenzamida) ${ }^{31 b}$

Uma mistura de $176 \mathrm{~mL}$ de $\mathrm{NaOH} 10 \%, 22,4 \mathrm{~g}(218 \mathrm{mmol})$ de

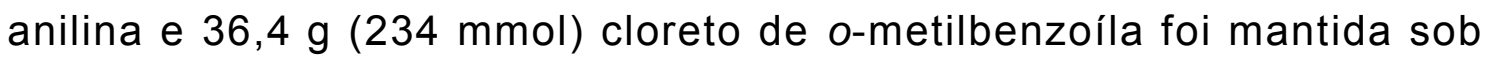
agitação intensa por 15 minutos. Após verificação do $\mathrm{pH}(>8)$, o sólido obtido foi filtrado a vácuo e lavado com água gelada. 
A anilida foi recristalizada de etanol e os cristais isolados foram deixados em um dessecador a vácuo sobre pentóxido de fósforo durante 48 horas (rendimento $82 \%-30 \mathrm{~g}$ ).

\section{c - $\quad$ - $-\left(\right.$ o-metilbenzilideno) anilina ${ }^{31}$}

Colocou-se $29,5 \mathrm{~g}(140 \mathrm{mmol})$ de o-toluanilida e $20 \mathrm{~mL}$ de benzeno seco em um balão de três bocas ligado a um condensador de destilação, mergulhado em banho de silicone. Quando o banho chegou a $50{ }^{\circ} \mathrm{C}, 30 \mathrm{~g}$ de $\mathrm{PCl}_{5}$ foram adicionados gradativamente à mistura durante 10 minutos. Então o banho teve sua temperatura aumentada para $75^{\circ} \mathrm{C}$, que foi mantida por 15 minutos. $\mathrm{O}$ benzeno e a maior parte do oxicloreto de fósforo foram removidos por destilação (pressão de aproximadamente $20 \mathrm{mmHg}$, banho a $95{ }^{\circ} \mathrm{C}$ ), restando um líquido viscoso que é o cloreto de $N$-fenil-o-toluimidila bruto, suficientemente para a próxima etapa.

Uma mistura de $50 \mathrm{~g}$ de $\mathrm{SnCl}_{2}(\mathrm{seco})^{52}$ e $225 \mathrm{~mL}$ de éter seco foi colocada em um balão de três bocas equipado com um agitador mecânico, condensador de refluxo e um tubo de vidro para a introdução de $\mathrm{HCl}$ seco. A mistura foi resfriada com gelo e o $\mathrm{HCl}_{(\mathrm{g})}$ seco borbulhado até a solução ficar saturada, sob contínua agitação. Em 3 horas, todo o $\mathrm{SnCl}_{2}$ se dissolveu, formando uma camada transparente viscosa.

52 J. W. Williams, Org. Synth., 1955 Coll. Vol. III, p 626. 
A fonte de $\mathrm{HCl}_{(\mathrm{g})}$ foi então desconectada e o cloreto de imidila previamente preparado foi, no mesmo instante, transferido para o balão de 3 bocas com $25 \mathrm{~mL}$ de éter seco (neste ponto houve uma certa liberação de calor, por isso o balão foi colocado em banho de gelo). A agitação foi mantida durante 1 hora e a mistura foi deixada à temperatura ambiente por uma noite (12 horas). Esta mistura foi utilizada diretamente na etapa seguinte.

d - o-tolualdeído (o-metilbenzaldeído) ${ }^{31}$

Para a preparação do o-tolualdeído, foram adicionados à mistura anterior, $100 \mathrm{~g}$ de gelo e $100 \mathrm{~mL}$ de água gelada, deixando esses reagentes sob agitação durante 10 minutos.

O éter foi destilado e o volume da mistura foi completado a $300 \mathrm{~mL}$ com água. A seguir efetuou-se uma destilação a vapor até que o destilado fosse obtido límpido.

O aldeído foi extraído do destilado utilizando o éter que foi recuperado no passo anterior. A fase etérea foi secada por 2 horas com sulfato de sódio anidro e o éter rotoevaporado.

O rendimento de o-tolualdeído (o-metilbenzaldeído) após destilação a pressão reduzida $\left(p e=90-93{ }^{\circ} \mathrm{C} / 19 \mathrm{mmHg}\right.$ ) é de $67 \%$ $(11,3 \mathrm{~g}$ - etapas c e d).. 
4.2. ácido o-metilcinâmico (1a)

A partir de $3,5 \mathrm{~g}(20 \mathrm{mmol})$ do o-metilbenzaldeído, preparou-se o ácido o-metilcinâmico (1a) seguindo procedimento descrito em VI.3.1, obtendo-se $4,0 \mathrm{~g}(85 \%)$. pf exp $: 143-146{ }^{\circ} \mathrm{C}\left(\mathrm{pf}_{\mathrm{lit}}{ }^{53}: 147^{\circ} \mathrm{C}\right)$.

4.3. o-metilcinamato de metila (1)

Utilizando o procedimento VI.3.2.b, a partir de 4,0 g de ácido obteve-se o éster que foi recristalizado com metanol e analizado por C.G. $(99 \%)$. Rendimento de $82 \%(3,9 \mathrm{~g})$. pe $=101^{\circ} \mathrm{C} / 0,6 \mathrm{mmHg}$.

(1) $\mathbf{R M N}{ }^{1} \mathbf{H}(200 \mathrm{MHz}): \delta$ em ppm $\left(\mathrm{CDCl}_{3} / \mathrm{TMS}\right) 2,44(3 \mathrm{H}, \mathrm{Me}$, s); $3,74(3 \mathrm{H}, \mathrm{OMe}, \mathrm{s}) ; 6,36(1 \mathrm{H},=\mathrm{CH}, \mathrm{d}, \mathrm{J}=15,8 \mathrm{~Hz}) ; 7,19-7,32$ $(3 \mathrm{H}, \mathrm{CH}, \mathrm{m}) ; 7,54(1 \mathrm{H}, \mathrm{CH}, \mathrm{d}, \mathrm{J}=7,0 \mathrm{~Hz}) ; 7,99(1 \mathrm{H},=\mathrm{CH}, \mathrm{d}$, $\mathrm{J}=15,8 \mathrm{~Hz})$.

${ }^{53}$ T. Posner, G. Schereiber, Ber., 57, 1924, 1131. 
5. o-nitrocinamato de metila (3)

5.1. Método 1 (a partir do o-nitrotolueno)

(Esquema IV.2 eEsquema IV.2.a, p.48)

a - $\quad$ Cloreto de p-nitroso-N,N-dimetilanilínio ${ }^{33}$

Uma solução de $10 \mathrm{~g}$ de dimetilanilina e $35 \mathrm{~mL}$ ácido clorídrico concentrado foi colocada em um balão de 3 bocas. Gelo foi adicionado até que a temperatura chegasse a $5^{\circ} \mathrm{C}$. Foi ligada a agitação magnética e uma solução de $6 \mathrm{~g}$ de nitrito de sódio em $10 \mathrm{~mL}$ de água foi vagarosamente adicionada através de um funil de adição. Durante este procedimento a temperatura foi mantida abaixo de $8{ }^{\circ} \mathrm{C}$ pela adição de gelo (aproximadamente 1 hora). Em seguida, a mistura foi deixada em repouso durante uma hora e então filtrada. O sólido foi lavado com $14 \mathrm{~mL}$ de solução de ácido clorídrico 1:1 e depois com $4 \mathrm{~mL}$ de etanol.

A quantidade de produto obtida, depois de secagem em dessecador, foi de $11,7 \mathrm{~g}$ (72 \% de rendimento). 


\section{b - o-nitrobenzaldeído ${ }^{34}$}

Em balão de $125 \mathrm{~mL}$, equipado com um condensador de refluxo protegido com tubo secante, foram colocadas $10 \mathrm{~g}(73 \mathrm{mmol}) \mathrm{de}$ o-nitrotolueno, $12 \mathrm{~g}(68 \mathrm{mmol})$ de NBS, $0,1 \mathrm{~g}$ de peróxido de benzoíla e $45 \mathrm{~mL}$ de tetracloreto de carbono seco. A mistura foi mantida sob refluxo até que todo sólido aparecesse na superfície do líquido (6 a 8 horas).

A mistura quente foi filtrada a vácuo e o sólido foi lavado com duas porções de $10 \mathrm{~mL}$ de tetracloreto de carbono quente. $\mathrm{O}$ solvente do filtrado foi removido por rotoevaporação a pressão reduzida e o sólido dissolvido em etanol anidro $(70 \mathrm{~mL})$ e piridina $(20 \mathrm{~mL})^{*}$.

A solução obtida foi aquecida sob refluxo por 45 minutos e imediatamente transferida para um erlenmeyer de boca larga. A cristalização foi iniciada depois da mistura ser resfriada. Os cristais de brometo de o-nitrobenzilpiridínio foram coletados e lavados com etanol frio.

O brometo de o-nitrobenzilpiridínio, $10 \mathrm{~g}$ de cloreto de $p$-nitroso$\mathrm{N}, \mathrm{N}$-dimetilanilínio e $80 \mathrm{~mL}$ de etanol foram introduzidos em um balão

* Em todos estes passos, especialmente na filtração, é muito importante que o brometo de o-nitrobenzila não entre em contato com os olhos, pois este é um poderoso agente lacrimejante, além de ser muito irritante em contato com a pele. 
de 3 bocas de $250 \mathrm{~mL}$, equipado com agitador mecânico, termômetro e funil de adição. O balão foi imerso em uma mistura de gelo e sal.

Sob agitação, adicionou-se solução de $6 \mathrm{~g}$ de $\mathrm{NaOH}$ dissolvidos em $50 \mathrm{~mL}$ de água fria, mantendo a temperatura entre $0-5{ }^{\circ} \mathrm{C}$. A cor mudou de amarelo para verde, depois marrom e por último laranja. A agitação foi mantida por uma hora. Foram então adicionados $50 \mathrm{~mL}$ de água e gelo ao frasco, e os cristais alaranjados de $\mathrm{N}$ ( $p$-dimetilaminofenil)- $\alpha$ - (o-nitrofenil)nitrona foram filtrados num funil de Büchner e lavados com água fria.

A nitrona obtida foi colocada num béquer de $400 \mathrm{~mL}$. Uma solução de ácido sulfúrico $3 \mathrm{M}$ foi adicionada sob agitação. Após dez minutos adicionou-se gelo picado e o o-nitrobenzaldeído foi filtrado, lavado com solução diluída de bicarbonato de sódio e seco em dessecador com pentóxido de fósforo. Foram obtidos 9,8 g de produto, com rendimento de $53 \%\left(\mathrm{pf}_{\mathrm{lit} .}{ }^{34}: 41-44{ }^{\circ} \mathrm{C} \mid \mathrm{pf}_{\text {exp. }}: 40-42{ }^{\circ} \mathrm{C}\right)$.

\section{c - ácido o-nitrocinâmico (3a)}

A partir de $3,5 \mathrm{~g}$ do o-nitrobenzaldeído, foi preparado o ácido o-nitrocinâmico (3a) pelo método VI.3.1 obtendo-se 4,0 g (rendimento $80 \%)\left(\mathrm{pf}_{\text {exp }}: 235-239^{\circ} \mathrm{C} \mid \mathrm{pf}_{\mathrm{lit} .}{ }^{54}: 242-243^{\circ} \mathrm{C}\right)$.

54 J. Frederich, J. Dippy, J. E. Page, J. Chem. Soc., 1938, 357. 
d - o-nitrocinamato de metila (3)

Esta esterificação feita, pelo método do item VI.3.2.b, com 4,0 g de ácido levou a $3,9 \mathrm{~g}$ do éster (rendimento de $92 \%$ ). 0 o-nitrocinamato de metila foi analisado por CG (100\%), RMN ${ }^{1} \mathrm{H}$ :

(3) RMN $^{1} \mathbf{H}(200 \mathrm{MHz}): \delta$ em ppm $\left(\mathrm{CDCl}_{3} / \mathrm{TMS}\right) 3,84(3 \mathrm{H}, \mathrm{OMe}$, s); 6,37 $(1 \mathrm{H},=\mathrm{CH}, \mathrm{d}, \mathrm{J}=16,0 \mathrm{~Hz}) ; 7,51-7,68(3 \mathrm{H}, \mathrm{CH}, \mathrm{m}) ; 8,06(1 \mathrm{H}$, $\mathrm{CH} ., \mathrm{d}, \mathrm{J}=8,0 \mathrm{~Hz}) ; 8,13(1 \mathrm{H},=\mathrm{CH}, \mathrm{d}, \mathrm{J}=16,0 \mathrm{~Hz})$.

5.2. Método 2 (a partir do álcool o-nitrobenzílico)

(Esquema IV.2 e IV.2.b, p.48)

\section{a - $\quad$ o-nitrobenzaldeído ${ }^{35}$}

Em um balão, $15 \mathrm{mmol}$ de clorocromato de piridínio (PCC) foram suspensos em $2 \mathrm{~mL}$ de diclorometano, e $6 \mathrm{~g}(40 \mathrm{mmol})$ de álcool onitrobenzílico em $6 \mathrm{~mL}$ de diclorometano foram rapidamente adicionados à mistura em temperatura ambiente, sob agitação magnética. Após 2 horas de reação, seguida por cromatografia de camada delgada, verificou-se que a oxidação havia se completado. A mistura escura foi diluída em 5 volumes de éter anidro, o solvente foi decantado e o sólido 
escuro no fundo do balão lavado mais duas vezes com este solvente retirando vestígios do produto. A solução orgânica foi filtrada através de celite e, como ela ainda apresentou coloração bastante escura, adicionou-se carvão ativo, aqueceu-se e filtrou-se a quente. O éter foi evaporado e o o-nitrobenzaldeído obtido com rendimento de $82 \%$ $4,85 \mathrm{~g}\left(\mathrm{pf}_{\mathrm{exp} .}: 39-42{ }^{\circ} \mathrm{C} \mid \mathrm{pf}_{\mathrm{ref}}{ }^{55}: 41-44^{\circ} \mathrm{C}\right)$.

b - $\quad$ ácido o-nitrocinâmico (3a)

A partir de $3,5 \mathrm{~g}$ do o-nitrobenzaldeído, foi preparado o ácido o-nitrocinâmico (item VI.3.1) e a quantidade obtida foi de $4,0 \mathrm{~g}$ (rendimento $80 \%)\left(\mathrm{pf}_{\text {exp }}: 235-239{ }^{\circ} \mathrm{C} \mid \mathrm{pf}_{\text {lit. }}{ }^{54}: 242-243^{\circ} \mathrm{C}\right.$ ).

c - $\quad$ o-nitrocinamato de metila (3)

Esta esterificação foi feita de acordo com o item VI.3.2.b, com 4,0 g de ácido e a reação proporcionou um rendimento de $92 \%$ (3,9 g).O o-nitrocinamato de metila (3) foi analisado por CG (98\%) e RMN ${ }^{1} \mathrm{H}$.

(3) $\mathrm{RMN}^{1} \mathbf{H}(200 \mathrm{MHz}): \delta$ em ppm ( $\left.\mathrm{CDCl}_{3} / \mathrm{TMS}\right) 3,84(3 \mathrm{H}, \mathrm{OMe}$, s); $6,37(1 \mathrm{H},=\mathrm{CH}, \mathrm{d}, \mathrm{J}=16,0 \mathrm{~Hz}) ; 7,51-7,68(3 \mathrm{H}, \mathrm{CH} ., \mathrm{m}) ; 8,04-$ $8,08(1 \mathrm{H}, \mathrm{CH} ., \mathrm{d}, \mathrm{J}=8,0 \mathrm{~Hz}) ; 8,13(1 \mathrm{H},=\mathrm{CH}, \mathrm{d}, \mathrm{J}=16,0 \mathrm{~Hz})$.

${ }^{55}$ A. Kalir, Org. Synth., 1973 Coll. Vol. V p. 825. 


\section{6. m-nitrocinamato de metila (7)}

(Esquema IV.3, p. 50)

a - $\quad$ Ácido m-nitrocinâmico (7a)

O ácido $7 \mathrm{a}$ foi obtido partindo-se do $\mathrm{m}$-nitrobenzaldeído $(4,5 \mathrm{~g} /$ $30 \mathrm{mmol})$, de acordo com o item IV.3.1 e chegou-se a 5,4 g (20 mmol - 86\%) $\left(\mathrm{pf}_{\text {exp }}: 198^{\circ} \mathrm{C} \mid \mathrm{pf}_{\text {lit. }}{ }^{54}: 201^{\circ} \mathrm{C}\right)$.

\section{b - m-nitrocinamato de metila (7)}

$5,4 \mathrm{~g}(20 \mathrm{mmol})$ de $7 \mathrm{a}$ foi esterificado pelo método do cloreto de ácido (item VI.3.2.b) levando ao $m$-nitrocinamato de metila (7), que foi recristalizado de metanol. Rendimento: $89 \%$ (5,1 g - $23 \mathrm{mmol}), \mathrm{pf}_{\text {exp }}$ : $118-123^{\circ} \mathrm{C}\left(\mathrm{pf}_{\text {lit. }}{ }^{56}: 122-124{ }^{\circ} \mathrm{C}\right)$. Análise C.G. (99\%) e RMN ${ }^{1} \mathrm{H}$.

(7) $\mathrm{RMN}^{1} \mathrm{H}(200 \mathrm{MHz}): \delta$ em ppm ( $\left.\mathrm{CDCl}_{3} / \mathrm{TMS}\right) 3,74(3 \mathrm{H}, \mathrm{OMe}$, s); $6,47(1 \mathrm{H},=\mathrm{CH}, \mathrm{d}, \mathrm{J}=16,0 \mathrm{~Hz}) ; 7,49(1 \mathrm{H}, \mathrm{CH}, \mathrm{t}, \mathrm{J}=8,0 \mathrm{~Hz}) ; 7,62$ $(1 \mathrm{H},=\mathrm{CH}, \mathrm{d}, \mathrm{J}=16,0 \mathrm{~Hz}) ; 7,74(1 \mathrm{H}, \mathrm{CH}, \mathrm{d}, \mathrm{J}=8,0 \mathrm{~Hz}) ; 8,13(1 \mathrm{H}$, $\mathrm{CH}, \mathrm{d}, \mathrm{J}=8,0 \mathrm{~Hz}) ; 8,26-6,28(1 \mathrm{H}, \mathrm{CH}, \mathrm{m})$.

${ }^{56}$ I. Hartman, P. W. Robertson, J. Chem. Soc. , 1945, 891. 


\section{Cinamatos de metila clorados $(2,4-6)$}

(Esquema IV.4, p.51)

7.1. o-clorocinamato de metila (2)

a - ácido o-clorocinâmico (2a)

- Procedimento: item VI.3.1:

- o-clorobenzaldeído: 8,0 g (50 mmol).

- ácido o-clorocinâmico (2a): 7,8 g (40 mmol).

- Rendimento: 80 \%.

- $\mathrm{pf}_{\mathrm{exp}}: 206-210^{\circ} \mathrm{C}\left(\mathrm{pf}_{\mathrm{lit}}{ }^{57}: 211^{\circ} \mathrm{C}\right)$.

b - o-clorocinamato de metila (2)

- Procedimento: item VI.3.2.b:

- ácido o-clorocinâmico (2a): 7,8 g (40 mmol).

- o-clorocinamato de metila $(2): 7,0 \mathrm{~g}(33 \mathrm{mmol})$.

- Rendimento: 83 \%.

- (pe: $101^{\circ} \mathrm{C} / 2 \mathrm{mmHg}$ ).

(2) $\mathrm{RMN}^{1} \mathrm{H}(300 \mathrm{MHz}): \delta$ em ppm $\left(\mathrm{CDCl}_{3} / \mathrm{TMS}\right) 3,81(3 \mathrm{H}, \mathrm{OMe}$, s); $6,44(1 \mathrm{H},=\mathrm{CH}, \mathrm{d}, \mathrm{J}=16,0 \mathrm{~Hz}) ; 6,37-7,40(3 \mathrm{H}, \mathrm{CH}, \mathrm{m}) ; 7,51-$ $7,54(1 \mathrm{H}, \mathrm{CH}, \mathrm{m}) ; 7,69(1 \mathrm{H},=\mathrm{CH}, \mathrm{d}, \mathrm{J}=16,0 \mathrm{~Hz})$.

57 S. Reich, J. Araus, J. Potok, H. Tempel., Helv. Chim. Acta, 1920, $\underline{3}$, 794. 
7.2. $m$-clorocinamato de metila (5)

a - $\quad$ ácido m-clorocinâmico (5a)

- Procedimento: item VI.3.1:

- m-clorobenzaldeído: 15,0 g (100 mmol).

- ácido $m$-clorocinâmico (5a): 15,1 g (80 mmol).

- Rendimento: 86 \%.

- $\mathrm{pf}_{\text {exp }}$ : $160-164^{\circ} \mathrm{C}\left(\mathrm{pf}_{\mathrm{lit} .}{ }^{57}: 165^{\circ} \mathrm{C}\right)$.

b - m-clorocinamato de metila (5)

- Procedimento: item VI.3.2.a:

- ácido $m$-clorocinâmico (5a): 15,1 g (80 mmol).

- m-clorocincinamato de metila (5): $13,4 \mathrm{~g} \mathrm{(67} \mathrm{mmol).}$

- Rendimento: $84 \%$

(5) $\mathrm{RMN}{ }^{1} \mathrm{H}(200 \mathrm{MHz}): \delta$ em ppm $\left(\mathrm{CDCl}_{3} / \mathrm{TMS}\right) 3,82(3 \mathrm{H}, \mathrm{OMe}$, s); $6,44(1 \mathrm{H}, \mathrm{d}, \mathrm{J}=15,8 \mathrm{~Hz}) ; 7,32-7,43(3 \mathrm{H}, \mathrm{m}) ; 7,51(1 \mathrm{H}, \mathrm{m}) ; 7,63$ $(1 \mathrm{H}, \mathrm{d}, \mathrm{J}=16,2 \mathrm{~Hz})$.

(5) $\mathrm{RMN}{ }^{13} \mathrm{C}(75 \mathrm{MHz}): \delta$ em ppm $\left(\mathrm{CDCl}_{3} / \mathrm{TMS}\right) 51,8 ; 119,4$; 126,$2 ; 127,3 ; 130,2 ; 134,0 ; 135,0 ; 136,3 ; 143,2 ; 167,0$. 
(5) Espectro de massas: m / z (intens.) 50 (45); 51 (72); 63 (16); 74 (23); 75 (61); 76 (18); 101 (61); 102 (73); 136 (14); 137 (44); 139 (17); 165 (100); 167 (33); 196 (45); 197 (8); 198 (15).

7.3. $p$-clorocinamato de metila (6)

a - ácido p-clorocinâmico (6a)

- Procedimento: item VI.3.1:

- $p$-clorobenzaldeído: $8 \mathrm{~g}(50 \mathrm{mmol})$.

- ácido p-clorocinâmico (6a): 8,19 g (42 mmol).

- Rendimento: $84 \%$.

- $\mathrm{pf}_{\text {exp }}: 244-249^{\circ} \mathrm{C}\left(\mathrm{pf}_{\text {lit. }}{ }^{57}: 248-250^{\circ} \mathrm{C}\right)$

\section{b - p-clorocinamato de metila (6)}

- Procedimento: item VI.3.2.a:

- ácido p-clorocinâmico (6a): 8,19 g (42 mmol).

- $p$-clorocinamato de metila $(6): 7,4 \mathrm{~g}(36 \mathrm{mmol})$.

- Rendimento: $89 \%$.

- Recristalização com metanol $\left(\mathrm{pf}_{\text {exp }}: 117-119^{\circ} \mathrm{C} \mid \mathrm{pf}_{\text {lit. }}{ }^{58}: 125-126^{\circ} \mathrm{C}\right)$

(6) $\mathrm{RMN}{ }^{1} \mathrm{H}(200 \mathrm{MHz}): \delta$ em ppm $\left(\mathrm{CDCl}_{3} / \mathrm{TMS}\right) 3,81$ (3H, OMe, s); 6,41 $(1 \mathrm{H},=\mathrm{CH}, \mathrm{d}, \mathrm{J}=16,0 \mathrm{~Hz}) ; 7,33-7,38(2 \mathrm{H}, \mathrm{CH}, \mathrm{m}) ; 7,42-$ $7,48(2 \mathrm{H}, \mathrm{CH}, \mathrm{m}) ; 7,64(1 \mathrm{H},=\mathrm{CH}, \mathrm{d}, \mathrm{J}=16,0 \mathrm{~Hz})$.

${ }^{58}$ G. Speroni, Chimica e Ind., 1952, 34, 391 (Beil. 9 IV 2033). 
(6) Espectro de massas: m / z (intens.) 50 (14); 51 (25); 74 (9); 75 (26); 101 (29); 102 (39); 136 (6); 137 (27); 165 (100); 166 (10); 167 (31); 195 (17); 196 (47); 197 (10); 198 (16).

7.4. $\quad m, p$-diclorocinamato de metila (4)

a - ácido m,p-diclorocinâmico (4a)

- Procedimento: item VI.3.1:

- m,p-diclorobenzaldeído: 10,0 g (55 mmol).

- ácido m,p-diclorocinâmico (4a): 8,2 g (42 mmol).

- Rendimento: $81 \%$.

- $\mathrm{pf}_{\text {exp }}: 213-216{ }^{\circ} \mathrm{C}\left(\mathrm{pf}_{\mathrm{lit}}{ }^{59}: 217-218^{\circ} \mathrm{C}\right)$.

\section{b - $\quad$ m,p-diclorocinamato de metila (4)}

- Procedimento: item VI.3.2.b:

- ácido m,p-diclorocinâmico (4a): 8,2 g (42 mmol).

- $m, p$-diclorocinamato de metila $(4): 8,9 \mathrm{~g}(38 \mathrm{mmol})$.

- Rendimento: $91 \%$.

- Recristalização com metanol (pf exp: $116-118{ }^{\circ} \mathrm{C} \mid \mathrm{pf}_{\text {lit. }}{ }^{60}: 116$ $\left.117^{\circ} \mathrm{C}\right)$

(4) $\mathrm{RMN}{ }^{1} \mathrm{H}(200 \mathrm{MHz}): \delta$ em ppm $\left(\mathrm{CDCl}_{3} / \mathrm{TMS}\right) 3,83(3 \mathrm{H}, \mathrm{OMe}$, s); $6,41(1 \mathrm{H},=\mathrm{CH}, \mathrm{d}, \mathrm{J}=16,0 \mathrm{~Hz}) ; 7,34(1 \mathrm{H}, \mathrm{CH}, \mathrm{d}, \mathrm{J}=8,0 \mathrm{~Hz}) ; 7,49$ $(1 \mathrm{H},=\mathrm{CH}, \mathrm{d}, \mathrm{J}=16,0 \mathrm{~Hz}) ; 7,59-7,62(1 \mathrm{H}, \mathrm{CH}, \mathrm{m})$.

\footnotetext{
${ }^{59}$ C. Walling e K. B. Wolfstirn, J. Am. Chem. Soc. , 1947, $\underline{69}, 852$.

${ }^{60}$ R. F. Meck, J. Am. Chem. Soc. , 1968, 으, 5518.
} 


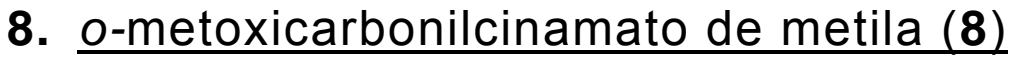

(Esquema IV.5, p.52)

\subsection{Ftalida ${ }^{36}$}

Em um balão de 3 bocas de $500 \mathrm{~mL}$ foram colocados $212 \mathrm{mg}$ de sulfato de cobre desidratado (ativador do zinco), $7 \mathrm{~mL}$ de água e $35 \mathrm{~g}$ (550 mmol) de pó de zinco. A mistura foi agitada até formar uma pasta e $70 \mathrm{~mL}$ de solução aquosa $20 \%$ de $\mathrm{NaOH}$ foram adicionados. Sob agitação, a mistura foi resfriada a $5{ }^{\circ} \mathrm{C}$, em banho de gelo, e a temperatura foi controlada por um termômetro acoplado ao balão.

Após a estabilização da temperatura, foram adicionados $30 \mathrm{~g}$ (200 mmol) de ftalimida, evitando que a temperatura ultrapassasse $8{ }^{\circ} \mathrm{C}$. Após a adição, a mistura foi agitada durante meia hora, diluída com $80 \mathrm{~mL}$ de água e então aquecida, com uma manta, até terminar o desprendimento de amônia. A mistura foi concentrada a cerca de $50 \mathrm{~mL}$ através de destilação a pressão reduzida e depois filtrada. O filtrado foi acidulado com aproximadamente $30 \mathrm{~mL}$ de ácido clorídrico concentrado, deixando o meio com pH menor que 2.

A mistura, na qual a ftalida se separou como um óleo, foi fervida por uma hora para completar a lactonização do ácido o-hidroximetilbenzóico e transferida para um béquer enquanto quente. 
Durante o resfriamento, o óleo solidificou na forma de uma dura placa de coloração rosada. Após deixar durante a noite em geladeira, a mistura foi filtrada a vácuo o sólido recristalizado de água.

As recristalizações foram feitas em porções de $10 \mathrm{~g}$, utilizando aproximadamente $500 \mathrm{~mL}$ de água. A água mãe foi sempre reutilizada nas recristalizações subseqüentes. Cada porção foi filtrada a quente e deixada resfriar lentamente formando cristais transparentes que foram separados por filtração e lavados com pequena quantidade de água gelada.

Depois da secagem dos cristais, foram obtidos $23,4 \mathrm{~g}$ de ftalida, com o rendimento de $88 \%\left(\mathrm{pf}_{\mathrm{ref}}{ }^{36}: 72-73^{\circ} \mathrm{C} \mid \mathrm{pf}_{\text {exp. }}: 72{ }^{\circ} \mathrm{C}\right)$. Sua análise por C.G. mostrou tratar-se do composto puro (> 97\%).

\subsection{2-bromoftalida ${ }^{36}$}

Inicialmente, o bromo foi seco por meio de algumas lavagens com ácido sulfúrico concentrado e, então, $54 \mathrm{~g}$ (340 mmol) deste foram colocados no primeiro balão da aparelhagem.

A montagem usada para a bromação continha 2 balões sendo que no primeiro foi colocado o bromo. Este foi arrastado por uma corrente de nitrogênio, passando por um tubo secante e chegando ao segundo balão que estava mergulhado em banho de silicone e equipado com termômetro, um tubo de entrada e um de saída de gás. 
No segundo balão foram colocados $45 \mathrm{~g}(340 \mathrm{mmol})$ de ftalida. O banho de óleo começou a ser aquecido e quando a sua temperatura chegou a $140{ }^{\circ} \mathrm{C}$, o fluxo de nitrogênio foi liberado. A temperatura dentro do balão foi mantida durante a reação entre 135 e $150{ }^{\circ} \mathrm{C}$, o que correspondia à temperatura do banho variando entre 140 e $155^{\circ} \mathrm{C}$.

O nitrogênio foi introduzido com uma velocidade tal que não houvesse a presença do bromo no tubo de saída (observada pela cor avermelhada). Este fluxo foi mantido até que a cor avermelhada sumisse do sistema (aproximadamente 7 horas).

Ainda quente, a mistura foi transferida para um balão e vestígios de ácido bromídrico foram retirados aquecendo o mesmo a $120{ }^{\circ} \mathrm{C}$, sob vácuo de trompa de água. Em seguida o produto foi destilado sob pressão reduzida $\left(128-132{ }^{\circ} \mathrm{C} / 2 \mathrm{mmHg}\right)$. Essa destilação é muito complicada, pois o destilado é sólido e acaba solidificando-se antes de chegar aos balões, obstruindo a passagem pelo condensador.

O destilado obtido nesta etapa mostrou ser suficientemente puro para uso na etapa seguinte. A quantidade obtida de 2-bromoftalida foi de $53,2 \mathrm{~g}$ o que corresponde a um rendimento de $74 \%$.

\section{3. $\quad$-carboxibenzaldeído ${ }^{37}$}

Uma mistura de 2-bromoftalida $(53,2 \mathrm{~g}, 250 \mathrm{mmol})$ e $77 \mathrm{~mL}$ de água foi colocada em um balão de 3 bocas de $250 \mathrm{~mL}$, com agitador 
mecânico acoplado, e aquecida em manta elétrica até a ocorrência completa da hidrólise, verificada pelo desaparecimento da camada de 2-bromoftalida (cerca de 30 minutos). Nesse ponto, a mistura reacional foi deixada por uma noite na geladeira, tempo no qual o produto solidificou.

A mistura foi filtrada, os cristais obtidos lavados com duas porções de $15 \mathrm{~mL}$ de água gelada e secos ao ar. Após a secagem, o produto foi recristalizado de $150 \mathrm{~mL}$ de água quente e novamente secado ao ar. Foram obtidos $24,6 \mathrm{~g}$ de o-carboxibenzaldeído (rendimento $66 \%$ ).

$\Rightarrow \quad$ Observação quanto ao o-carboxibenzaldeído:

O o-carboxibenzaldeído pode se transformar com o tempo na 3-hidroxiftalida, através do equilíbrio existente entre estas duas formas ${ }^{38}$. A posição do equilíbrio dependerá do $\mathrm{pH}$ do meio sendo a forma aberta favorecida em meio alcalino ou fortemente ácido ${ }^{39}$.

No caso de ser adquirido comercialmente, o benzaldeído estará provavelmente na forma de 3-hidroxiftalida ${ }^{39}$.

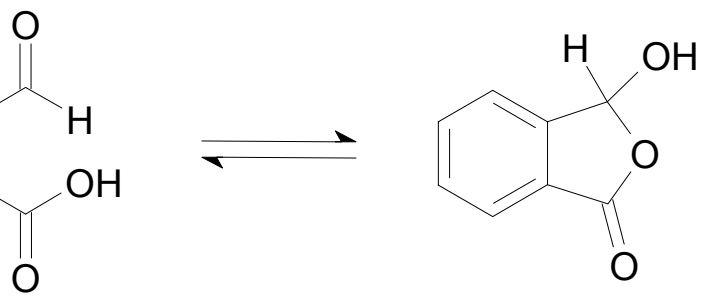

Esquema VI.1 Equilíbrio entre a 3-hidroxiftalida e o o-carboxibenzaldeído. 


\section{4. Ácido o-carboxicinâmico (8a)}

A partir de $4 \mathrm{~g}$ (24 mmol) do o-carboxibenzaldeído, foi preparado o ácido seguindo o item VI.3.1 e a quantidade obtida foi de $4,3 \mathrm{~g}$ (rendimento $80 \%$ )

Devido ao fato do ponto de fusão medido para o composto após a síntese não ter sido o do ácido (8a) $\left(205^{\circ} \mathrm{C}\right)$, mas o da lactona (8'a) correspondente $\left(158{ }^{\circ} \mathrm{C}\right)$, que teve sua estrutura constatada por RMN, um passo foi acrescentado para a obtenção do ácido, que foi o aquecimento da lactona em meio de solução aquosa de $\mathrm{NaOH}$ (Esquema VI.2) $)^{40,41}$<smiles>O=C(O)CC1OCc2ccccc21</smiles>

8'a

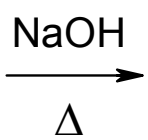

$\Delta$<smiles>O=C(O)/C=C/c1ccccc1C(=O)O</smiles>

$8 \mathbf{a}$

Esquema VI.2 Preparação do ácido o-carboxicinâmico

A lactona do ácido o-carboxicinâmico (8'a) $(3,0 \mathrm{~g})$ foi colocada, sob refluxo, em meio de hidróxido de sódio $25 \%(6,25 \mathrm{~g}$ de $\mathrm{NaOH}$ e $19 \mathrm{~mL}$ de água), durante duas horas. Após a reação, o balão foi resfriado e o líquido transferido do balão para um erlenmeyer gelado, 
para então ser feita a acidulação com ácido clorídrico diluído até $\mathrm{pH}<3$, com formação de um sólido.

A mistura foi filtrada, o sólido lavado com água e em seguida recristalizado com álcool. Foram obtidos $1,9 \mathrm{~g}$ de ácido $\left(\mathrm{pf}_{\text {exp.: }}\right.$ 195$199^{\circ} \mathrm{C} \mid \mathrm{pf}_{\mathrm{ref}}{ }^{41}: 202-206^{\circ} \mathrm{C}$ ), o que corresponde a um rendimento de $64 \%$

8.5. o-metoxicarbonilcinamato de metila (8).

A partir de 2,6 g (13 $\mathrm{mmol})$ do ácido o-carboxicinâmico (8a), foi preparado o cloreto de ácido com o dobro da quantidade dos demais reagentes, cloreto de tionila e metanol, descrita no item VI.3.2.b, sendo obtidas $2,7 \mathrm{~g}(12 \mathrm{mmol})$ de uma mistura de produtos que apresentava o-metoxicarbonilcinamato de metila (8) e sua correspondente forma ciclizada (8').

Devido a presença deste subproduto ( 8' - Figura VI.1), foi feita cromatografia em camada delgada, para verificar a viabilidade da separação destes produtos através de uma coluna cromatográfica de sílica. Assim através de uma coluna filtrante foi utilizado tendo como eluente misturas de hexano e acetato de etila, e o o-metoxicarbonilcinamato de metila (8) $\left(\mathrm{pf}_{\text {exp. }}: 192-196{ }^{\circ} \mathrm{C} \mid \mathrm{pf}_{\mathrm{ref}}{ }^{61}: 195\right.$ $\left.{ }^{\circ} \mathrm{C}\right)$. e o subproduto foram separados.

${ }^{61}$ O. Neunhoeffer, H. Kölbel, Ber. $\underline{62}, 1935,255$. 
A análise dos produtos foi feita por C.G. onde se comprovou a separação, o que permitiu a obtenção dos espectros de RMN ${ }^{1} \mathrm{H}$ de 8 e 8'.<smiles>CC(=O)CC1OC(=O)c2ccccc21</smiles>

Figura VI.1 Subproduto da reação de esterificação do acido cinâmico.

(8) $\mathrm{RMN}^{1} \mathbf{H}$ (200 MHz): $\delta$ em ppm ( $\left.\mathrm{CDCl}_{3} / \mathrm{TMS}\right) 3,82$ (3H, OMe, s); 3,93 $(3 \mathrm{H}, \mathrm{OMe}, \mathrm{s}) ; 6,30(1 \mathrm{H},=\mathrm{CH}, \mathrm{d}, \mathrm{J}=16,0 \mathrm{~Hz}) ; 7,39-7,94(3$ $\mathrm{H}, \mathrm{CH}, \mathrm{m}) ; 7,96(1 \mathrm{H}, \mathrm{CH}, \mathrm{d}, \mathrm{J}=8,0 \mathrm{~Hz}) ; 8,44(1 \mathrm{H},=\mathrm{CH}, \mathrm{d}, \mathrm{J}=16,0$ $\mathrm{Hz})$.

(8') RMN ${ }^{1} \mathbf{H}$ (200 MHz): $\delta$ em ppm ( $\left.\mathrm{CDCl}_{3} / \mathrm{TMS}\right) 2,92\left(2 \mathrm{H}, \mathrm{CH}_{2}\right.$, d, J = 6,6 Hz); 3,76 (3 H, OMe, s); 5,90 (1 H, CH, t, J = 6,6 Hz); 7,53 $(1 \mathrm{H}, \mathrm{CH}, \mathrm{t}, \mathrm{J}=7,0 \mathrm{~Hz}) ; 7,85(1 \mathrm{H}, \mathrm{CH}, \mathrm{d}, \mathrm{J}=7,5 \mathrm{~Hz}) ; 7,70(1 \mathrm{H}, \mathrm{CH}$, d, J = 7,5 Hz); 7,92 (1 H, CH, d, J = 7,5 Hz). 


\section{Parte Experimental B - Experimentos Eletroquímicos}

\section{Voltametria Cíclica}

Neste trabalho, a voltametria cíclica foi realizada para determinação dos potenciais de redução dos cinamatos estudados, que posteriormente foram empregados nas respectivas eletrólises preparativas.

Nos experimentos de voltametria cíclica foram utilizados um potenciostato / galvanostato Princeton Applied Research modelo 273 A e um registrador $X Y$, modelo RE0074 de mesma marca.

Os experimentos foram realizados em DMF contendo perclorato de tetraetilamônio (TEAP) como eletrólito suporte e o eletrodo de trabalho foi mercúrio depositado em platina.

Condições experimentais: DMF / 0,1 mol L-1 TEAP; eletrodo de trabalho: mercúrio depositado em platina; eletrodo de referência: fio de prata em solução de DMF / 0,1 mol L-1 TEAP / 0,05 mol L-1 iodeto de tetrabutilamônio (TBAI); velocidade de varredura: $200 \mathrm{mVs}^{-1}$; substrato: $10^{-3} \mathrm{~mol} \mathrm{~L}^{-1}$. 


\section{Eletrólises preparativas a potencial controlado}

Nas eletrólises preparativas foi empregado um potenciostato / galvanostato Princeton Applied Research modelo 173 equipado com um seguidor de corrente modelo 176. A quantidade de carga consumida no decorrer das eletrólises foi medida através de um integrador eletrônico construído no IQ-USP.

A cela utilizada para os experimentos de eletrólise foi a com dois compartimentos separados e as condições experimentais foram as seguintes: DMF / 0,1 mol L-1 TEAP; eletrodo de trabalho: poço de mercúrio de $2,5 \mathrm{~cm}$ de diâmetro; eletrodo de referência: fio de prata em solução de DMF / 0,1 mol L-1 TEAP / 0,05 mol L-1 TBAl; substrato: $10^{-1} \mathrm{~mol} \mathrm{~L}^{-1}$.

2.1. Procedimento experimental padrão para isolamento do produto de eletrólise.

Após o término da eletrólise, que era determinado pela queda da corrente inicialmente observada ao valor de $5 \%$ desta, o conteúdo do compartimento catódico foi retirado da cela e colocado em um erlenmeyer contendo uma solução aquosa $0,1 \mathrm{M}$ de $\mathrm{HCl}$. Após verificar $\mathrm{opH}$ da mistura $(\mathrm{pH}<3)$, esta foi extraída com éter etílico 
$(3 \times 20 \mathrm{~mL})$. A fase orgânica obtida foi lavada com solução de bicarbonato de sódio saturada $(2 \times 20 \mathrm{~mL})^{*}$; água $(2 \times 20 \mathrm{~mL})$ e solução saturada de $\mathrm{NaCl}(20 \mathrm{~mL})$ e secada com sulfato de magnésio. O éter foi destilado em um roto-evaporador obtendo-se a mistura de produtos da eletrólise. Os seus componentes foram separados por uma coluna cromatográfica com sílica gel utilizando como solventes misturas de hexano e acetato de etila e, ao final, metanol. Quando a mistura dos produtos de eletrólise era sólida a etapa de cromatografia era precedida de uma cristalização fracionada por meio de um solvente apropriado.

A fase aquosa com bicarbonato foi acidulada com ácido clorídrico diluído até $\mathrm{pH}<3$ e extraída três vezes com $20 \mathrm{~mL}$ de éter etílico. O extrato orgânico após lavagem com três porções de $20 \mathrm{~mL}$ de água e uma de $20 \mathrm{~mL}$ de solução saturada com $\mathrm{NaCl}$ foi secado com sulfato de magnésio. O éter foi evaporado e qualquer ácido orgânico formado durante a eletrólise foi isolado.

\footnotetext{
* Somente nos ultimos experimentos $\mathrm{KHCO}_{3}$ foi utilizado.
} 
2.2. Eletrólises do cinamato de metila (9)

Tabela VII.1 Resultados das eletrólises preparativas de $\mathbf{9}^{\mathrm{a}}$.

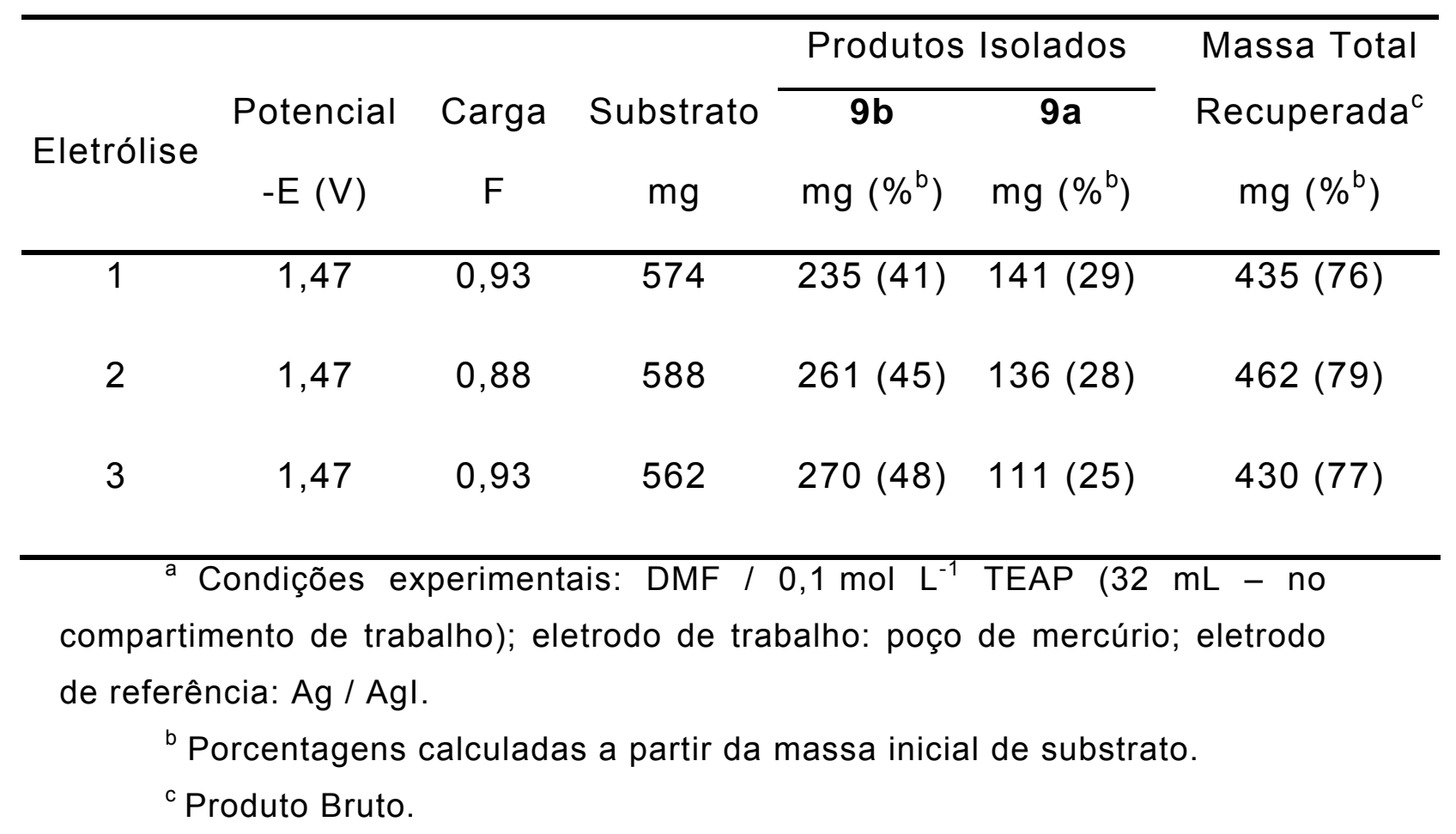

Produtos obtidos nestas eletrólises:

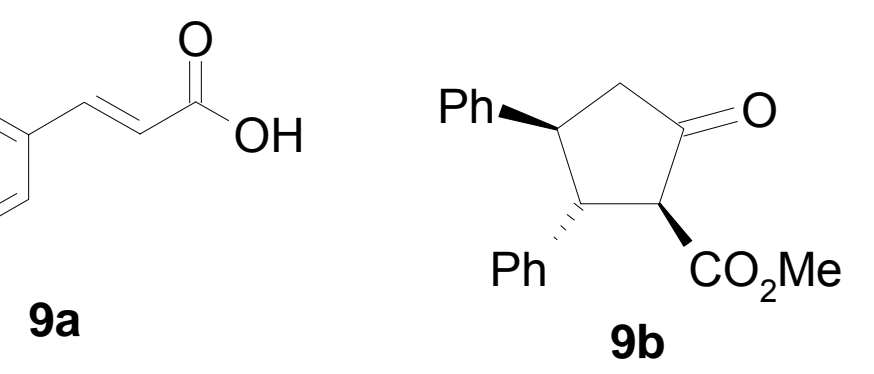


2.3. Eletrólises do o-metilcinamato de metila (1)

Tabela VII.2 Resultados das eletrólises preparativas de $\mathbf{1}^{\mathrm{a}}$.

\begin{tabular}{|c|c|c|c|c|c|c|c|}
\hline \multirow[b]{2}{*}{ Eletrólise } & \multirow[b]{2}{*}{$\begin{array}{l}\text { Potencial } \\
\text {-E (V) }\end{array}$} & \multirow[b]{2}{*}{$\begin{array}{c}\text { Carga } \\
\text { F }\end{array}$} & \multirow[b]{2}{*}{$\begin{array}{c}\text { Substrato } \\
\text { mg }\end{array}$} & \multicolumn{3}{|c|}{ Produtos Isolados } & \multirow{2}{*}{$\begin{array}{c}\text { Massa Total } \\
\text { Recuperada } \\
\text { mg }\left(\%^{\mathrm{b}}\right)\end{array}$} \\
\hline & & & & $\begin{array}{c}1 \mathrm{~b} \\
\mathrm{mg}\left(\%^{\mathrm{b}}\right)\end{array}$ & $\begin{array}{c}1 \mathrm{c} \\
\mathrm{mg}\left(\%^{\mathrm{b}}\right)\end{array}$ & $\begin{array}{c}9 \\
\mathrm{mg}\left(\%^{\mathrm{b}}\right)\end{array}$ & \\
\hline 1 & 1,38 & 0,82 & 617 & $90(15)$ & $191(31)$ & $129(21)$ & $461(75)$ \\
\hline 2 & 1,45 & 0,85 & 611 & $126(21)$ & $130(21)$ & $182(30)$ & $495(81)$ \\
\hline 3 & 1,45 & 0,84 & 616 & $96(16)$ & $116(19)$ & $126(20)$ & $402(65)$ \\
\hline 4 & 1,45 & 0,67 & 616 & $106(17)$ & $122(20)$ & $152(25)$ & $450(73)$ \\
\hline 5 & 1,45 & 0,69 & 616 & $103(17)$ & $165(27)$ & $151(26)$ & $462(75)$ \\
\hline 6 & 1,45 & 0,90 & 618 & $60(10)$ & $153(25)$ & $203(33)$ & $471(76)$ \\
\hline $\begin{array}{l}\text { comp } \\
\text { de re }\end{array}$ & $\begin{array}{l}\text { a Condiçõ } \\
\text { artimento d } \\
\text { erência: } A g\end{array}$ & $\begin{array}{l}\text { es expe } \\
\text { e trabal } \\
\text { / Agl. }\end{array}$ & $\begin{array}{l}\text { erimentais: } \\
\text { ho); eletroc }\end{array}$ & $\begin{array}{l}\text { DMF / } 0 \\
\text { do de trab }\end{array}$ & $\begin{array}{l}1 \mathrm{~mol} \mathrm{~L}^{-1} \\
\text { Iho: poço }\end{array}$ & $\begin{array}{l}\text { TEAP (3 } \\
\text { de mercúl }\end{array}$ & $\begin{array}{l}\mathrm{mL}-\mathrm{no} \\
\text { \%; eletrodo }\end{array}$ \\
\hline & $\begin{array}{l}{ }^{\mathrm{b}} \text { Porcenta } \\
{ }^{\mathrm{c}} \text { Produto }\end{array}$ & $\begin{array}{l}\text { gens ca } \\
\text { Bruto. }\end{array}$ & Iculadas a & partir da & ssa inicia & I de subs & \\
\hline
\end{tabular}

Produtos obtidos nestas eletrólises:<smiles>CC=CC(=O)O</smiles>

$1 a$<smiles>COCCC1C(=O)C[C@@H](COC)C1COC</smiles>

1b
o-Me- $\mathrm{H}_{4} \mathrm{C}_{6}$<smiles>COCCCCCCCCCOC</smiles>
1c 
a - $\quad$ Análise de $\mathbf{1 b}$

(1b) $\mathrm{RMN}{ }^{1} \mathrm{H}$ (300 MHz): $\delta$ em ppm $\left(\mathrm{CDCl}_{3} / \mathrm{TMS}\right)$ 1,67 (3H, s); 2,37 (3H, s); 2,90 (1H, dd, J = 5,0 Hz e 19,0 Hz); 2,98 (1H, dd, J = 7,5 $\mathrm{Hz}$ e $18,7 \mathrm{~Hz}) ; 3,68(3 \mathrm{H}, \mathrm{s}) ; 3,83(1 \mathrm{H}, \mathrm{d}, \mathrm{J}=11,4 \mathrm{~Hz}$ - Sinal diminui com $\left.\mathrm{D}_{2} \mathrm{O}\right) ; 4,15-4,20(1 \mathrm{H}, \mathrm{ddd}, \mathrm{J}=4,0 \mathrm{~Hz} ; 5,0 \mathrm{~Hz}$ e $7,5 \mathrm{~Hz}) ; 4,55(1 \mathrm{H}, \mathrm{dd}$, $J=6,5 \mathrm{~Hz}$ e 11,4 Hz); 6,12 (1H, d, J = 7,8 Hz); 6,76 - 6,83 (2H, m); 6,89 - 6,92 (1H, m); 7,03 - 7,05 (2H, m); 7,08 - 7,11 (2H, m). Espectro 1.

(1b) RMN ${ }^{13} \mathrm{C}$ (75 MHz): $\delta$ em ppm $\left(\mathrm{CDCl}_{3} / \mathrm{TMS}\right)$ 18,9; 19,7; 38,$6 ; 45,7 ; 45,7 ; 52,7 ; 58,7 ; 125,5 ; 125,9 ; 126,0 ; 126,2 ; 126,9 ; 130,1$; 130,$4 ; 135,6 ; 136,9 ; 137,8 ; 137,9 ; 168,9 ; 221,4$. Espectro 2.

(1b) DEPT $135^{\circ}$ (75 MHz): $\delta$ em ppm (CDCl $/$ TMS) 18,9; 19,7; 38,$5 ; 45,6\left(\mathrm{p} /\right.$ baixo $\left.-\mathrm{CH}_{2}\right) ; 45,7 ; 52,7 ; 58,7 ; 125,4 ; 125,9 ; 125,9 ; 126,1$; 126,9; 130,1; 130,4. Espectro 3.

(1b) COSY, HETCOR e NOESY: Espectros 4, 5 e 6.

(1b) Espectro de massas m / z (intens.): 77 (10); 91 (26); 115 (49); 116 (32); 117 (58); 118 (100); 145 (25); 322 (24); 323 (6). 
b - $\quad$ Análise de 1c

(1c) $\mathbf{R M N}{ }^{1} \mathbf{H}(300 \mathrm{MHz}): \delta$ em ppm $\left(\mathrm{CDCl}_{3} / \mathrm{TMS}\right) 1,93(3 \mathrm{H}, \mathrm{s})$; 2,01 $(3 \mathrm{H}, \mathrm{s}) ; 2,72(1 \mathrm{H}, \mathrm{dd}, \mathrm{J}=11,7 \mathrm{~Hz}$ e $18,6 \mathrm{~Hz}) ; 2,98(1 \mathrm{H}, \mathrm{dd}, \mathrm{J}=7,8$ $\mathrm{Hz}$ e 18,9 Hz); 3,68 (1H, d, J = 11,7 Hz); 3,71 (3H, s); 3,80 (1H, ddd, $\mathrm{J}=8,0 \mathrm{~Hz}$ e $11,7 \mathrm{~Hz}$ e $11,7 \mathrm{~Hz}) ; 4,33(1 \mathrm{H}, \mathrm{dd}, \mathrm{J}=11,7 \mathrm{~Hz}$ e $11,8 \mathrm{~Hz})$; $6.95(1 \mathrm{H}, \mathrm{s}) ; 6,97(1 \mathrm{H}, \mathrm{s}) ; 7,03-7,09(2 \mathrm{H}, \mathrm{m}) ; 7,20(2 \mathrm{H}, \mathrm{dd}, \mathrm{J}=8,4 \mathrm{~Hz}$ e 17,7 Hz); 7,37 (1H, d, J = 7,8 Hz); 7,49 (1H, dd, J = 7,8 Hz). Espectro 7.

(1c) RMN ${ }^{13} \mathbf{C}(75 \mathrm{MHz}): \delta$ em ppm ( $\left.\mathrm{CDCl}_{3} / \mathrm{TMS}\right)$ 19,5; 19,5; 43,$3 ; 46,9 ; 48,7 ; 52,6 ; 64,0 ; 125,4 ; 125,6 ; 126,3 ; 126,4 ; 126,7 ; 126,9$; 130,$4 ; 130,5 ; 136,5 ; 137,2 ; 137,7 ; 138,4 ; 168,8 ; 208,7$. Espectro 8.

(1c) DEPT $135^{\circ}$ (75 MHz): $\delta$ em ppm ( $\left.\mathrm{CDCl}_{3} / \mathrm{TMS}\right)$ 19,6; 19,6; 46,9 (p / baixo $-\mathrm{CH}_{2}$ ); 43,3 48,7; 52,6; 64,0;125,4; 125,6; 126,3; 126,4; 126,$7 ; 126,9 ; 130,4 ; 130,5$. Espectro 9.

(1b) COSY e HETCOR: Espectros 10 e 11.

(1c) Espectro de massas: m / z (intens.) 65 (9); 91 (22); 115 (43); 116 (32); 117 (49); 118 (100); 145 (25); 322 (15); 323 (4). 
c - $\quad$ Análise de 1a

$$
\mathrm{pf}_{\text {exp }}: 143-146{ }^{\circ} \mathrm{C} \mid \mathrm{pf}_{\mathrm{lit}}{ }^{53}: 147^{\circ} \mathrm{C}
$$

2.4. Eletrólises do o-nitrocinamato de metila (3)

Tabela VII.3 Resultados das eletrólises preparativas de $\mathbf{3}^{\mathbf{a}}$.

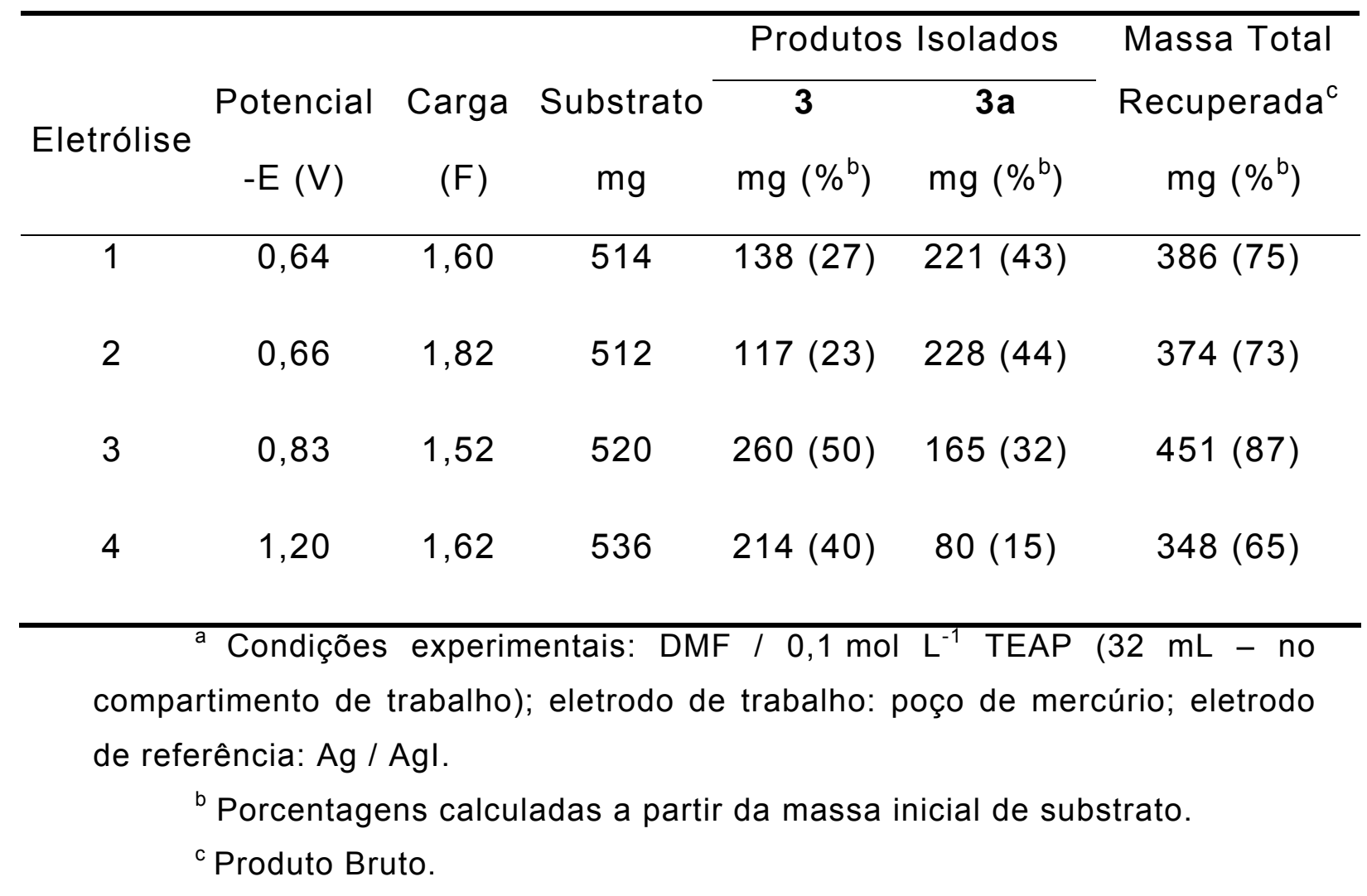

Produtos obtidos nestas eletrólises:<smiles>COC(=O)/C=C/c1ccccc1[N+](=O)[O-]</smiles>

3<smiles>O=C(O)/C=C/c1ccccc1[N+](=O)[O-]</smiles>

3a 


\section{a - $\quad$ Análise de 3}

Identificado pela comparação do espectro de $\mathrm{RMN}^{1} \mathrm{H}$ com o do composto 3 de partida ( $\mathrm{pf}_{\mathrm{exp}}: 68-70^{\circ} \mathrm{C} \mid \mathrm{pf}_{\mathrm{lit}}{ }^{56} 72^{\circ} \mathrm{C}$ ).

b - $\quad$ Análise de 3a

$$
\mathrm{pf}_{\text {exp }}: 233-238^{\circ} \mathrm{C} \mid \mathrm{pf}_{\mathrm{lit}}{ }^{54}: 242-243^{\circ} \mathrm{C}
$$

2.5. Eletrólises do $m$-nitrocinamato de metila (7)

Tabela VII.4 Resultados das eletrólises preparativas de $7^{\mathrm{a}}$.

\begin{tabular}{|c|c|c|c|c|c|c|}
\hline \multirow[b]{2}{*}{ Eletrólise } & \multirow[b]{2}{*}{$\begin{array}{c}\text { Potencial } \\
-E(V)\end{array}$} & \multirow[b]{2}{*}{$\begin{array}{c}\text { Carga } \\
\qquad \mathrm{F}\end{array}$} & \multirow[b]{2}{*}{$\begin{array}{c}\text { Substrato } \\
\text { mg }\end{array}$} & \multicolumn{2}{|c|}{ Produtos Isolados } & \multirow{2}{*}{$\begin{array}{l}\text { Massa total } \\
\text { Recuperada } \\
\text { mg }\left(\%^{\mathrm{b}}\right)\end{array}$} \\
\hline & & & & $\begin{array}{c}7 \\
\mathrm{mg}\left(\%^{\mathrm{b}}\right)\end{array}$ & $\begin{array}{c}7 a \\
m g\left(\%^{b}\right)\end{array}$ & \\
\hline 1 & 0,68 & 0,72 & 517 & $180(35)$ & $150(29)$ & 356 (69) \\
\hline 2 & 0,68 & 0,78 & 510 & $128(25)$ & $265(52)$ & $463(90)$ \\
\hline 3 & 1,32 & 2,04 & 514 & $44(9)$ & $98(19)$ & $168(33)$ \\
\hline 4 & 1,32 & 3,36 & 517 & $15(3)$ & $440(85)$ & $493(95)$ \\
\hline 5 & 1,32 & 3,86 & 509 & $5(1)$ & $316(62)$ & $359(69)$ \\
\hline
\end{tabular}
compartimento de trabalho); eletrodo de trabalho: poço de mercúrio; eletrodo de referência: Ag / Agl.

${ }^{\mathrm{b}}$ Porcentagens calculadas a partir da massa inicial de substrato.

${ }^{\mathrm{C}}$ Produto Bruto. 
Produtos obtidos nestas eletrólises:<smiles>COC(=O)/C=C/c1cccc([N+](=O)[O-])c1</smiles>

7<smiles>O=C(O)/C=C/c1cccc([N+](=O)[O-])c1</smiles>

$7 a$

a - $\quad$ Análise de 7

Identificado pela comparação do espectro de $\mathrm{RMN}^{1} \mathrm{H}$ com o do composto 7 de partida.

b - $\quad$ Análise de 7a

$$
\text { (pf } \left.f_{\text {exp }}: 196-199^{\circ} \mathrm{C} \mid \mathrm{pf}_{\text {lit. }}{ }^{56}: 201^{\circ} \mathrm{C}\right)
$$


2.6. Eletrólises do o-clorocinamato de metila (2)

Tabela VII.5 Resultados das eletrólises preparativas de $\mathbf{2}^{\mathrm{a}}$.

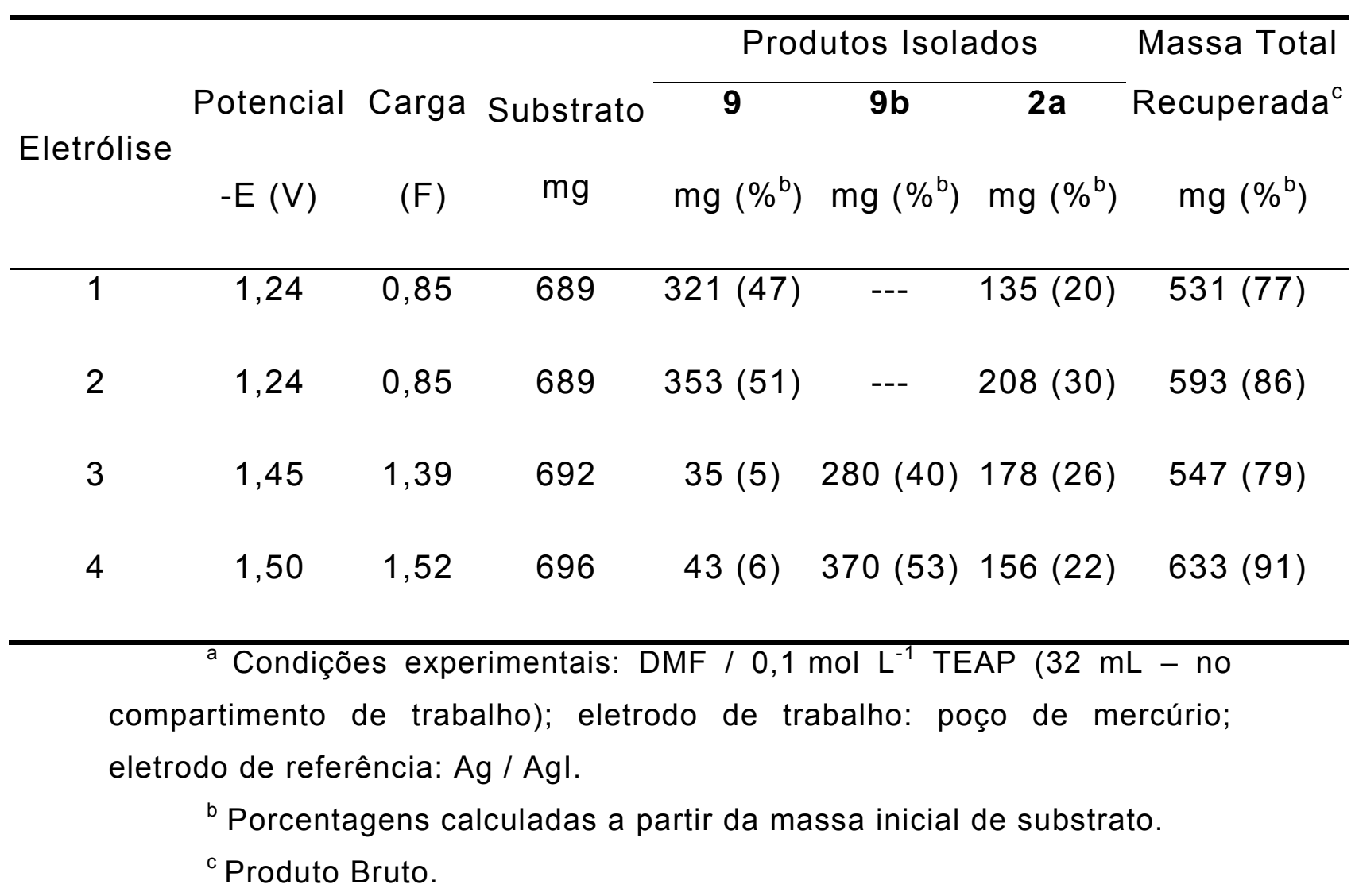

Produtos obtidos nestas eletrólises:<smiles>COC(=O)/C=C/c1ccccc1</smiles> 


\section{a - $\quad$ Análise de 9}

CG comparativo do produto de eletrólise com composto 2 e com o cinamato de metila comercial comprovou que se tratava do produto de desalogenação (9).

$$
\text { pf exp }: 35^{\circ} \mathrm{C} \mid \mathrm{pf}_{\text {lit. }} .62: 36^{\circ} \mathrm{C}
$$

(9) Espectro de massas: m I z (intens.): 77 (10); 91 (26); 115 (49); 116 (32); 117 (58); 118 (100); 144 (15); 145 (25); 185 (11); 322 (24); $323(6)$.

b - $\quad$ Análise de 2a $\mathrm{pf}_{\text {exp }}: 206-210^{\circ} \mathrm{C} \mid \mathrm{pf}_{\mathrm{lit}}{ }^{57}: 211^{\circ} \mathrm{C}$

c - $\quad$ Análise de $9 b$

RMN ${ }^{1} \mathrm{H}$ concorda com ref. ${ }^{20}\left(\mathrm{pf}_{\text {exp. }}: 122-125^{\circ} \mathrm{C} \mid \mathrm{pf}_{\text {lit. }}{ }^{20}: 126\right.$ $\left.127^{\circ} \mathrm{C}\right)$.

${ }^{62}$ H. L. Goebel, H. H. Wenxke, J. Am. Chem. Soc. , 1938, $\underline{60}, 697$. 
2.7. Eletrólises do $m, p$-diclorocinamato de metila (4)

Tabela VII.6 Resultados das eletrólises preparativas de $4^{\mathrm{a}}$.

\begin{tabular}{|c|c|c|c|c|c|c|}
\hline \multirow[b]{2}{*}{ Eletrólise } & \multirow[b]{2}{*}{$\begin{array}{c}\text { Potencial } \\
-E(V)\end{array}$} & \multirow[b]{2}{*}{$\begin{array}{c}\text { Carga } \\
\mathrm{F}\end{array}$} & \multirow[b]{2}{*}{$\begin{array}{c}\text { Substrato } \\
\text { mg }\end{array}$} & \multicolumn{2}{|c|}{ Produtos Isolados } & \multirow{2}{*}{$\begin{array}{c}\text { Massa Total } \\
\text { Recuperada } \\
\text { mg }\left(\%^{\mathrm{b}}\right)\end{array}$} \\
\hline & & & & $\begin{array}{c}5 \\
\mathrm{mg}\left(\%^{\mathrm{b}}\right)\end{array}$ & $\begin{array}{c}\mathbf{4 a} \\
\mathrm{mg}\left(\%^{\mathrm{b}}\right)\end{array}$ & \\
\hline 1 & 1,16 & 0,94 & 574 & $210(37)$ & $4(1)$ & $235(41)$ \\
\hline 2 & 1,16 & 1,11 & 578 & $243(42)$ & $89(15)$ & $384(66)$ \\
\hline \multirow[t]{2}{*}{3} & 1,20 & 1,14 & 533 & $297(56)$ & $215(40)$ & $490(92)$ \\
\hline & & & & $\begin{array}{l}\text { Mistura }{ }^{d} \\
\mathrm{mg}\left(\%^{b}\right)\end{array}$ & $\begin{array}{c}4 a \\
m g\left(\%^{b}\right)\end{array}$ & $\begin{array}{c}\text { M. Recuperada } \\
\mathrm{mg}\left(\%^{\mathrm{b}}\right)\end{array}$ \\
\hline 4 & 1,26 & 0,76 & 575 & $130(23)$ & $133(23)$ & $246(43)$ \\
\hline 5 & 1,26 & 1,10 & 576 & $212(37)$ & $83(14)$ & $388(67)$ \\
\hline 6 & 1,26 & 0,76 & 574 & $170(30)$ & $58(10)$ & $329(57)$ \\
\hline 7 & 1,30 & 0,81 & 573 & $160(28)$ & $78(14)$ & $354(62)$ \\
\hline
\end{tabular}

compartimento de trabalho); eletrodo de trabalho: poço de mercúrio; eletrodo de referência: $\mathrm{Ag} / \mathrm{Agl}$.

${ }^{b}$ Porcentagens calculadas a partir da massa inicial de substrato.

${ }^{\mathrm{c}}$ Produto Bruto.

${ }^{d}$ Mistura rica no composto $\mathbf{5 b}$, porém contendo outros dímeros.

Produtos obtidos nestas eletrólises:

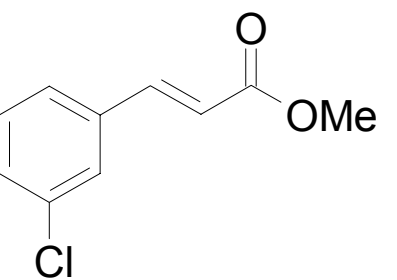

5

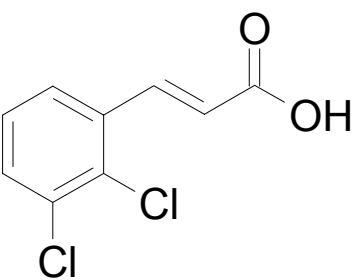

$4 a$

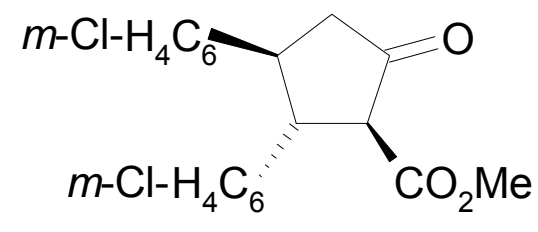

$5 b$ 


\section{a - $\quad$ Análise de $\mathbf{5}$}

Identificado pela comparação do espectro de $\mathrm{RMN}{ }^{1} \mathrm{H}$ com o do composto 5 preparado.

\section{$\boldsymbol{b}$ - $\quad$ Análise de $\mathbf{5 b}$}

(5b) $\mathrm{RMN}{ }^{1} \mathrm{H}(500 \mathrm{MHz}): \delta$ em ppm $\left(\mathrm{CDCl}_{3} / \mathrm{TMS}\right) 2,67(1 \mathrm{H}, \mathrm{dd}$, $J=12,0 \mathrm{~Hz}, 18,0 \mathrm{~Hz}) ; 2,97(1 \mathrm{H}, \mathrm{dd}, \mathrm{J}=8,0 \mathrm{~Hz}, 18,0 \mathrm{~Hz}) ; 3,45(1 \mathrm{H}, \mathrm{dt}$, $J=8,0 \mathrm{~Hz}, 12,0 \mathrm{~Hz}, 12) ; 3,56(1 \mathrm{H}, \mathrm{d}, \mathrm{J}=12,0 \mathrm{~Hz}) ; 3,74(3 \mathrm{H}, \mathrm{s}) ; 3,87$ $(1 \mathrm{H}, \mathrm{t}, \mathrm{J}=12,0 \mathrm{~Hz}) ; 7,00-7,03(2 \mathrm{H}, \mathrm{m}) ; 7,15-7,16(2 \mathrm{H}, \mathrm{m}) ; 7,18-7,19$ $(4 \mathrm{H}, \mathrm{m})$. Espectro 12.

(5b) RMN ${ }^{13} \mathrm{C}$ (125 MHz): $\delta$ em ppm ( $\left.\mathrm{CDCl}_{3} / \mathrm{TMS}\right)$ 46,6; 47,0; 52,$7 ; 52,8 ; 63,4 ; 125,6 ; 125,8 ; 127,3 ; 127,4 ; 127,7 ; 127,9 ; 130,1 ; 130,1$; 134,$6 ; 134,7 ; 140,5 ; 141,3 ; 168,1 ; 206,8$. Espectro 13.

(5b) DEPT $135^{\circ}$ (125 MHz): $\delta$ em ppm $\mathrm{CDCl}_{3} / \mathrm{TMS}$ ) 46,6; 47,0; 52,$7 ; 52,8 ; 63,4 ; 125,6 ; 125,8 ; 127,3 ; 127,4 ; 127,7 ; 127,9 ; 130,1 ; 130,1$.

\section{Espectro 14.}

(5b) Espectro de massas: m / z (intens.) 78 (12); 102 (27); 103 (22); 104 (19); 137 (100); 139 (17); 140 (33); 165 (26); 362 (12); 364 (9); $365(2) ; 366(2)$. 


\section{c - $\quad$ Análise de 4a}

$$
\mathrm{pf}_{\text {exp }}: 200-205^{\circ} \mathrm{C} \mid \mathrm{pf}_{\text {lit. }}{ }^{59}: 217-218^{\circ} \mathrm{C}
$$

2.8. Eletrólises do $m$-clorocinamato de metila (5)

Tabela VII.7 Resultados das eletrólises preparativas de $5^{\text {a }}$.

\begin{tabular}{|c|c|c|c|c|c|c|}
\hline \multirow[b]{2}{*}{ Eletrólise } & \multirow[b]{2}{*}{$\begin{array}{c}\text { Potencial } \\
-E(V)\end{array}$} & \multirow[b]{2}{*}{$\begin{array}{c}\text { Carga } \\
\qquad(\mathrm{F})\end{array}$} & \multirow[b]{2}{*}{$\begin{array}{c}\text { Substrato } \\
\text { mg }\end{array}$} & \multicolumn{2}{|c|}{ Produtos Isolados } & \multirow{2}{*}{$\begin{array}{c}\text { Massa Total } \\
\text { Recuperada } \\
\text { mg }\left(\%^{\mathrm{b}}\right)\end{array}$} \\
\hline & & & & $\begin{array}{c}\mathbf{5 b} \\
\mathrm{mg}\left(\%^{\mathrm{b}}\right)\end{array}$ & $\begin{array}{c}5 \mathbf{a} \\
\mathrm{mg}\left(\%^{\mathrm{b}}\right)\end{array}$ & \\
\hline 1 & 1,30 & 0,89 & 550 & $264(48)$ & $140(26)$ & $427(78)$ \\
\hline 2 & 1,30 & 0,86 & 556 & $256(46)$ & $218(21)$ & $446(80)$ \\
\hline
\end{tabular}

compartimento de trabalho); eletrodo de trabalho: poço de mercúrio; eletrodo de referência: Ag / Agl.

${ }^{b}$ Porcentagens calculadas a partir da massa inicial de substrato.

${ }^{\mathrm{C}}$ Produto Bruto.

Produtos obtidos nestas eletrólises:

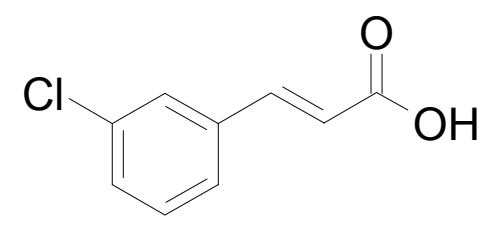

$5 a$

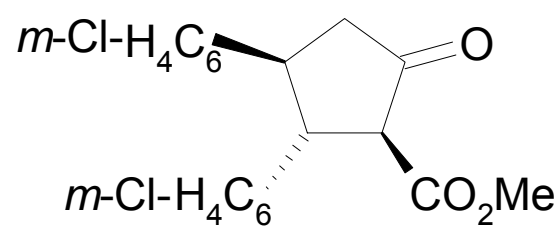

$5 b$

a - $\quad$ Análise de $\mathbf{5 b}$

Espectros 12 - 14 .

b - Análise de 5a

$$
\left(\mathrm{pf}_{\text {exp }}: 156-161^{\circ} \mathrm{C} \mid \mathrm{pf}_{\mathrm{it.} .}{ }^{57}: 164-165^{\circ} \mathrm{C}\right)
$$


2.9. Eletrólises do $p$-clorocinamato de metila (6)

Tabela VII. 8 Resultados das eletrólises preparativas de $6^{a}$.

\begin{tabular}{|c|c|c|c|c|c|c|c|}
\hline \multirow[b]{2}{*}{ Eletrólise } & \multirow[b]{2}{*}{ Potencial } & \multirow[b]{2}{*}{ Carga } & \multirow[b]{2}{*}{$\begin{array}{c}\text { Substrato } \\
\mathrm{mg}\end{array}$} & \multicolumn{3}{|c|}{ Produtos } & \multirow{2}{*}{$\begin{array}{c}\text { Massa Total } \\
\text { Recuperada } \\
\text { mg }\left(\%^{b}\right)\end{array}$} \\
\hline & & & & $\begin{array}{c}9 \\
\mathrm{mg}(\%)\end{array}$ & $\begin{array}{c}\mathbf{6 b} \\
\mathrm{mg}(\%)\end{array}$ & $\begin{array}{c}6 \mathbf{6 a} \\
\mathrm{mg}(\%)\end{array}$ & \\
\hline 1 & 1,20 & 0,95 & 492 & $186\left(38^{c}\right)$ & $--\left(12^{d}\right)$ & $130\left(26^{c}\right)$ & $426(87)$ \\
\hline 2 & 1,25 & 0,86 & 548 & $--\left(53^{d}\right)$ & $--\left(17^{d}\right)$ & $--\left(21^{d}\right)$ & $499(91)$ \\
\hline 3 & 1,25 & 1,04 & 548 & $--\left(5^{d}\right)$ & $--\left(40^{d}\right)$ & $--\left(26^{d}\right)$ & 469 (86) \\
\hline 4 & 1,36 & 1,06 & 494 & $--\left(6^{d}\right)$ & $370\left(53^{c}\right)$ & $158\left(22^{c}\right)$ & $421(85)$ \\
\hline
\end{tabular}

compartimento de trabalho); eletrodo de trabalho: poço de mercúrio; eletrodo de referência: Ag / Agl.

${ }^{\mathrm{b}}$ Produto Bruto.

c Produtos isolados, porcentagens calculadas a partir da massa inicial de substrato.

${ }^{d}$ Produtos de eletrólise analisados através de CG e EM e não isolados.

Produtos obtidos nestas eletrólises:

$\mathrm{O}$

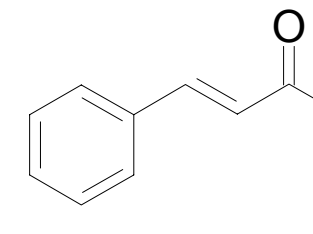

9
$\mathrm{OMe}$

$\mathrm{Cl}$

9
$\mathrm{O}$

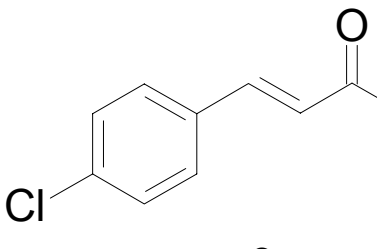

$6 a$

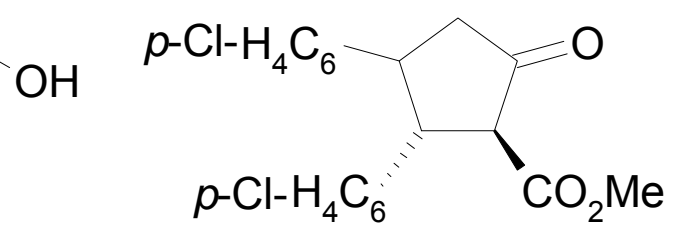

6b

\section{a - $\quad$ Análise de 9}

CG comparativo com padrões. $\left(\mathrm{pf}_{\text {exp }}: 34-36{ }^{\circ} \mathrm{C} \mid \mathrm{pf}_{\text {lit. }}{ }^{62}: 36{ }^{\circ} \mathrm{C}\right)$ 
b - $\quad$ Análise de 6a

$$
\text { (pf exp }: 264-269{ }^{\circ} \mathrm{C} \mid \mathrm{pf}_{\text {lit. }}{ }^{56}: 284^{\circ} \mathrm{C} \text { ) }
$$

c - $\quad$ Análise de $6 \boldsymbol{b}$

(6b) $\mathbf{R M N}{ }^{1} \mathbf{H}(500 \mathrm{MHz}): \delta$ em ppm $\left(\mathrm{CDCl}_{3} / \mathrm{TMS}\right) 2,67(1 \mathrm{H}, \mathrm{q}$, $J=12,0 \mathrm{~Hz}, 18,0 \mathrm{~Hz}) ; 2,96(1 \mathrm{H}, \mathrm{q}, J=8,0 \mathrm{~Hz}, 18 \mathrm{~Hz}) ; 3,42(1 \mathrm{H}, \mathrm{dt}$, $\mathrm{J}=8,0 \mathrm{~Hz}, 12,0 \mathrm{~Hz}, 12,0 \mathrm{~Hz}) ; 3,55(1 \mathrm{H}, \mathrm{d}, \mathrm{J}=12,0 \mathrm{~Hz}) ; 3,72(3 \mathrm{H}, \mathrm{s})$; $3,83(1 \mathrm{H}, \mathrm{t}, \mathrm{J}=12,0 \mathrm{~Hz}) ; 7,05-7,08(4 \mathrm{H}, \mathrm{m}) ; 7,21-7,24(4 \mathrm{H}, \mathrm{m})$. Espectro 15.

(6b) RMN ${ }^{13} \mathrm{C}(125 \mathrm{MHz}): \delta$ em ppm ( $\left.\mathrm{CDCl}_{3} / \mathrm{TMS}\right)$ 46,5; 47,0; 52,$8 ; 52,9 ; 63,4 ; 128,1 ; 128,6 ; 128,7 ; 129,0 ; 129,1 ; 133,1 ; 133,4 ; 136,9$; 137,7; 168,3; 207,1. Espectro 16.

(6b) DEPT $135^{\circ}$ (125 MHz): $\delta$ em ppm ( $\left.\mathrm{CDCl}_{3} / \mathrm{TMS}\right)$ 46,6; 47,0; 52,$7 ; 52,8 ; 63,4 ; 125,6 ; 125,8 ; 127,3 ; 127,4 ; 127,7 ; 127,9 ; 130,1 ; 130,1$. Espectro 17.

(6b) Espectro de massas: m I z (intens.) 77 (12); 101 (25); 102 (19); 103 (17); 138 (100); 139 (14); 140 (31); 165 (24); 362 (11); 364 (8);365 (2); 366 (2). Espectro 18. 
2.10. Eletrólises do o-metoxicarbonilcinamato de metila (8)

Tabela VII.9 Resultados das eletrólises preparativas de $\mathbf{8}^{\text {a }}$.

\begin{tabular}{|c|c|c|c|c|c|c|c|}
\hline \multirow{3}{*}{ Eletrólise } & \multirow[b]{2}{*}{ Potencia } & \multirow[b]{2}{*}{ Carga $\mathrm{M}$} & \multirow[b]{2}{*}{. Inicial } & \multicolumn{3}{|c|}{ Produtos Isolados ${ }^{b}$} & \multirow{3}{*}{$\begin{array}{c}\text { Massa Total } \\
\text { Recuperada } \\
\text { mg }\left(\%^{d}\right)\end{array}$} \\
\hline & & & & $8 b$ & $8 c$ & $8 a$ & \\
\hline & $-E(V)$ & $\mathrm{F}$ & $\mathrm{mg}$ & $\mathrm{mg}\left(\%{ }^{\mathrm{d}}\right)$ & $\mathrm{mg}\left(\%^{\mathrm{d}}\right)$ & $\mathrm{mg}\left(\%^{\mathrm{d}}\right)$ & \\
\hline 1 & 1,26 & 0,93 & 770 & $215(28)$ & $170(22)$ & $125(16)$ & $550(71)$ \\
\hline 2 & 1,25 & 0,91 & 772 & $240(31)$ & 148 (19) & $110(14)$ & $538(70)$ \\
\hline 3 & 1,26 & 0,49 & 769 & $235(31)$ & $161(21)$ & $154(20)$ & $590(77)$ \\
\hline 4 & 1,26 & 0,86 & 758 & $154(20)$ & $125(16)$ & $109(14)$ & $428(56)$ \\
\hline
\end{tabular}

${ }^{a}$ Condições experimentais: DMF / 0,1 $\mathrm{mol} \mathrm{L}^{-1}$ TEAP $(32 \mathrm{~mL}-$ no compartimento de trabalho); eletrodo de trabalho: poço de mercúrio; eletrodo de referência: Ag / Agl.

${ }^{\text {b }}$ Alem destes produtos foi isolado o composto $8 \mathbf{d}$ em quantidades de $5-9 \%$.

${ }^{\mathrm{c}}$ Produto Bruto.

${ }^{d}$ Porcentagens calculadas a partir da massa inicial de substrato.

Produtos obtidos nestas eletrólises:

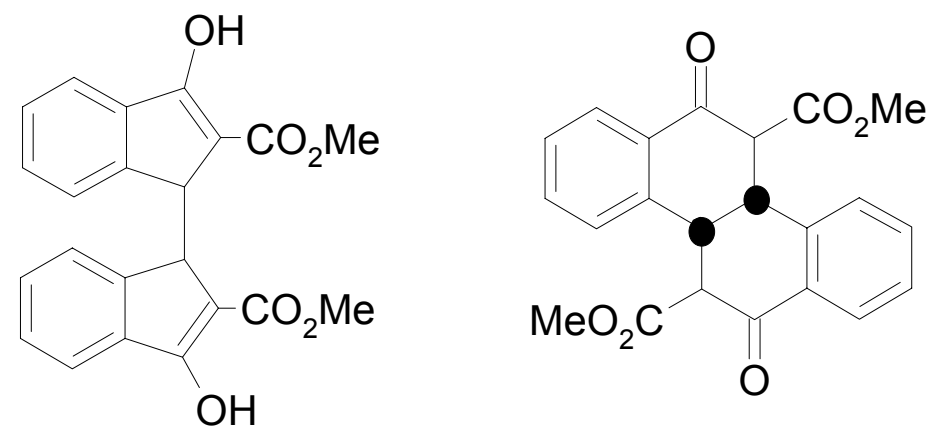

$8 b$ 8c

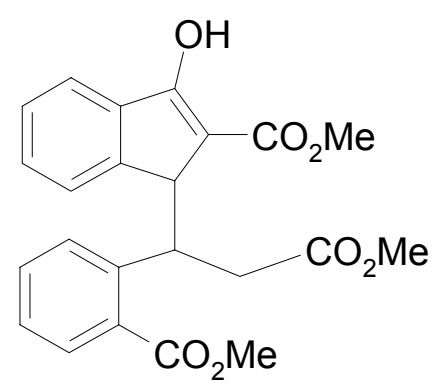

sub-produto 


\section{a - $\quad$ Análise de $\mathbf{8 b}$}

(8b) RMN ${ }^{1} \mathbf{H}$ (200 MHz): $\delta$ em ppm (d6-DMSO / TMS) 3,84 $(6 \mathrm{H}$, s); 4,25 (2H, s); 6,94 (2H, d, J = 8,8 Hz); 7,23 $(4 \mathrm{H}, \mathrm{m}) ; 6,94(2 \mathrm{H}, \mathrm{d}$, $\mathrm{J}=8,8 \mathrm{~Hz}) ; 12,77\left(2 \mathrm{H}, \mathrm{s}\right.$ - Troca com $\left.\mathrm{D}_{2} \mathrm{O}\right)$. Espectro 19.

(8b) RMN ${ }^{13}$ C (75 MHz): $\delta$ em ppm (d6-DMSO / TMS) 35,4; 51,9; 97,$1 ; 124,6 ; 126,19 ; 126,8 ; 129,9 ; 131,3 ; 139,5 ; 166,4 ; 173,4$. Espectro 20.

(8b) DEPT $135^{\circ}$ (75 MHz): $\delta$ em ppm (d6-DMSO / TMS) 35,4; 51,$9 ; 124,6 ; 126,19 ; 126,8 ; 131,3$. Espectro 21.

(8b) COSY e HETCOR: Espectros 22 e 23.

(8b) Análise Elementar (CHN): C22H18O6 - Calc: C 69,84\%, H 4,79\%. Observado: C 66,50\%, H 5,15\%.

(8b) Espectro de massas: m I z (intens.) 40 (24); 59 (17); 75 (10); 76 (11); 77 (7); 101 (34); 102 (28); 115 (9); 129 (10); 130 (32); 131 (9); 145 (13); 157 (100); 158 (18); 189 (73); 190 (27); 202 (8); 246 (8); 247 (6); 259 (10); 346 (4). Espectro 24. 
b - $\quad$ Análise de 8c

(8c) $\mathbf{R M N}{ }^{1} \mathrm{H}: \delta$ em ppm $\left(\mathrm{CDCl}_{3} / \mathrm{TMS}\right) 2,93(2 \mathrm{H}, \mathrm{m}, \mathrm{J}=4,4 \mathrm{~Hz})$; $3,55(6 \mathrm{H}, \mathrm{s}) ; 4,77(2 \mathrm{H}, \mathrm{J}=3,9 \mathrm{~Hz}) ; 7,44-7,52(2 \mathrm{H}, \mathrm{m}) ; 7,60-7,70$ $(4 \mathrm{H}, \mathrm{m}) ; 7,80(2 \mathrm{H}, \mathrm{d}, \mathrm{J}=8 \mathrm{~Hz})$. Espectro 25.

(8c) $\mathbf{R M N}{ }^{13} \mathbf{C}: \delta$ em ppm ( $\left.\mathrm{CDCl}_{3} / \mathrm{TMS}\right) 197,2 ; 168,8 ; 153,7$; 135,$7 ; 135,6 ; 129,0 ; 125,5 ; 125,1 ; 55,5 ; 52,7 ; 44,6$. Espectro 26.

(8c) DEPT $135^{\circ}$ RMN: $\delta$ em ppm ( $\left.\mathrm{CDCl}_{3} / \mathrm{TMS}\right)$ 135,7; 129,0; 125,$5 ; 125,1 ; 55,5 ; 52,7 ; 44,6$. Espectro 27.

(8c) COSY e HETCOR: Espectros 28 e 29.

(8c) Análise Elementar (CHN): C22H18O6 - Calc: C 69,84\%, H $4,79 \%$. Observado: C 70,21 \%, H 4,66 \%.

(8c) Espectro de massas: m / z (intens.) 39 (100); 43 (12); 44 (20); 88 (8); 101 (42); 18 (28); 157 (17); 189 (8); 200 (14); 201 (13); 202 (37); 203 (9); 230 (17); 231 (13); 246 (14); 258 (13); 259 (34); 260 (9); 286 (50);287 (33); 346 (10); 378 (24); 379 (5). Espectro 30. 


\section{c - $\quad$ Análise de $\mathbf{8 d}$}

(8d) RMN ${ }^{1} \mathrm{H}: \quad \delta$ em ppm $\left(\mathrm{CDCl}_{3} / \mathrm{TMS}\right) \delta=2,42$ (dd, J $(\mathrm{H}, \mathrm{H})=18,0 \mathrm{~Hz}, 8,0 \mathrm{~Hz}, 1 \mathrm{H}, \mathrm{CH}), 3,03(\mathrm{dd}, \mathrm{J}(\mathrm{H}, \mathrm{H})=18,0 \mathrm{~Hz}, 4,0 \mathrm{~Hz}, 1$ $\mathrm{H}, \mathrm{CH}), 3,63\left(\mathrm{~s}, 3 \mathrm{H}, \mathrm{CH}_{3}\right), 3,72\left(\mathrm{~s}, 3 \mathrm{H}, \mathrm{CH}_{3}\right), 3,95\left(\mathrm{~s}, 3 \mathrm{H}, \mathrm{CH}_{3}\right), 4,11$ 4,21 (m, $1 \mathrm{H}, \mathrm{CH}), 5,08(\mathrm{~d}, \mathrm{~J}(\mathrm{H}, \mathrm{H})=8,0 \mathrm{~Hz}, 2 \mathrm{H}, \mathrm{CH}), 7,69-7,73(\mathrm{~m}, 1 \mathrm{H}$, $\mathrm{CH})$, 7,00-7,09 (m, $2 \mathrm{H}, \mathrm{CH})$, 7,12-7,19 $(\mathrm{m}, 1 \mathrm{H}, \mathrm{CH})$, 7,61-7,65 (m, $1 \mathrm{H}$, $\mathrm{CH}), 7,91-7,97(\mathrm{~m}, 1 \mathrm{H}, \mathrm{CH}), 12,43\left(\mathrm{~s}, 1 \mathrm{H}, \mathrm{OH}\right.$ - troca com $\left.\mathrm{D}_{2} \mathrm{O}\right)$.

\section{Espectro 31.}

d - $\quad$ Análise de 8a

$$
\text { (PFexp.: } \left.193-199^{\circ} \mathrm{C} \mid \mathrm{PF}_{\text {ref. }}{ }^{41}: 202-206^{\circ} \mathrm{C}\right) \text {. }
$$




\section{Anexos}

\section{Anexos}

Resultados de análises por

ressonância magnética nuclear e

espectrometria de massas. 


\section{ÍNDICE}

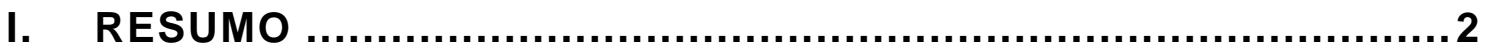

II. INTRODUÇÃO: ÁCIDOS E ÉSTERES CINÂMICOS ....................6

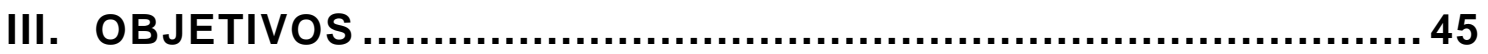

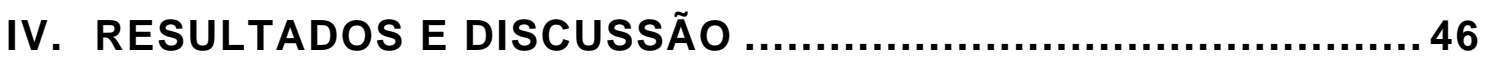

1. Preparação dos substratos ...................................... 46

2. Experimentos eletroquímicos …................................54

2.1.Voltametria Cíclica ........................................... 54

2.2.Eletrólises preparativas a potencial controlado .............62 62

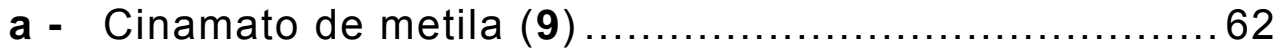

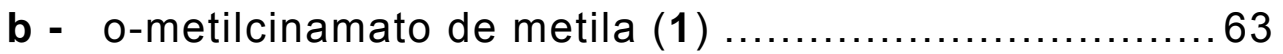

c - Nitrocinamatos (3 e 7) .................................. 68

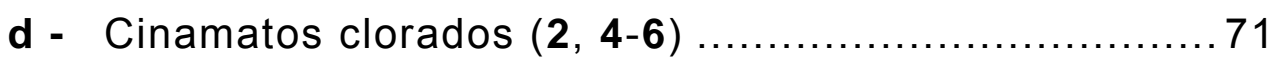

e - o-metoxicarbonilcinamato de metila (8) .................. 82

2.3.Cálculos $A b$ Initio .............................................. 90

a - Nitro-derivados ............................................. 91

b - Cloro-derivados ............................................... 94

V. CONCLUSÃO .................................................................. 99

VI. PARTE EXPERIMENTAL A .............................................. 104

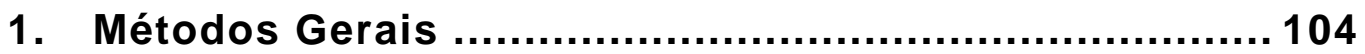

2. Solventes e Reagentes ......................................... 105 
3. Procedimentos padrão de preparação 106

3.1. Ácido cinâmico .................................................. 106

3.2. Cinamato de metila ......................................... 107

4. 0 -metilcinamato de metila (1) .................................. 109

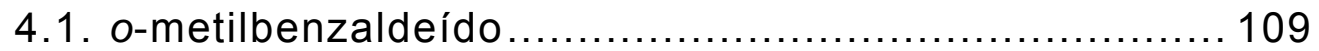

4.2. Ácido o-metilcinâmico (1a).................................. 112

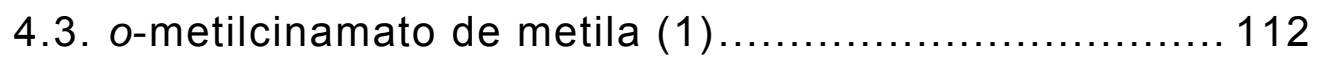

5. o-nitrocinamato de metila (3) .............................. 113

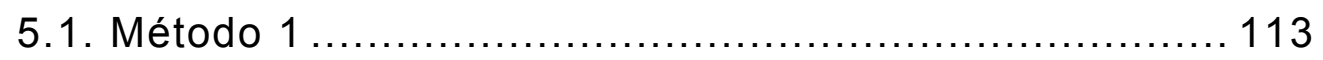

a - Cloreto de p-nitroso-N,N-dimetilanilínio................... 113

b - o-nitrobenzaldeído......................................... 114

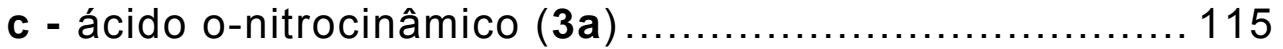

d - o-nitrocinamato de metila (3) .......................... 116

5.2. Método 2 ...................................................... 116

a - o-nitrobenzaldeído ........................................ 116

b - ácido o-nitrocinâmico (3a) .............................. 117

c - o-nitrocinamato de metila (3) .......................... 117

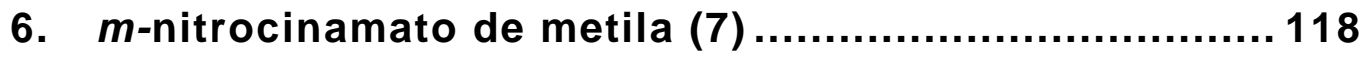

7. Cinamatos de metila clorados $(2,4-6) \ldots \ldots \ldots \ldots \ldots \ldots . \ldots . \ldots . \ldots . \ldots 19$

7.1. o-clorocinamato de metila (2)............................ 119

7.2. m-clorocinamato de metila (5) .......................... 120

7.3. $p$-clorocinamato de metila (6) ............................ 121

7.4. $m, p$-diclorocinamato de metila $(4)$....................... 122

8. o-metoxicarbonilcinamato de metila (8) .................... 123

8.1. Ftalida .................................................... 123

8.2. 2-bromoftalida ................................................. 124

8.3. o-carboxibenzaldeído ......................................... 125

8.4. Ácido o-carboxicinâmico .................................... 127

8.5. o-metoxicarbonilcinamato de metila (8)................. 128 
VII. PARTE EXPERIMENTAL B

1. Voltametria Cíclica .............................................. 130

2. Eletrólises preparativas a potencial controlado.......... 131

2.1. Isolamento dos produtos de eletrólise. ................... 131

2.2. Eletrólises do cinamato de metila (9) ..................... 133

2.3. Eletrólises do o-metilcinamato de metila (1).............. 134

2.4. Eletrólises do o-nitrocinamato de metila (3) ............... 137

2.5. Eletrólises do $m$-nitrocinamato de metila (7) ............ 138

2.6. Eletrólises do o-clorocinamato de metila (2)............. 140

2.7. Eletrólises do $m, p$-diclorocinamato de metila (4) ........ 142

2.8. Eletrólises do $m$-clorocinamato de metila (5)............. 144

2.9. Eletrólises do $p$-clorocinamato de metila (6)............. 145

2.10. Eletrólises do o-metoxicarbonilcinamato de metila.... 147

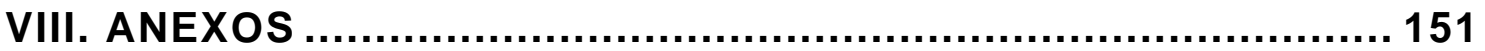

